\title{
HIGH-PRESSURE VISCOSITY AND DENSITY OF POLYMER SOLUTIONS AT THE CRITICAL POLYMER CONCENTRATION IN NEAR-CRITICAL AND SUPERCRITICAL FLUIDS
}

\author{
By Cigdem Dindar
}

\author{
A THESIS \\ Submitted in Partial Fulfillment of the \\ Requirements for the Degree of Masters of Science \\ (in Chemical Engineering) \\ The Graduate School \\ Virginia Polytechnic Institute and State University
}

September 26, 2001

Key Words: high-pressure, viscosity, density, polymer solution, supercritical fluids

\section{Advisory Committee:}

Erdogan Kiran Professor of Chemical Engineering, Department Head, Advisor

Donald G. Baird Harry C. Wyatt Professor of Chemical Engineering

Eva Marand Associate Professor of Chemical Engineering 


\title{
ABSTRACT \\ HIGH-PRESSURE VISCOSITY AND DENSITY OF POLYMER SOLUTIONS \\ AT THE CRITICAL POLYMER CONCENTRATION \\ IN NEAR-CRITICAL AND SUPERCRITICAL FLUIDS
}

\section{By Cigdem Dindar \\ Thesis Advisor: Erdogan Kiran, Ph.D. \\ An Abstract of the Thesis Presented in Partial Fulfillment of the Requirements for the Degree of Masters of Science (in Chemical Engineering)}

September 2001

\begin{abstract}
The motivation for the determination of the viscosity of polymer solutions in dense fluids at the critical polymer concentration stems from the need to understand the factors that influence the time scale of phase separation in systems that undergo spinodal decomposition upon a pressure quench. In a recent investigation of PDMS $+\mathrm{CO}_{2}$ and $\mathrm{PE}$ $+\mathrm{n}$-pentane where molecular weights of the polymers and the critical polymer concentrations were comparable, significant differences were observed in the time evolution of new phase growth. Among the reasons that contribute to the difference in phase separation kinetics is the viscosity of the solutions.
\end{abstract}

This thesis has been carried out to experimentally demonstrate the differences in viscosities of solutions at their critical polymer concentration. Specifically, the thesis focused on the high-pressure density and viscosity of solutions of poly(dimethylsiloxane) $\left(M_{w}=93,700, M_{w} / M_{n}=2.99\right)$ in supercritical carbon dioxide and of polyethylene $\left(M_{w}=\right.$ 121,000, $M_{w} / M_{n}=4.3$ ) in near-critical n-pentane. The measurements have been carried out at the critical polymer concentrations, which is $5.5 \mathrm{wt} \%$ for solution of PDMS in $\mathrm{CO}_{2}$ and 5.75 wt $\%$ for solution of $\mathrm{PE}$ in n-pentane. For PDMS $+\mathrm{CO}_{2}$ system, the measurements were conducted at $55,70,85$ and $100{ }^{\circ} \mathrm{C}$ and pressures up to $50 \mathrm{MPa}$. For 
$\mathrm{PE}+\mathrm{n}$-pentane system, the measurements were conducted at 140 and $150{ }^{\circ} \mathrm{C}$ and again up to $50 \mathrm{MPa}$. All measurements were conducted in the one-phase homogenous regions. At these temperatures and pressures, the viscosities were observed to be in the range from $0.14 \mathrm{mPa} . \mathrm{s}$ to $0.22 \mathrm{mPa}$.s for PDMS $+\mathrm{CO}_{2}$, and from $2.3 \mathrm{mPa}$.s to $4.6 \mathrm{mPa}$.s for $\mathrm{PE}+\mathrm{n}-$ pentane systems. In both systems the viscosities increase with pressure and decrease with temperature. The temperature and pressure dependence could be described by Arrhenius type relationships in terms of flow activation energy $\left(E^{\#}\right)$ and flow activation volume $\left(V^{\#}\right)$ parameters. The flow activation energies in PDMS $+\mathrm{CO}_{2}$ system were about $7 \mathrm{~kJ} / \mathrm{mol}$ compared to about $18 \mathrm{~kJ} / \mathrm{mol}$ for the $\mathrm{PE}+\mathrm{n}$-pentane system. The activation volumes were in the range $40-64 \mathrm{~cm}^{3} / \mathrm{mol}$ for PDMS $+\mathrm{CO}_{2}$ system and $65-75 \mathrm{~cm}^{3} / \mathrm{mol}$ for the PE $+n$-pentane solution. The higher values of $E^{\#}$ and $V^{\#}$ represent the higher sensitivity of viscosity to temperature and pressure changes in the $\mathrm{PE}+\mathrm{n}$-pentane system. The viscosity data could also be correlated in terms of density using free-volume based Doolittle type equations. Density is shown to be an effective scaling parameter to describe T/P dependency of viscosity. The closed packed volumes suggested from density correlations were found to be around $0.33 \mathrm{~cm}^{3} / \mathrm{g}$ for the PDMS and $0.48 \mathrm{~cm}^{3} / \mathrm{g}$ for the PE systems. Comparison of the viscosity data in these systems with the data on the kinetics of pressure-induced phase separation confirms that the slower kinetics in the $\mathrm{PE}+\mathrm{n}$-pentane stems from the higher viscosity in this solution compared to the PDMS + $\mathrm{CO}_{2}$ system, despite the similarity in the molecular weight of the polymer and the critical polymer concentrations.

These viscosity and density measurements were conducted in a special falling-body type viscometer. In the course of this thesis a more reliable procedure for determining the terminal velocity of the falling sinker was implemented. This is based on the precise and more complete description of the position of the sinker with time with the aid of a set of linear variable differential transformers (LVDTs). The design of the new arrangement and procedure for terminal velocity determination and calibration procedures for the viscometer are also presented. The densities and viscosities are determined with an accuracy of $\pm 1 \%$ and $\pm 5 \%$ or better, respectively. 


\section{ACKNOWLEDGEMENT}

I would like to express my gratitude to Professor Erdogan Kiran, my advisor, for his constant guidance and constructive criticism which have helped me to accomplish this work and improve my technical abilities.

This is an opportunity to express my sincere thanks also to the departmental staff for all the help and advice I received over the years, and to all my friends for their continuous support both here at Virginia Tech and at the University of Maine. My special appreciation also goes to my friends Daniel J. Jolicoeur for his invaluable assistance with the mechanical work at University of Maine, and to Riley Chan with his great support in electronics here at Virginia Tech. I would also like to thank my colleague Wei Zhang for his help during every stage of this work in the laboratory.

I would like to thank my thesis committee members Donald G. Baird and Eva Marand for their interest in my work.

Finally, I would like to thank my dear parents Enver and Suzan Dindar for their priceless support, love and never failing faith in me. 
TABLE OF CONTENTS

\begin{tabular}{|c|c|c|}
\hline \multicolumn{3}{|r|}{ Page } \\
\hline List of Table & & vii \\
\hline \multicolumn{2}{|c|}{ List of Figures } & ix \\
\hline Chapter 1 & INTRODUCTION & 1 \\
\hline Chapter 2 & VISCOSITY MEASUREMENTS AT HIGH PRESSURES & 4 \\
\hline \multirow[t]{2}{*}{ Chapter 3} & EXPERIMENTAL SYSTEM AND OPERATIONAL & 16 \\
\hline & PROCEDURES & \\
\hline
\end{tabular}

3.1. Experimental System 16

3.2. Operational Procedures 23

$\begin{array}{lll}\text { Chapter } 4 & \text { CALIBRATION } & 28\end{array}$

4.1. Calibration Method Used in the Present Study 28

4.2. Determination of Terminal Velocity 30

4.3. Materials 37

4.4. n-Pentane 37

4.4.1. Density 37

4.4.2. Calibration Constant and Error Analysis $\quad 40$

4.4.3. Viscosity 44

4.5. Carbon dioxide 47

Chapter 5 VISCOSITY AND DENSITY OF POLYMER SOLUTIONS AT 53

THE CRITICAL POLYMER CONCENTRATION

5.1. Viscosity of PDMS $+\mathrm{CO}_{2}$ Solutions

5.2. Viscosity of PE $+\mathrm{n}-$ Pentane Solutions $\quad 60$

5.3. Analysis of Viscosity Data 67

5.3.1. Temperature Dependence of Viscosity $\quad 67$

5.3.2. Pressure Dependence of Viscosity 71

$\begin{array}{lll}\text { 5.3.3. Density Dependence of Viscosity } & 77\end{array}$ 
5.3.4. Significance of Viscosity in Phase Separation 88

Chapter 6 CONCLUSIONS AND RECOMMENDATIONS 94

$\begin{array}{ll}\text { REFERENCES } & 98\end{array}$

$\begin{array}{ll}\text { APPENDIX A } & 108\end{array}$

$\begin{array}{ll}\text { APPENDIX B } & 116\end{array}$

$\begin{array}{ll}\text { BIOGRAPHY } & 130\end{array}$ 


\section{LIST OF TABLES}

Table

Page

4.1. Density of n-pentane

38

4.2. Average calibration constants obtained from calibrations with n-pentane

4.3. Measurements of density and viscosity of $n$-pentane from the present study

4.4. Calibration constants obtained from calibrations with carbon dioxide

4.5. Measurements of density and viscosity of carbon dioxide

5.1. Density and viscosity of 5.5 wt $\%$ PDMS $\left(\mathrm{M}_{\mathrm{w}}=93,700\right)$ in $\mathrm{CO}_{2}$

5.2. Density and viscosity of $5.74 \mathrm{wt} \% \mathrm{PE}\left(\mathrm{M}_{\mathrm{w}}=93,700\right)$ in n-pentane

5.3. Activation energy, $E^{\#}$, for $5.5 \mathrm{wt} \%$ solution of PDMS $\left(\mathrm{M}_{\mathrm{w}}=93,700\right)$ in $\mathrm{CO}_{2}$

5.4. Activation energy, $E^{\#}$, for 1,2 and $5 \mathrm{wt} \%$ solutions of PDMS $\left(\mathrm{M}_{\mathrm{w}}\right.$ $=38,900)$ in $\mathrm{CO}_{2}$

5.5. Activation energy, $E^{\#}$, for $5.74 \mathrm{wt} \%$ solution of $\mathrm{PE}\left(\mathrm{M}_{\mathrm{w}}=93,700\right)$ in $\mathrm{n}$ pentane

5.6. Activation energy, $E^{\#}$, for 1 wt $\%$ solutions of $P E\left(M_{w}=93,700\right)$ in $n$ pentane

5.7. Activation volume, $V^{\#}$, for $5.5 \mathrm{wt} \%$ solution of PDMS $\left(\mathrm{M}_{\mathrm{w}}=93,700\right)$ in $\mathrm{CO}_{2}$

5.8. Activation volume, $\mathrm{V}^{\#}$, for 1,2 and $5 \mathrm{wt} \%$ solutions of PDMS $\left(\mathrm{M}_{\mathrm{w}}\right.$ $=38,900)$ in $\mathrm{CO}_{2}$

5.9. Activation volume, $V^{\#}$, for $5.74 \mathrm{wt} \%$ solution of $\mathrm{PE}\left(\mathrm{M}_{\mathrm{w}}=93,700\right)$ in n-pentane

5.10. Activation volume, $V^{\#}$, forl wt $\%$ solutions of $P E\left(M_{w}=93,700\right)$ in $n$ pentane

5.11. Coefficients for the exponential equation $\eta=A \exp \left[B /\left(1-V_{o} \rho\right)\right]$ for the 
density dependence of viscosity for $5.5 \mathrm{wt} \%$ PDMS solution $\left(\mathrm{M}_{\mathrm{w}}=\right.$ $\left.93,700, \mathrm{M}_{\mathrm{w}} / \mathrm{M}_{\mathrm{n}}=2.99\right)$ in $\mathrm{CO}_{2}$

5.12. Coefficients for the exponential equation $\eta=A \exp \left[B /\left(1-V_{o} \rho\right)\right]$ for the density dependence of viscosity for 1,2 and $5 \mathrm{wt} \%$ PDMS solutions $\left(\mathrm{M}_{\mathrm{w}}=38,900\right)$ in $\mathrm{CO}_{2}$

5.13 Coefficients for the exponential equation $\eta=A \exp \left[B /\left(1-V_{o} \rho\right)\right]$ for the density dependence of viscosity of $5.74 \mathrm{wt} \% \mathrm{PE}\left(\mathrm{M}_{\mathrm{w}}=121,000\right.$, $\mathrm{M}_{\mathrm{w}} / \mathrm{M}_{\mathrm{n}}=4.3$ ) solution in $\mathrm{n}$-Pentane

5.14 Coefficients for the exponential equation $\eta=A \exp \left[B /\left(1-V_{o} \rho\right)\right]$ for the density dependence of viscosity of $1 \mathrm{wt} \%$ PE solutions in n-Pentane 


\section{LIST OF FIGURES}

Figure Page

3.1 Flow Diagram of Viscometer 18

3.2 Side View of the Viscometer 19

3.3 Schematic of windings of Viscosity LVDT's 21

3.4 LVDT response as a function of the fall time for the sinker in $\mathrm{n}$ pentane 26 at $100^{\circ} \mathrm{C}$ and $20.97 \mathrm{MPa}$

4.1. LVDT signal in volts vs sinker position in the fall tube.

4.2. Normalized plot of LVDT response with sinker position 34

4.3. Normalized LVDT response versus fall time in n-pentane at $100^{\circ} \mathrm{C}$ and 35 $20.97 \mathrm{MPa}$.

4.4. Sinker fall distance vs time in n-pentane at $100^{\circ} \mathrm{C}$ and $20.97 \mathrm{MPa}$. The 36 slope is the fall velocity.

4.5. Comparison of experimental densities of n-pentane obtained in this study with the literature data taken from Kiran and Sen [15].

4.6. Variation of calibration constants with pressure. Overall average 41 calibration constant, $\mathrm{K}_{\mathrm{avg}}, 0.0199$, is shown as a straight line.

4.7. Variation of calibration constant obtained from n-pentane calibration with temperature.

4.8. Variation of viscosity, calculated using $K_{\mathrm{avg}}$, with pressure. 46

4.9. Examples "Distance versus Time" data obtained from measurements 48 with $\mathrm{CO}_{2}$ (where slope $=\mathrm{V}_{\text {ter }}$ ). (a) at $37^{\circ} \mathrm{C}$ and $20 \mathrm{MPa}$; (b) at $97^{\circ} \mathrm{C}$ and $40 \mathrm{MPa}$.

4.10. Variation of calibration constant calculated from carbon dioxide 49 measurements with pressure.

4.11. Variation of calibration constant calculated from carbon dioxide 50 measurements with temperature.

4.12. Difference in viscosities of carbon dioxide when experimentally 52 determined viscosities, using $\mathrm{K}_{\mathrm{avg}}$, 0.0199, are compared with the data 
taken from literature $\left(\Delta \eta=\eta_{\text {Kavg }}-\eta_{\text {lit }}\right)$ with pressure.

5.1 5.5 wt \% PDMS $\left(\mathrm{M}_{\mathrm{w}}=93,700 ; \mathrm{M}_{\mathrm{w}} / \mathrm{M}_{\mathrm{n}}=2.99\right)$ in $\mathrm{CO}_{2}$ at $70{ }^{\circ} \mathrm{C}$ and 48.5 MPa.

5.2 Variation of viscosity with pressure for 5.5 wt \% solution of PDMS 64 $\left(\mathrm{M}_{\mathrm{w}}=93,700\right)$ in carbon dioxide at different temperatures.

5.3 5.74 wt \% PE $\left(\mathrm{M}_{\mathrm{w}}=121,000 ; \mathrm{M}_{\mathrm{w}} / \mathrm{M}_{\mathrm{n}}=4.3\right)$ in n-pentane at $150{ }^{\circ} \mathrm{C}$ and $30.2 \mathrm{MPa}$.

5.4 Variation of viscosity with pressure for 5.74 wt \% solution of PE $\left(M_{w}=66\right.$ 121,000) in n-Pentane at different temperatures.

5.5 Variation of $\ln \eta$ with reciprocal temperature, $1 / \mathrm{T}$, for $5.5 \mathrm{wt} \%$ solution 68 of PDMS $\left(M_{w}=93,700\right)$ in carbon dioxide at different pressures.

5.6 Variation of $\ln \eta$ with reciprocal temperature, $1 / \mathrm{T}$, for 5.74 wt \% 72 solution of PE $\left(\mathrm{M}_{\mathrm{w}}=121,000\right)$ in $\mathrm{n}$-pentane at different pressures.

5.7 Variation of $\ln \eta$ with pressure for $5.5 \mathrm{wt} \%$ solution of PDMS $\left(\mathrm{M}_{\mathrm{w}} 73\right.$ $=93,700)$ in carbon dioxide at different temperatures.

5.8 Variation of $\ln \eta$ with pressure for 5.74 wt $\%$ solution of $\mathrm{PE}\left(\mathrm{M}_{\mathrm{w}}=76\right.$ $121,000)$ in n-Pentane at different temperatures.

5.9 Variation of density with pressure for $5.5 \mathrm{wt} \%$ solution of PDMS (M $\mathrm{M}_{\mathrm{w}} 79$ $=93,700$ ) in carbon dioxide at different temperatures.

5.10 Variation of viscosity with density for 5.5 wt \% solution of PDMS (M $M_{\mathrm{w}} \quad 80$ $=93,700)$ in carbon dioxide.

5.11 Variation of viscosity with density for $5.5 \mathrm{wt} \%$ solution of PDMS in carbon dioxide and fitted Doolittle type of equation for this system.

Fitted Equation: $\mathrm{Y}=0.000454 * \mathrm{EXP}(4.156 /(1-0.3297 * \mathrm{X}))$

5.12 Variation of density with pressure for 5.74 wt \% solution of PE $\left(M_{w}=84\right.$ $121,000)$ in n-Pentane at different temperatures.

5.13 Variation of viscosity with density for 5.74 wt \% solution of PE $\left(\mathrm{M}_{\mathrm{w}}=85\right.$ 121,000) in n-Pentane.

5.14 Variation of viscosity with density for 5.74 wt $\%$ solution of PE in $n-$ pentane and fitted Doolittle type of equation for this system. 
Fitted Equation: $\mathrm{Y}=6.369 * \mathrm{EXP}(11.44 /(1-0.4772 * \mathrm{X}))$

5.15 Pressure-composition phase diagram of a polymer solution at constant temperature.

5.16 The evolution of the scattered light intensities with time as a function of the wave number $\mathrm{q}$ after a pressure quench $\Delta \mathrm{P}=0.7 \mathrm{MPa}$ in $5.75 \%$ by mass solution of $\mathrm{n}$-PE $(121,000)$ in pentane at $150{ }^{\circ} \mathrm{C}$. The total observation time is $24.0 \mathrm{~s}$. (From ref. [69])

5.17 The evolution of the scattered light intensities with time as a function 93 of the wave number $\mathrm{q}$ after a pressure quench of $\Delta \mathrm{P}=0.25 \mathrm{MPa}$ in 5.5 $\%$ by mass solution of PDMS in $\mathrm{CO}_{2}$ at $75{ }^{\circ} \mathrm{C}$. The total observation time is $14.4 \mathrm{~s}$ (From ref. [68, 69]). 


\section{CHAPTER 1}

\section{INTRODUCTION}

Information on high-pressure viscosity and density of polymer solutions are very important in a variety of applications such as high-pressure synthesis, molten polymer processing, enhanced oil recovery, and lubrication with polymer additives. The viscosity is also a significant factor that influences phase separation processes. Also, with the growing interest in the possible use of near-critical and supercritical fluids in polymer synthesis and modifications, there is an extensive need for basic and applied data at high pressures.

The objectives of this study were two-fold: first to improve on the method for determining the terminal velocity of the falling sinker of the high-temperature highpressure viscometer built in our laboratory earlier, and the second to determine the viscosity of polymer solutions at the critical polymer concentration at high pressures to demonstrate not only the influence of pressure and temperature on viscosity, but also to demonstrate the role of viscosity in kinetics of new-phase growth..

Chapter 2 presents a literature review, Chapter 3 and 4 provide the detail of the experimental system and the calibration procedure, and Chapter 5 presents the viscosity data on the selected polymer solution systems.

In Chapter 2, the various types of viscometers that are used at high pressures are described, and literature work related with different measurement techniques is reviewed. 
Chapter 3 presents considerable detail on the experimental system especially on the new design features. In this work, the high-pressure high-temperature falling sinker type of viscometer that had been built earlier in our laboratory has been used to measure the viscosity. During the course of this thesis modifications were made to the sensing coil design to develop a more reliable procedure for determining the terminal velocity of the sinker and thus to improve the accuracy of the viscosity measurements.

Chapter 4 describes the procedure to determine the terminal velocity of the falling sinker with this new coil design and to validate a new calibration procedure based on these terminal velocity calculations using $\mathrm{n}$-pentane and carbon dioxide.

For more than a decade, Professor Kiran's research group has focused on the measurement of high pressure viscosity of pure solvents as well as dilute polymer solutions with the falling-sinker viscometer that is used in this thesis. Previously studied systems include $\mathrm{n}$-alkanes, polystyrene solutions in $\mathrm{n}$-butane, polyethylene in $\mathrm{n}$-pentane, poly(dimethylsiloxane) in supercritical carbon dioxide and polystyrene in n-hexane. For this thesis, viscosities and densities of solutions of poly(dimethylsiloxane) (PDMS) in $\mathrm{CO}_{2}$ and polyethylene (PE) in $\mathrm{n}$ pentane have been measured at the critical concentration. The results are presented and discussed in Chapter 5. This study is part of a broader scope investigation of polymer solutions, and complements the studies on the kinetics of pressure-induced phase separation at critical polymer concentration. Time-scale of phase separation plays a very important role on the pathway to new polymeric materials, and viscosity is an important factor that influences the time-scale of new phase development in systems undergoing phase separation. Solutions at the critical polymer concentrations undergo phase separation by spinodal decomposition. Two different polymer + solvent systems that undergo spinodal decomposition at the critical polymer concentration may exhibit different kinetics. It was therefore of interest to determine the viscosity of these two inherently different polymer solutions at their critical polymer concentrations. 
The conclusion and recommendations based on this study are summarized in Chapter 6 . Appendix A and B are provided to give detailed information related with the corresponding sections throughout the thesis. 


\section{CHAPTER 2}

\section{VISCOSITY MEASUREMENTS AT HIGH PRESSURES}

Viscosity plays a very important role in various engineering calculations since masstransfer and fluid flow calculations are based on this property. Physical systems and applications such as flow of fuids, whether flow in porous media or in wells or pipes, the flow of blood, lubrication of engine parts, the dynamics of rain drops, volcanic eruptions, planetary and stellar magnetic field generation are controlled to some degree by fluid viscosity. The viscosity of a solution is very important because it determines the settling rates of particles within the solution during crystallization processes, and heat transfer rates in heat exchange equipment required for heating or cooling the solution in many processes. Not only in crystallization but also in filtration and diffusion processes viscosity is fundamental.

High-pressure viscosity measurements have extensive practical importance. In the field of lubrication, the change of viscosity with pressure is a critical parameter in determining the metal-metal contact [1]. The petrochemical industry needs reliable viscosity data at high pressure for hydrocarbon mixtures to validate their process designs [2]. Viscosity measurements of electrolyte solutions under high pressure have been important in designing power generating plants and other facilities using geothermal brine or sea water, and in the study of dynamic properties of ions or solvent molecules at high pressures [3]. The high-pressure viscosity is also needed to estimate the diffusion rate of the molecules in a fluid [1]. Knowledge on viscosity of polymer solutions is extremely important for many processes involving polymer formation and solution processing [1-5]. 
Even though numerous publications have appeared on the effect of changes in temperature, solvent quality, concentration, polymer chain architecture and molecular weight on viscosity of polymer solutions, influence of pressure has not been studied as extensively. However, knowledge of polymer solution viscosity has gained special significance due to rapid developments in processing of polymers in supercritical or dense fluids over the past decade [4].

Measurement of viscosity of polymeric fluids under high pressure is not easy since constructing a viscometer that can operate above ambient conditions brings many technical problems, the most common one being sealing. Studying pressure-dependence of viscosity has indeed always been a challenge because of the technical problems with nearly all types of classical viscometers $[5,6]$.

The common types of viscometers that are used to determine the viscosities at high pressures can be grouped according to the chronological development of the technique as follows:

- Capillary Flow Viscometers

- Rolling or Falling Body Viscometers

- Vibrating-quartz Viscometers

- Vibrating-wire Viscometers

- Diamond-anvil Cell

- Other techniques (Rotational viscometers, high-pressure high-shear stress Couette viscometer, magnetoviscometer, centrifuge ball viscometer, dynamic light scattering)

These techniques have been widely used for measurements at high pressures and/or temperatures more than a century. In this section, the general working principles of these viscometers will be reviewed with few examples. 


\section{A. CAPILLARY FLOW VISCOMETERS}

Röntgen is reported to be the first to measure pressure dependence of the viscosity of water [7]. He worked with pressures up to 20 bar using a capillary flow viscometer [7]. In this method a liquid is forced through a fine-bore tube, and viscosity $(\eta)$ of the liquid is determined from the measured volumetric rate $(\mathrm{V} / \mathrm{t})$, the pressure drop $(\Delta \mathrm{P})$, and the tube dimensions according to the Poiseuille equation

$\eta=\pi \mathrm{r}^{4}(\Delta \mathrm{P}) \mathrm{t} /(8 \mathrm{Vl})$

where $\mathrm{r}$ and 1 are the radius and the length of the capillary. This relationship is only applicable for Newtonian fluids. For non-Newtonian fluids such as those obeying Bingham-body model, power law model and Eyring model, different relationships are used [8].

Barnett and Basco, in 1969, used a capillary-type viscometer which is capable of measurements up to $6 \mathrm{GPa}$ [1]. The design of this viscometer relies on the fluid flow between two portions of viscometer that are under slightly different pressure while the entire viscometer is at a high overall pressure. It was used to measure viscosities in the range from $10^{7}$ to $10^{12} \mathrm{cP}$ [7].

Kobayashi and Nagashima measured the viscosities of pure 2.2.2-trifluoroethanol and its aqueous solutions in the temperature range $273-453 \mathrm{~K}$ and pressures up to $40 \mathrm{MPa}$ with a closed circuit capillary viscometer [9].

A high-pressure capillary viscometer was designed and built by Kashulines to measure the viscosities of supercritical carbon dioxide containing several types of dissolved liquid solutes [10]. Later, the same instrument was used to measure the viscosities of supercritical carbon dioxide-lipid mixtures pressures up to $30 \mathrm{MPa}$ and temperatures up 
to $333.15 \mathrm{~K}$ by Yener et al. [11]. The viscosities of supercritical carbon dioxidebiomaterial(s) mixtures over a pressure range of 10.6-25.0 $\mathrm{MPa}$ have been reported by Tuan et al. also using this viscometer [10].

\section{B. ROLLING OR FALLING BODY VISCOMETERS}

Flowers is known as the first to point out and demonstrate the potential of rolling-ball viscometers in 1914. Since then many attempts has been made to relate the viscosity of the fluid with the velocity of a rolling or falling body [12]. Bridgman is known to be the first to measure viscosity up to very high-pressure range (1.2 $\mathrm{GPa})$ using falling body viscometer. In his work, the velocity of falling weight was detected electronically and through an empirical equation the relative viscosity was calculated. His viscometer consisted of a cylinder into which the falling weight was placed, and then the whole system was placed in a pressure chamber. Sealing complexities and the need for very high pressures in order for the weight to fall were only a few limitations of this system. Later, Bridgman used an improved high-pressure device where the entire pressure chamber was filled with the fluid under study, and only the fluids compatible with the components of the pressure chamber could be analyzed [1].

Stokes' law which relates the viscosity of a Newtonian fluid to the velocity of a falling sphere is the principle of falling ball viscometers. If a sphere of radius $R$ and density, $\rho_{s}$ falls through a fluid of density $\rho$ and viscosity $\eta$ at a constant velocity $v_{t}$, the following relationship is found

$\eta=(2 / 9)\left(\rho_{\mathrm{s}}-\rho\right) g \mathrm{R}^{2} / \mathrm{v}_{\mathrm{t}}$

Eqn. 2.2

where $\mathrm{g}$ is the gravitational acceleration [28, 29]. With these viscometers, fall times should be measured when the ball reaches the terminal velocity. 
In rolling ball viscometers, similar to the falling ball viscometers, the speed of the rolling sphere down in a cylindrical tube inclined at a fixed angle to the horizontal is used to determine the viscosity. In this case, the velocity, $v_{t}$, in the equation is the translational velocity of the rolling sphere.

Falling cylinder, or sinker, viscometers are based on the similar working principle to that of the falling ball viscometers, the only difference being the shape of the weight. Determination of the absolute viscosity requires the precise knowledge of the geometry of the falling cylinder and the forces acting on it. Therefore most measurements are made relative to viscosity standards. General equation of the viscosity for Newtonian fluid is described by Lohrenz et al. in 1960 [5] as follows:

$\eta=\frac{t\left(\rho_{s}-\rho_{f}\right)\left(r_{1}^{2} g\right)\left[\left(r_{2}^{2}+r_{1}^{2}\right) \ln \left(r_{2} / r_{1}\right)-\left(r_{2}^{2}-r_{1}^{2}\right)\right]}{2 L\left(r_{2}^{2}+r_{1}^{2}\right)}$

Eqn. 2.3

where $\eta$ is the viscosity, $t$ is the fall time, $\rho_{s}$ is the density of the sinker, and $\rho_{\mathrm{f}}$ is the density of the fluid, $L$ is the vertical fall distance, $r_{1}$ and $r_{2}$ are the radius of the sinker and inner radius of the fall tube respectively [5].

A rolling ball viscometer was constructed by Schmidt and Wolf which can be operated up to 4000 bar for the measurements of both dilute and concentrated polymer solutions [13]. They measured polystyrene/tert-butyl acetate solution viscosities temperatures up to 403 $\mathrm{K}$ and pressures higher than 4000 bars. They studied the intrinsic viscosity and Huggins coefficient as a function of temperature and pressure by estimating densities using the Tait-Equation.

Stanislawski and Luft developed a rolling ball viscometer, which consists of a glass tube, closed at one end, with a steel ball inside [14]. An dectromagnet was placed at the open end of the tube, and this arrangement was installed in a high-pressure autoclave. Two 
pairs of measuring coils are used to detect the rolling ball inductively. This instrument was used at pressures up to $195 \mathrm{MPa}$ and temperatures up to $413 \mathrm{~K}$ to measure the viscosity of alcohol-ethene mixtures by Sulzner et al. [14].

Sawamura et al. designed corrosion resistance type rolling-ball viscometer for electrolyte solutions under high pressure, which consisted of an optical detector, a glass inner tube, and a glass ball to avoid corrosion of the pressure vessel and contamination of the sample solution [3].

In 1991, a falling-cylinder viscometer which can operate up to $473 \mathrm{~K}$ and $70 \mathrm{MPa}$ was designed by Kiran and his coworkers [5, 15]. The viscometer consisted of a fall tube, a view cell and a variable volume attachment. Density measurements are based on the measurement of the inside volume of the viscometer and the knowledge of the mass of the sample loaded. The viscosity measurements are based on the measurement of the fall time of a sinker falling vertically in a cylindrical tube. In this instrument a ferromagnetic 416 stainless steel sinker was used. In the present study this system has been used with a different sinker [16] and an improved coil design that helps to determine the fall times and terminal velocities in a more precise manner.

Depending on the viscometer and experimental conditions various falling or rolling body types have been used for determination of velocity. Sawamura et al. used a glass ball in their high-pressure rolling ball viscometer of a corrosion resistant type [3]. A nonmagnetic 316 stainless steel sinker with a density of $7.28 \mathrm{~g} / \mathrm{cm}^{3}$ and small ferrite core embedded into is used at a high pressure self-centering falling-body viscometer by Malhotra et al. [17]. While studying non-Newtonian fluids with a rolling-ball viscometer Briscoe et al. used bronze balls with a density of $8.32 \mathrm{~g} / \mathrm{cm}^{3}$ [18]. Nickel boron spheres (diameter about $50 \mu \mathrm{m}$ ) are used with a density of $7.6 \mathrm{~g} / \mathrm{cm}^{3}$, which gives a good density contrast with hydrocarbon fluids whose densities are in the range of $0.8-1.5 \mathrm{~g} / \mathrm{cm}^{3}$ by King et al. in their high pressure diamond anvil cell [1]. LeBlanc and Secco used a Pt 
sphere with a diameter $0.7-0.74 \mathrm{~mm}$, while measuring the viscosity of melt samples of natural jadeite between 1350 and $1450^{\circ} \mathrm{C}$ and up to $2.4 \mathrm{GPa}$ [19].

\section{VIBRATING-QUARTZ VISCOMETERS}

Torsionally vibrating quartz crystal viscometer, introduced by Mason in 1947, was suitable for high-pressure measurements because of its simplicity, small size, absence of macroscopically moving parts, no use of pressure differences, and reduced number of required electrical connections [20]. It consists of a quartz cylinder with four very thin gold electrodes deposited on the latheral surface. A sinusoidal wave applied to the electrodes produces a torsional vibration of the same frequency as the excitation wave, damped by the fluid around the crystal. The amount of damping is measured by the change in the electrical impedance of the crystal and reflects the product viscosity - density of the surrounding fluid [20-23]. Viscosities were calculated using the equation established by Welber and Quimby:

$\eta=(\pi \mathrm{f} / \rho)\left[(\mathrm{M} / \mathrm{S})\left(\Delta \mathrm{f} / \mathrm{f}-\Delta \mathrm{f}_{\mathrm{o}} / \mathrm{f}_{\mathrm{o}}\right)\right]^{2}$

Eqn. 2.4

where $\mathrm{f}$ is the resonant frequency in the fluid, $\Delta \mathrm{f}$ is the bandwidth in the fluid, $\rho$ the fluid density, $\mathrm{M}$ mass of the quartz crystal of area $\mathrm{S}, \mathrm{f}$ the resonant frequency in vacuum, and $\Delta \mathrm{f}_{\mathrm{o}}$ the resonant bandwidth in vacuum.

Based on this technique, Santos and Castro used a torsionally vibrating quartz crystal viscometer up to $200 \mathrm{MPa}$ and $373.15 \mathrm{~K}$ [22]. First of all, products of density and viscosity are calculated, then densities are obtained from the equations of Kashiwagi et al [21]. Viscosity values determined for each temperature are then fitted with a Tait - like equation,

$\left(\operatorname{lm} / \ln \eta_{\mathrm{o}}\right)=\mathrm{E} \ln \left[(\mathrm{D}+\mathrm{P}) /\left(\mathrm{D}+\mathrm{P}_{\mathrm{o}}\right)\right]$

Eqn. 2.5 
In order to check the operating conditions of the viscometer and to try to establish its accuracy, same group using fluid viscosity measured with another viscometer, calculated the residual damping of the transducer [21, 22]. Following the same procedure, viscosities were fitted to a Tait-like equation. It was concluded that Tait-like equation for the viscosity is rather inadequate for large ranges of pressure because of the exponential dependence of viscosity on pressure, and does not have any physical meaning as it does for the density dependence of pressure, where it originated.

\section{VIBRATING-WIRE VISCOMETERS}

Vibrating-wire type of viscometers is an alternative method that makes use of the effect of the fluid on the oscillations of a body immersed in the fluid. The first vibrating-wire viscometer was developed in1964 by Tough et al [25]. Cylindrical wire was chosen as the most suitable geometry for high pressure operations [12, 24]. The method involves setting a thin tungsten wire into traversal vibration and determining the damping of this motion by the surrounding sample liquid. The wire is set into vibration by means of Lorentz force generated by an alternating electrical current and a magnetic field raised by an electromagnet. After electrical current is stopped, the free damped oscillation of the wire in the magnetic field causes an induction voltage which is amplified, sampled and stored on a computer disk. The damping of this signal is a measure for the viscosity of the sample fluid [25, 26]. In the working equation of vibrating-wire, the viscosity and the density are coupled. But the sensitivity of density is in practice too low for precise determination of this property. Therefore previous knowledge of the density of the fluid is necessary in order to determine its viscosity accurately. In 1998, Pádua et al. explored a new arrangement for the vibrating wire sensor in which the wire is tensioned by a suspended weight, or sinker. The density of the fluid is determined by hydrostatic weighing, with the wire acting as a force sensor [26, 27]. In 1997, Gulik extended the operation range of vibrating-wire viscometer by determining the viscosity of liquid carbon dioxide below ambient temperatures, between $217 \mathrm{~K}$ to $304 \mathrm{~K}$, and pressures up to $500 \mathrm{MPa}[25]$. 
Assael et al. [12] described the design and operation of the vibrating-wire viscometer capable of measuring pressures up to $100 \mathrm{MPa}$, based on the similar procedure Santos and Castro followed. They also used a Tait-like equation similar to Eqn 2.5 for viscosity where $\mathrm{P}_{\mathrm{o}}$ is 0.1 and both $\mathrm{E}$ and $\mathrm{D}$ obtained from nonlinear least squares procedure. Assael et.al. [27] used Tait-type of equation for density calculations;

$\left(\rho-\rho_{o}\right) / \rho=C \log [(B+P) /(B+0.1)]$

Eqn.2.6

$\mathrm{B}$ and $\mathrm{C}$ are the coefficients $\left(\mathrm{C}=0.216\right.$ was proposed by Dymond et al [27]), $\rho_{\mathrm{o}}$ is the density at $0.1 \mathrm{MPa}$.

The advantage of vibrating-wire technique is that it does not require extensive calibration procedures, once the physical parameters of the sensor are determined (length, radius, and Young modulus of the wire, volume and mass of the weight), no additional calibrations are necessary for operation in different fluids or at conditions away from room temperature and atmospheric pressure. The disadvantage is density cannot be determined along with the viscosity in most of them. Other techniques need to be explored for density calculations [26].

\section{E. DIAMOND ANVIL CELL}

Diamond-anvil cell consists of two small diamond surfaces between which the sample is squeezed. The small size and extreme pressure range make this an ideal device for many experiments. The pioneering effort in adapting the diamond cell to high- pressure viscosity measurements was made by Piermarini, Forman and Block in 1978 [1]. They presented their results using their falling-ball viscometer on 4:1 methanol:ethanol mixtures at pressures up to $7 \mathrm{GPa}$, corresponding to maximum viscosity of $10^{7} \mathrm{cP}$. Fujishiro, Nakamura, and Matsuhiro, in 1986, improved the same device by changing the 
optics and electronics for measuring the sphere position and obtained more accurate results up to pressures of $3.8 \mathrm{GPa}$ and viscosities of $10^{7} \mathrm{cP}[1]$.

In 1992, King et al. developed a high-pressure viscometer based on their diamond anvil cell where a sphere rolls down a diamond surface under the force of gravity and its position is tracked electronically [1]. This combination improved the precision of the viscosity measurements compared to the measurements done using diamond-anvil cell viscometers based on falling-ball principle. The viscosity range is $0.5-10^{7} \mathrm{cP}$ and the measurements are done above $1 \mathrm{GPa}$. $[1,28,29]$. In their set-up, a video camera relays the image of the ball to a video dimension analyzer (VDA) which returns a voltage proportional to the displacement of the ball. The computer gives displacement and time by making periodic readings of the VDA output. Slope of the line gives the velocity of the ball, and this is used to calculate the viscosity by a modified Stokes equation

$\eta=\gamma\left[2 \mathrm{R}^{2} \mathrm{~g}\left(\rho_{\mathrm{s}}-\rho_{\mathrm{f}}\right) \cos \theta\right] / 9 v$

Eqn.2.7

where $\mathrm{R}$ is the radius of the sphere, $\mathrm{g}$ is the acceleration of the gravity, $\rho_{\mathrm{s}}$ is the sphere density, $\rho_{\mathrm{f}}$ is the fluid density, $\theta$ is the tilt angle of the cell, $v$ is the velocity of the ball, and $\gamma$ is the wall correction. This equation is only applicable to Newtonian fluids. Density of the fluid was calculated from an equation of state using data from the literature. The difficulty that limits to use of this equation is that one must know the $\gamma$, wall correction factor, prior to the measurements. They assumed that wall correction factor is independent of pressure, and stays constant throughout the experiments $[1,34,35]$. Measuring the radius of the sphere very precisely is another problem since this is a microscopic sphere. (4\% uncertainty in the radius of sphere may lead to up to $8 \%$ error in calculating viscosity). In conventional rolling-ball, or falling-ball, type of viscometers these problems can be solved by repetitive use of the same sphere calibrated in a fluid of known viscosity. When diamond anvil cell is used as a falling ball viscometer some other complications arise due to the fact that the actual starting point of the trajectory will be 
whereever the ball comes to rest on the bottom of the pressure chamber before the cell is rotated. This will change the wall effects and thus will cause variations in the velocity of the sphere observed by some workers [1]. Another limitation is most diamond anvil cells that are used as rolling ball viscometers are capable only at ambient temperatures [30].

\section{F. OTHER TECHNIQUES}

Rotational Viscometers: Rotational viscometers consist of two members which are able to rotate relative to one another with a common axis of symmetry. One of the members when rotated produces shearing action on the liquid which is transmitted to the other member. The torque required to produce a given angular velocity is related with the viscosity of the fluid. The most common designs are: coaxial cylinder viscometers, rotating disk viscometers, cone-and-plate viscometer and con-cylindrical viscometer. The properties of both Newtonian and non-Newtonian materials can be studied [8].

High-pressure high-shear stress Couette viscometer: A Couette-type viscometer/ rheometer was developed by Jimenez and Kostic to measure viscosity and elastic properties of low-viscous, non-Newtonian, and visco-elastic fluids, like dilute polymer solutions [31]. Viscosities from 0.5 to $50000 \mathrm{cP}$ could be determined. Authors did not emphasize the operating pressure and temperature range of the instrument. A highpressure high-shear stress Couette viscometer is used up to $200 \mathrm{MPa}$ pressure and $90{ }^{\circ} \mathrm{C}$ temperature by Bair [32, 33].

Magnetoviscometer: Mattischek and Sobczak used a magnetic viscometer based on Stokes falling sphere principle that can operate up to $70{ }^{\circ} \mathrm{C}$ and 1000 bars [6]. Their magnetoviscometer is a simple brass cylinder which is closed with a screw after being filled with the fluid of the study and an appropriate iron sphere. The cell is fixed in a heating block, which can be rotated in the center of a magnetic field. A thermocouple and two coils are attached to the block to detect the sphere and measure the velocity of it. The distance between the coils and the time for the sphere to pass both coils are known, and 
these information is used to calculate velocity of the sphere and thus viscosity of the sample fluid. Advantages of this pressure cell are: hermetically sealed pressure cell, good pressure stability, no pressure gradient and small sample chamber.

Centrifugal-force diamond anvil cell: Cook et al. developed a centrifugal-force diamond anvil cell, to determine high viscosities for cases when the force of gravity is not sufficient to move the sphere [34]. The cell is placed into a centrifuge and a centrifugal force is applied to accelerate the sphere. This way high pressure viscosities greater than $10^{9} \mathrm{cP}$ and up to $10 \mathrm{GPa}$ pressures could be measured [35]. A centrifuge ball viscometer was developed for fluids, with a wide viscosity range of about $10^{-1}$ to $10^{5}$ Pas, which can operate over $400{ }^{\circ} \mathrm{C}$ [36]. With variable centrifugal acceleration, the measurement time to determine the ball viscosity could be reduced dramatically for highly viscous polymer melts. About $0.5 \mathrm{ml}$ of sample volume is needed for the measurements.

Dynamic light scattering: A common application of dynamic light scattering is determination of polymer chain dimensions where the polymer is dissolved in a solvent of known viscosity. With this technique inverse diffusion time, $\Gamma$, can be determined. This is related to the scattering factor, $\mathrm{q}$, by the equation $\Gamma=\mathrm{Dq}^{2}$ where $\mathrm{D}$ is the diffusion coefficient. Viscosity can be determined if the diffusion coefficient is measured for a probe particle of known size. Using light scattering method viscosities in the range of $10^{-}$ ${ }^{1}$ to $10^{2} \mathrm{cP}$ can be determined [35].

\section{G. VISCOSITY MEASUREMENT TECHNIQUE USED IN THE PRESENT STUDY}

A viscometer which was developed in our laboratory earlier [5] that is based on falling cylinder method has been used in the present study. Viscosities of polymer solutions have been measured with this viscometer previously [63-67]. Even though the instrument was the same, some changes were implemented in order to evaluate terminal velocity with greater reliability. These new design features are described in the next chapter. 


\section{CHAPTER 3}

\section{EXPERIMENTAL SYSTEM AND OPERATIONAL PROCEDURES}

\subsection{Experimental System}

The High Pressure- High Temperature viscometer used in our study is shown in Figures 3.1. and 3.2. The system was developed and constructed earlier [5, 15]. The system consists of three main parts which are: 1) solvent delivery system, 2) viscometer with its variable volume cell attachment and 3) the control and data acquisition units. Below are brief descriptions of the system components and the details of new design features that have been implemented in the course of the present study.

The solvent delivery line and the pressurization line, shown in the flow diagram in Figure 3.1. are used to load and pressurize the viscometer system. A high-pressure liquid pump, equipped with a cooling jacket, is used on both solvent and pressure lines to pump the fluid sample and pressurizing fluid. A pressure generator is connected to the pressure line. It is used to regulate the position of the piston in the variable volume part of the view cell and thus controls and manipulates the pressure in the view cell. A check valve is placed at each line to prevent fluids from going back in the lines. In Figure 3.2, the viscometer and variable-volume cell system is shown. It consists of a mixing cell, a movable piston and a fall tube. The mixing chamber has two sample ports, $S 1$ and $S 2$, which are used to charge fluids and solids, respectively. A magnetic stirring bar in the mixing cavity is used to stir the contents of the view cell with the help of electromagnetic coils around the cell. 
The fall tube is made of nonferromagnetic 316 stainless steel. The sinker, $0.7781 \mathrm{~cm}$ in diameter and $2.094 \mathrm{~cm}$ in length (with $4 \mathrm{~g} / \mathrm{cm}^{3}$ density), is made of an aluminum core and ferromagnetic 416 stainless steel shell and thus magnetically permeable [16]. The leading end of the sinker is hemispherical. The ratio of sinker-to-tube radii is 0.9799 , which is greater than 0.93 needed to insure concentric fall and error-free fall time measurements $[5,16]$.

The viscometer is housed in an oven the temperature of which is controlled with a PID controller. The controller is connected to $120 \mathrm{~W}$ heaters that are attached to the ends of the oven, in a way to achieve a uniform temperature distribution. A fan and a circulation pipe are used to provide good circulation of air inside the oven, especially along the height of the fall tube.

The viscometer temperature is measured with an accuracy of $\pm 1.5 \mathrm{~K}$ using a J-type thermocouple with a resolution of $0.1 \mathrm{~K}$. The temperature is measured at two locations; one being in the middle of the oven with this thermocouple and the other one is with the RTD probe of the temperature controller. Both readings agree assuring that uniformity of temperature.

The viscometer pressure is measured with an accuracy of $\pm 0.06 \mathrm{MPa}$ using a Dynisco flush mount type transducer that is attached to the view cell body. The reading is obtained using a microvoltmeter with a resolution of $0.007 \mathrm{MPa}$. 


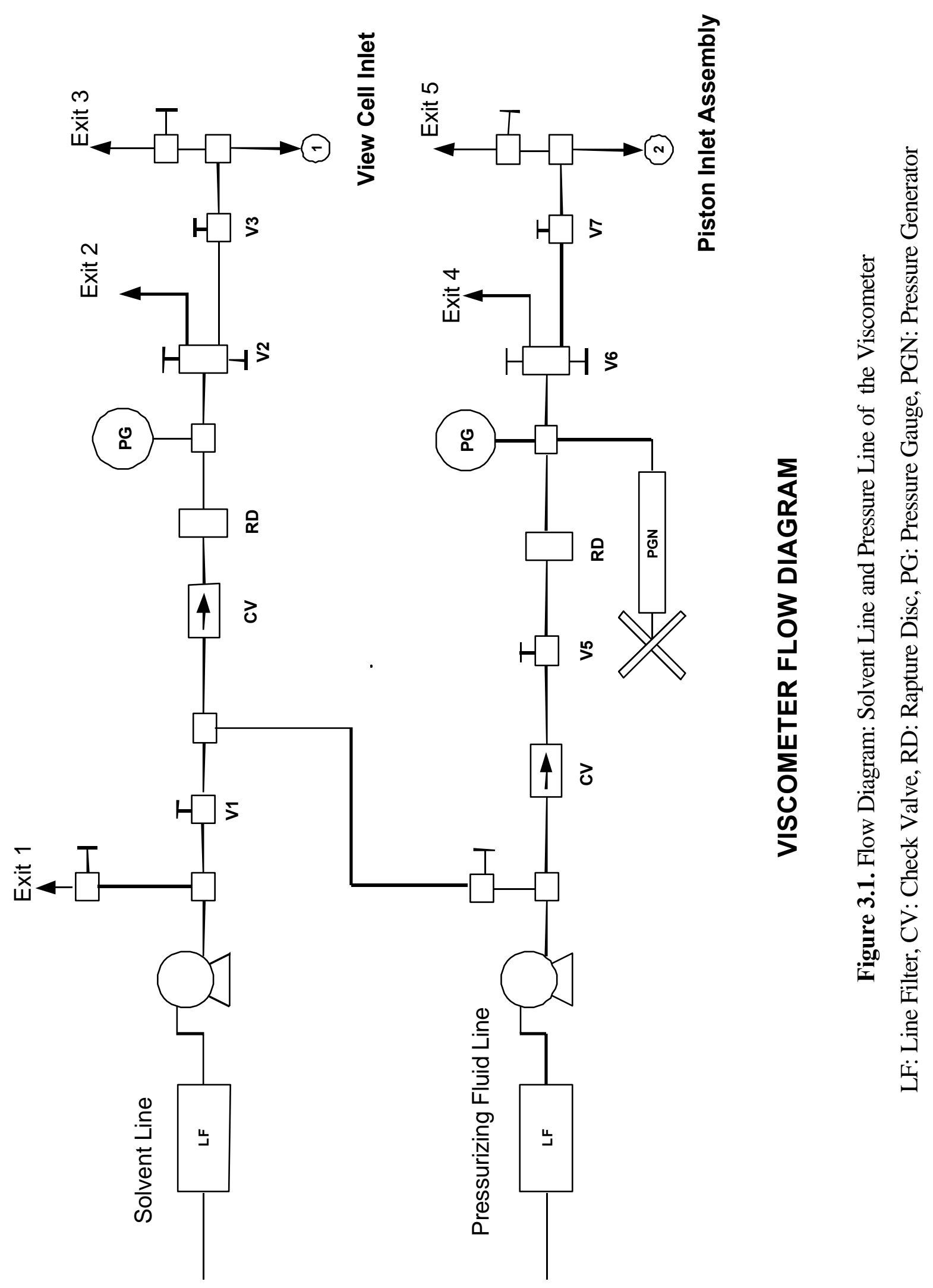




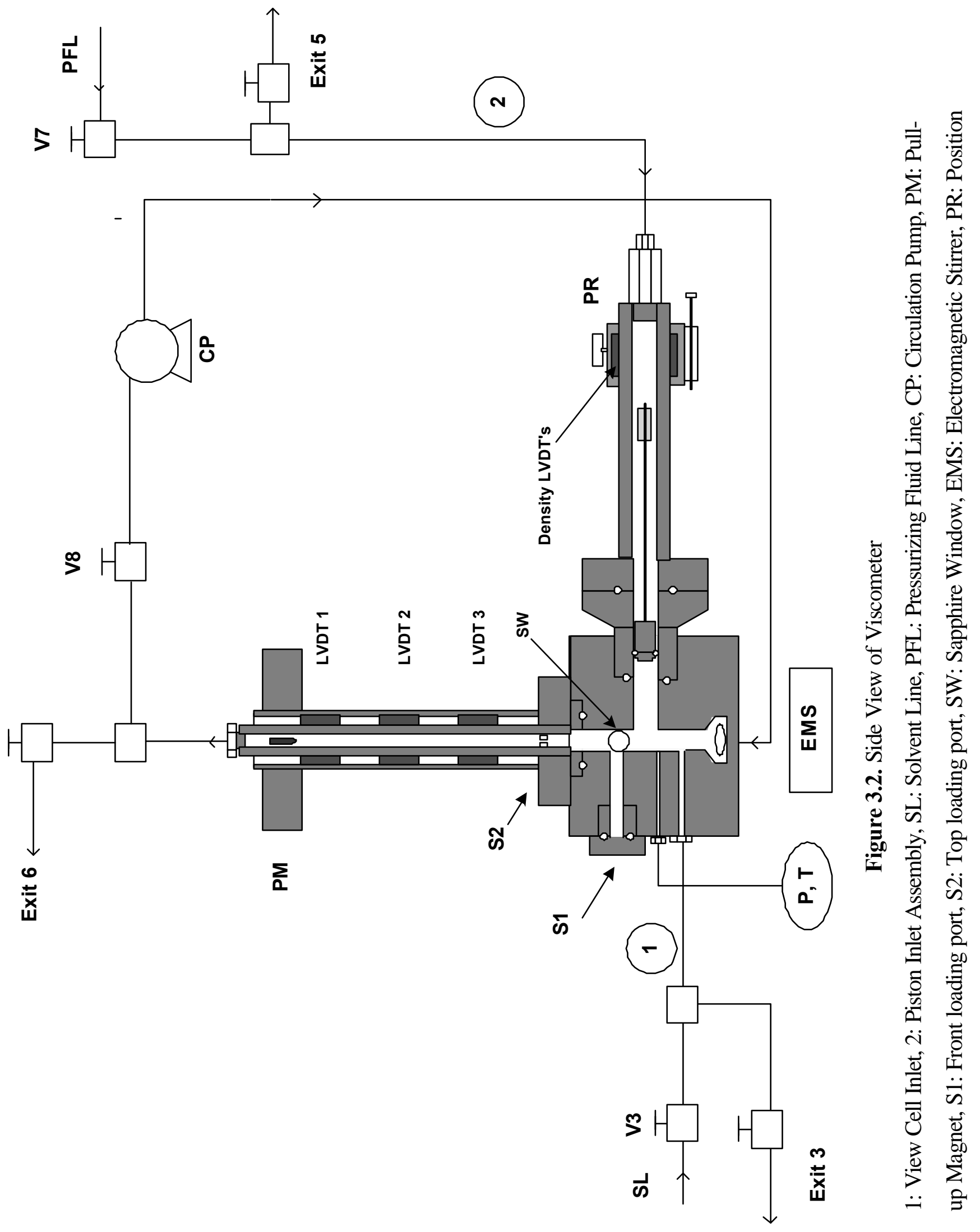




\section{New Design Features}

\section{a. New LVDT Coils and Washer for Viscosity Measurements}

Three LVDT coils (Linear Variable Differential Transformer) that are placed along the viscometer fall tube are used to determine the fall time and the terminal velocity of the sinker that is used in viscosity determination. The present instrument and operational procedure have been modified to improve reliability of the terminal velocity and thus to improve the accuracy of the viscosity measurements. We now use one long LVDT washer, made of brass, that accommodates three coils. This is in contrast to the three separate washers that were being used previously. The total length of the washer is 11.10 $\mathrm{cm}$, where coil lengths are about $3.53 \mathrm{~cm}$. The outer diameter is $1.91 \mathrm{~cm}$ and each LVDT coil has one primary and two secondary coils as shown in Figure 3.3. The outlets from the first and the second coils are introduced as the inlets for the second and the third coils respectively, and the inlets of the first coil and the outlets of the third coil are connected both for the primary and the secondary. The primary of the first LVDT coil is excited by a sine wave signal generator and the output signal from the secondaries are sent to an LVDT signal conditioner unit. A balanced demodulator chip is used in the signal conditioner to produce a DC voltage which corresponds the position of the ferromagnetic sinker while it passes through the LVDT coils. The output of the LVDT signal conditioner is sent both to a DC ammeter to monitor the fall of the sinker visually on the control panel, and to the computer through an A/D interface which stores the "voltage and real time" readings. After each fall time measurement a pull-up magnet, whose speed and position can be adjusted by a control unit, is used to bring the sinker back to the top of the fall tube. The pull-up magnet is energized with DC voltage using a variac and $\mathrm{AC} / \mathrm{DC}$ converter. 


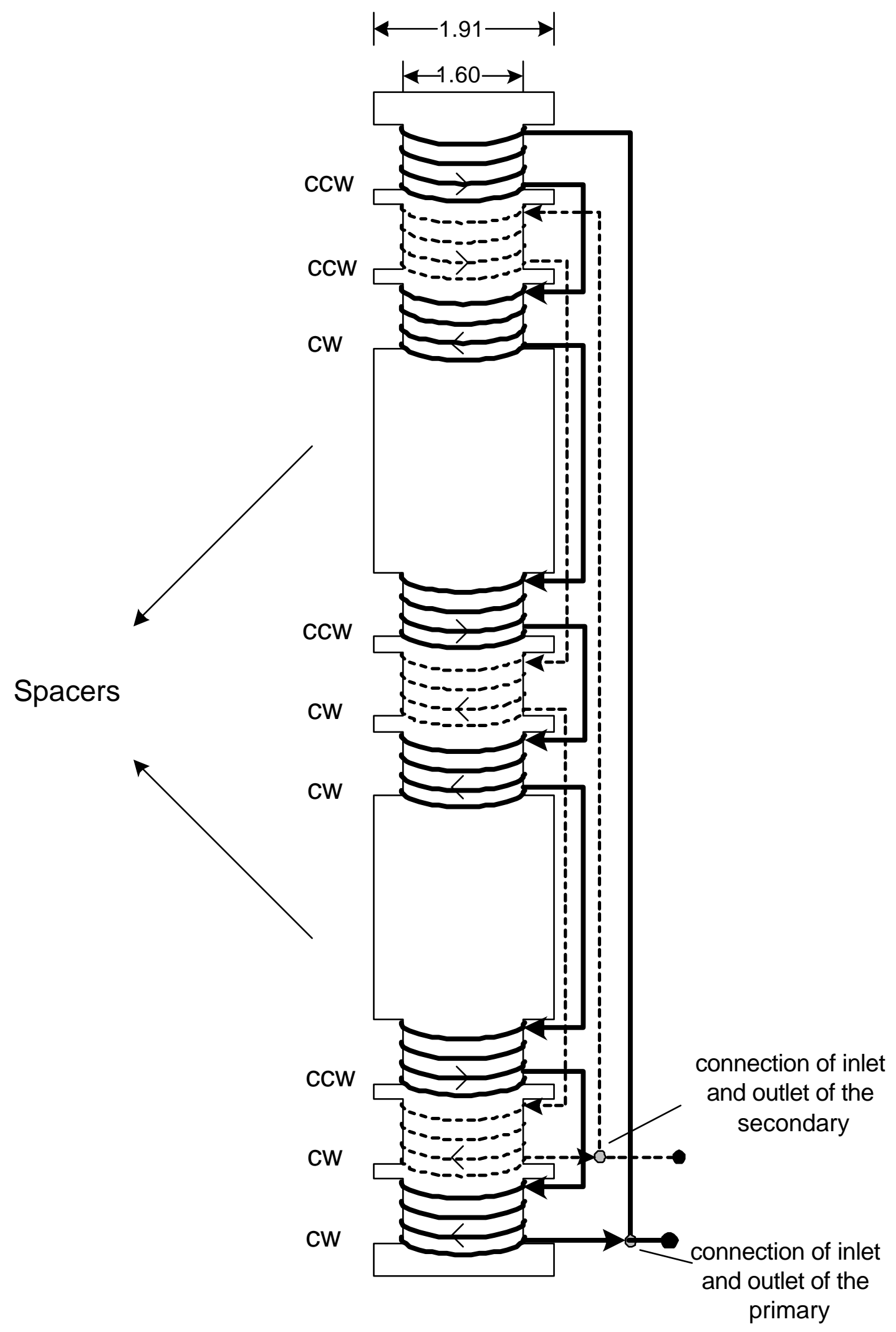

Figure 3.3. Schematic of windings of the viscosity LVDT's $\mathrm{cw}=$ clockwise, $\mathrm{ccw}=$ counter clockwise 


\section{b. New LVDT Coil for Density Measurements}

Another LVDT coil is used to determine the position of the piston in the piston assembly and thus the precise measurements of changes in internal volume of the view cell can be made during an experiment so does density measurement. This LVDT coil has also one primary and two secondary coils. The washer of LVDT coil is made of aluminum. The coil is moved along the tube to locate the exact position of the ferromagnetic slug connected to the end of the piston with a stainless steel rod. The length of displacement is measured from a zero reference point representing the position of the piston is all the way out, i.e., when the internal volume of the viscometer is at its maximum $\left(42.6 \mathrm{~cm}^{3}\right)$. When the ferromagnetic slug is at the center of the coil, the ammeter connected to the coil indicates zero, and this way, the distance traveled from the zero reference point is recorded. This distance is monitored by a digital position read out device, Mitutoyo, Model 572-211-50 with an accuracy of $\pm 0.013 \mathrm{~mm}$, which is attached to a position read out assembly.

\section{c. Circulation Loop}

A micro gear pump is used to circulate the contents of the cell through the fall tube, to increase the efficiency of achieving homogenous mixing and complete dissolution. In the previous design, circulation was achieved by a magnetic solenoid pump. Another slight design change was introduced to the circulation loop. The circulation was carried from the top of the fall tube attachment to the side of the view cell. In the new design it is carried form the top of the fall tube to the bottom of the view cell, Figure 3.2. This has improved the homogeneity of the view cell contents and helped ease the cleaning process, especially while working with the polymer solutions. 


\section{d. Inner Volume}

Since the circulation loop was changed, the total inner volume of the system was redetermined. It changed from $39.7 \mathrm{~cm}^{3}$ to $42.6 \mathrm{~cm}^{3}$. The inner volume of the system was determined by using toluene, and then verified by using n-pentane and carbon dioxide at conditions where density data for these fluids are available. Density data together with the known amount of fluid that has been charged to he system are used to calculate the inner volume.

\subsection{Operational Procedures}

Charging Solvents: Fluids that are not volatile at room temperature can be charged from a bottle placed at the end of the solvent line before the line filter (Figure 3.1, Flow Diagram). The volatile fluids or compressed gases can be charged the same way but instead of a bottle, a specially designed transfer vessel is connected to the end of the solvent line. The fluid container is placed on a balance, Mettler PM6100 accurate to $\pm 0.01 \mathrm{~g}$. First of all some solvent is charged to the solvent line up to the viscometer inlet valve, V3, which is kept closed at first. Leaving Exit1 and Exit 2 open consecutively, charging continues until a few drops of fluid is observed to come out of the line. This helps to fill the lines only with the desired solvent, and insures that pump is working. After closing the exits, right before pressure starts to build up in the lines, the balance is zeroed and inlet valve, V3, is opened. Pumping continues until the desired amount of solvent is charged into the view cell. Then, the pump is stopped, the inlet valve is closed and the balance reading is recorded. When the system is charged with the fluids of known density, the actual amount charged could be verified by measuring the volume occupied at the charge temperature and pressure. When charging the viscometer already containing fluid, the pressure in the solvent line is brought to the same pressure as in the view cell, then inlet valve is opened and fluid is pumped.

Charging the Polymer: The amount of polymer is weighed using Mettler H51 AR type of balance with an accuracy of $\pm 0.00001 \mathrm{~g}$. The loading of a liquid polymer (such as 
polydimethylsiloxane) is done through the front sample port, S1, using a syringe. The weight of the syringe is measured and recorded before drawing the liquid polymer and after discharging the polymer. The difference between these two measurements is the amount of polymer left in the syringe. This amount is subtracted from the original weight of the polymer. The loading of solid polymer is done through the top of the view cell, S2 by removing the fall tube attachment during the loading process. When working with polymer solutions (mixtures) the polymer (solute) is loaded first, which is then followed by the solvent charge.

Pressurization: Once the viscometer is charged with the desired amount of polymer and solvent, or pure solvent, the pressurizing fluid (in this study we used pentane) is pumped through the pressure line into the pressure generator and to the piston assembly which holds the backside of the piston. While filling the pressure line, to achieve air-free line, first the exit valves (Exit 4 and 5) are kept open until some fluid is observed to come out. The desired pressure level in the view cell is achieved by the piston movement, which is controlled and manipulated by the pressure generator, with the pressurizing fluid.

Temperature control: The temperature of the view cell is increased or decreased by adjusting the temperature of the circulating air inside the oven that houses the view cell. The heating is carried out slowly to prevent any undesirable temperature gradients across the cell body.

Circulation: The electromagnetic stirrer and the circulation pump are used to obtain homogeneity of temperature and concentration of the viscometer contents during heating up and at equilibrium. Electromagnetic stirrer is kept on all the time during measurements, whereas the circulation pump is stopped at the time of fall time measurement. By observing the cell contents through sapphire windows the homogeneity of the solution can be verified. 
Data acquisition: Data collection starts when the system reaches thermal and mechanical equilibrium. The sinker is pulled up to the top of the fall tube by magnetizing the pull-up magnet, which is moved up by a motor. By demagnetizing the pull up magnet, the sinker is let fall down from the top of the tube with the effect of gravitational force. The data acquisition, which involves the recording of the time from the computer clock and the voltage outputs from the LVDT coils while the sinker is falling down, starts with a key stroke at the same time with demagnetization of pull-up magnet. It ends with another key stroke when the sinker reaches the bottom of the fall tube, and this is monitored from the control panel with the help of an ampmeter connected to the viscometer LVDT's. Whenever fall time measurements are taken, the temperature, pressure and the position of the piston are recorded. While the readings from the piston LVDT and the known total amount of sample loaded are used to calculate density, this density information and the fall time data are used to calculate the viscosity of the view cell contents after proper calibrations are implemented.

A typical output from the LVDT coils during a fall time measurement is shown in Figure 3.4. The voltage output starts at a zero baseline. Then a positive peak is followed by a negative peak. This represents the sinker passing the first coil. Similar outputs are observed when sinker passes through the second and the third coils.

Discharging and Cleaning: Discharging is done from Exit 3 and/or Exit 6. The temperature of the viscometer should be raised to over boiling point of the solvent to discharge any residual solvent in the viscometer. In case of polymer solutions, the viscometer is charged with a solvent which can dissolve the polymer. Fresh solvent is recharged several times to ensure complete polymer removal. The viscometer temperature is raised and the exit valves are kept open for a few hours to get rid of the traces of the solvent. Also, the viscometer and the lines are purged with carbon dioxide several times. 


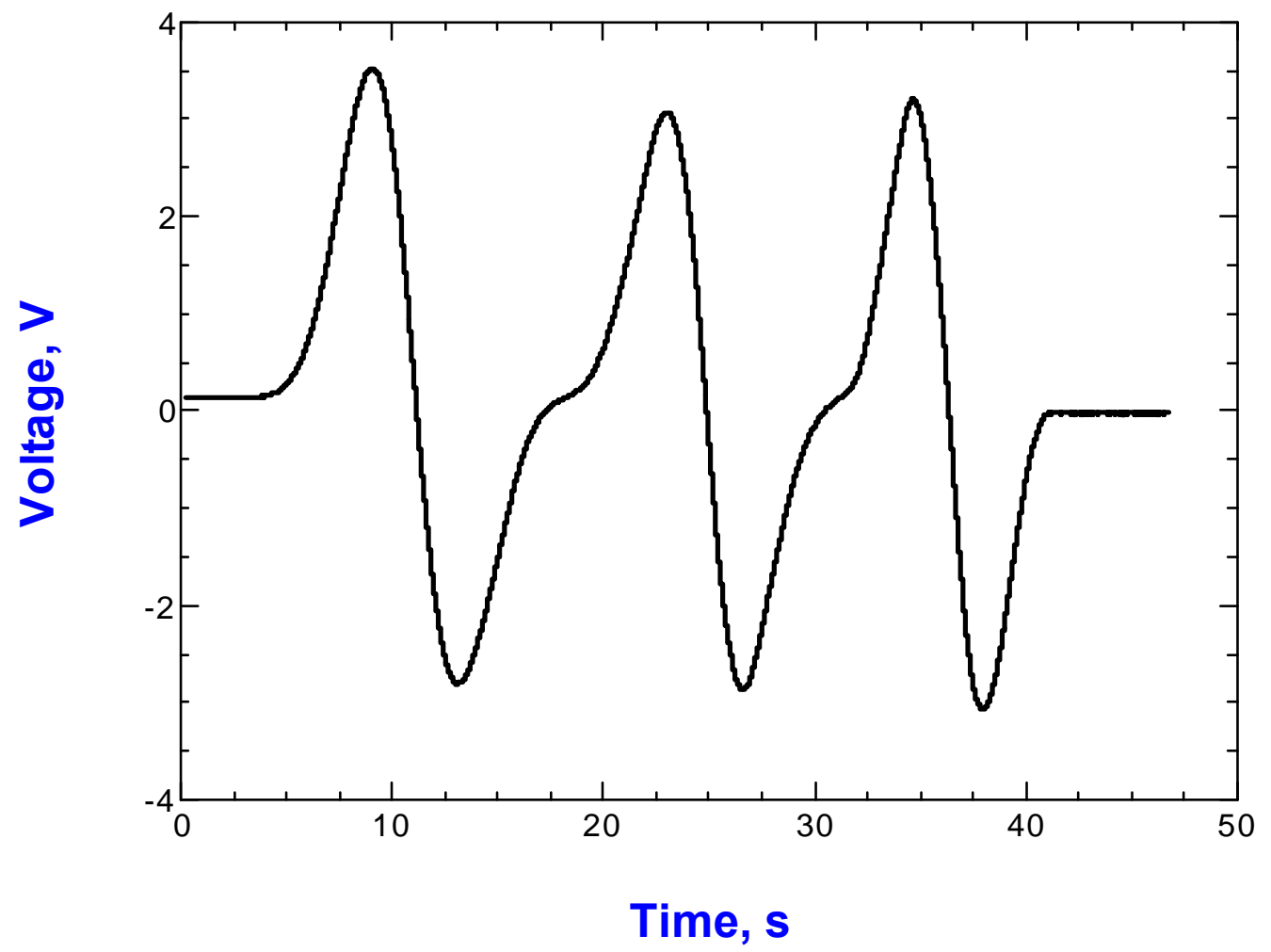

Figure 3.4 LVDT response as a function of the fall time for the sinker in npentane at $100{ }^{\circ} \mathrm{C}$ and $20.97 \mathrm{MPa}$. 
When discharging polymer solutions or cleaning, Exit 3 should be used, in order not to cause any clogging at the lines coming from the top of the fall tube, and the system should be pressurized with solvents, such as toluene, pentane or carbon dioxide. 


\section{CHAPTER 4}

\section{CALIBRATION}

The objective of this section is to introduce a procedure to determine the terminal velocity of the falling sinker with the new coil design and to validate a new calibration procedure based on these terminal velocity calculations.

\subsection{Calibration Method Used in the Present Study}

As already indicated the present instrument incorporates an important modification to the design previously published $[5,15]$. The modification was implemented during the course of the present thesis work in order to develop a more accurate and reliable procedure for determining the terminal velocity of the sinker, and thus improve the reliability of the instrument calibration constant as well as the accuracy of the viscosity measurements. In the present design one long LVDT washer is used which has built in with grooves for three LVDT coils with fixed predetermined distance in between. In the earlier design three separate LVDT coils positioned at different distance were used. The precise distance between coils had to be determined after installation and measurement of the LVDT signal.

The experimental method consists of measurement of fall time of a sinker through a fluid of known viscosity at known temperature and pressure. The general working equation is obtained by redefining Lohrenz's equation [5],

$$
\boldsymbol{\eta}=\frac{t\left(\rho_{s}-\boldsymbol{\rho}_{f}\right)\left(r_{1}^{2} g\right)\left[\left(r_{2}^{2}+r_{1}^{2}\right) \ln \left(r_{2} / r_{1}\right)-\left(r_{2}^{2}-r_{1}^{2}\right)\right]}{2 L\left(r_{2}^{2}+r_{1}^{2}\right)}
$$


$\mathrm{L} / \mathrm{t}$ is referred as terminal velocity, $\mathrm{V}_{\text {ter }}(\mathrm{t}), \rho_{\mathrm{s}}$ is the density of the sinker, $\rho_{\mathrm{f}}$ is the density of the fluid at the temperature and pressure viscosity calculated, while the rest of the geometric terms are defined as instrument constant, $\mathrm{K}$, which also includes the conversion factor to obtain viscosity in mPa.s when density is expressed in units of $\mathrm{g} / \mathrm{cm}^{3}$ and velocity of the sinker is expressed in units of $\mathrm{cm} / \mathrm{s}$.

$\eta=\left[K / V_{\text {ter }}(t)\right]\left(\rho_{\mathrm{s}}-\rho_{\mathrm{f}}\right)$

Eqn. 4.1.

Although this working equation is primarily valid for Newtonian fluids, if the shear rate is low or if the shear dependence of the viscosity is not considered, the equation can also be used for estimating the viscosity of non-Newtonian fluids [15, 49].

In the terminal velocity determination, prior to the present thesis, the time corresponding to the sinker passing the center of each coil (or reflected by the zero voltage reading) were recorded, and from the distance between the coils, velocity could be determined. If the difference in sinker velocity based on coil 1 and 2, and 2 and 3 is small, one could assure that the sinker had reached its terminal velocity by the time it passed through the coil. This procedure however was found to be ambiguous. In the present study, a rigorous calibration procedure was implemented to generate complete position versus time history for the sinker as it falls and passes through the coils. Knowledge of full position-time history eliminates the need to pull the sinker all the way up the fall tube in order to determine the average velocity using overall fall time. The velocity can be determined starting from any point the sinker is pulled up to. For example, while working with highly viscous fluids, the sinker can be pulled up to a distance that corresponds to only one coil length and still the terminal velocity can be calculated.

Prior to the present study, the calibration constant, K, was obtained from the slope of the plot $\eta\left(\rho_{s}-\rho\right)$ as a function of fall time $t$, corresponding to each distance between any pair 
of the three coils, by using the known viscosity and density of a set of calibration fluids. For viscosity determination at high temperatures and pressures calibration constant was modified to consider its dependence on temperature and pressure. Thus, a temperatureand pressure-dependent correction factor, $\mathrm{X}(\mathrm{T}, \mathrm{P})$, was incorporated to the equation. Then the relationship for viscosity became,

$\eta=\{\mathrm{K}(\mathrm{t}) / \mathrm{X}(\mathrm{T}, \mathrm{P})\}\left[\rho_{\mathrm{s}}-\rho\right]$

Eqn. 4.2

The calibration constant in the present study is calculated by simply using known viscosity, density, and terminal velocity for the each measurement carried out at a specific temperature and pressure. By averaging all the calibration values, a $\mathrm{K}_{\mathrm{avg}}$ is assigned and used as the calibration constant throughout all the viscosity calculations in this study. By analyzing the calibration constants determined at different pressures and temperature, it has been found that even though calibration constant $\mathrm{K}$ does show some temperature and pressure dependence the error obtained when a constant calibration constant is used instead of a pressure and temperature dependent one is still in the experimental error range.

\subsection{Determination of Terminal Velocity}

The first step of calibration procedure was to determine the voltage versus distance information by manually moving the sinker along the viscometer fall tube in the absence of any fluid. The total length available for the fall of the sinker in the tube is $14 \mathrm{~cm}$. The sinker, $0.7781 \mathrm{~cm}$ in diameter and $2.094 \mathrm{~cm}$ in length (with $4 \mathrm{~g} / \mathrm{cm}^{3}$ density), is made of an aluminum core and ferromagnetic 416 stainless steel shell and thus magnetically permeable [16].

Voltage-Distance : The ferromagnetic sinker was attached to the end of a glass rode which has the same diameter with sinker but longer than the fall tube. The position when the glass rod is all the way inside the tube is recorded as the initial point. Then the rod is 
pulled up by $1 \mathrm{~mm}$ increments, and the distance from the initial point as well as the corresponding voltage reading are recorded. A voltmeter connected to the ends of the LVDT coils is used for reading the voltage. This procedure is repeated in reverse direction, i.e. the all-the-way-out position of the rod, while still a voltage reading can be recorded, is assigned as the initial position, and the rod is moved down into the tube. Again the distance and the voltage readings are determined at every $\mathrm{mm}$ increments. Distance and its corresponding voltage data obtained at both ways are found to be exactly the same. The distance-voltage diagram determined this way is shown in Figure 4.1.

Voltage-time : The second step of the calibration is to obtain Voltage versus Time data.

For this evaluation we worked with pentane solvent. The amount of pentane charged is very important to get accurate density measurement and so viscosity. Using Milton Roy pump the solvent line is filled with n-pentane keeping the inlet valve, V3, closed (See Figure 2.1). By the time this line starts building up pressure, the balance is zeroed and the inlet valve is opened. To make sure that there is not any air trapped in the system twostep charging procedure is carried out. The discharge valve, V3 is kept closed while exit 6 is kept open. N-pentane is charged into the cell until a few drops come out of exit 6 . Then it is closed and pumping continued until the pressure in the cell starts building. The system temperature is set to $50{ }^{\circ} \mathrm{C}$, which is higher than the boiling point of n-pentane $\left(35-36^{\circ} \mathrm{C}\right)$. After temperature equilibrium is reached, the top discharge valve, exit 6 , is opened and kept open for about 10 minutes, to give sufficient time for all pentane to evaporate. The condensing pentane vapor is collected in a glass ubing that is attached to the end of the valve. Exit 6 is closed, and the glass attachment is disconnected. This procedure helps to have an air-free system. The system can be charged with solvent again either at this temperature or after cooling. Exit 6 is kept closed while charging the system for the second time. The amount charged is recorded. The viscometer is heated up to the measurement temperature. Sufficient time is allowed to bring the viscometer and its contents to reach thermal equilibrium. 


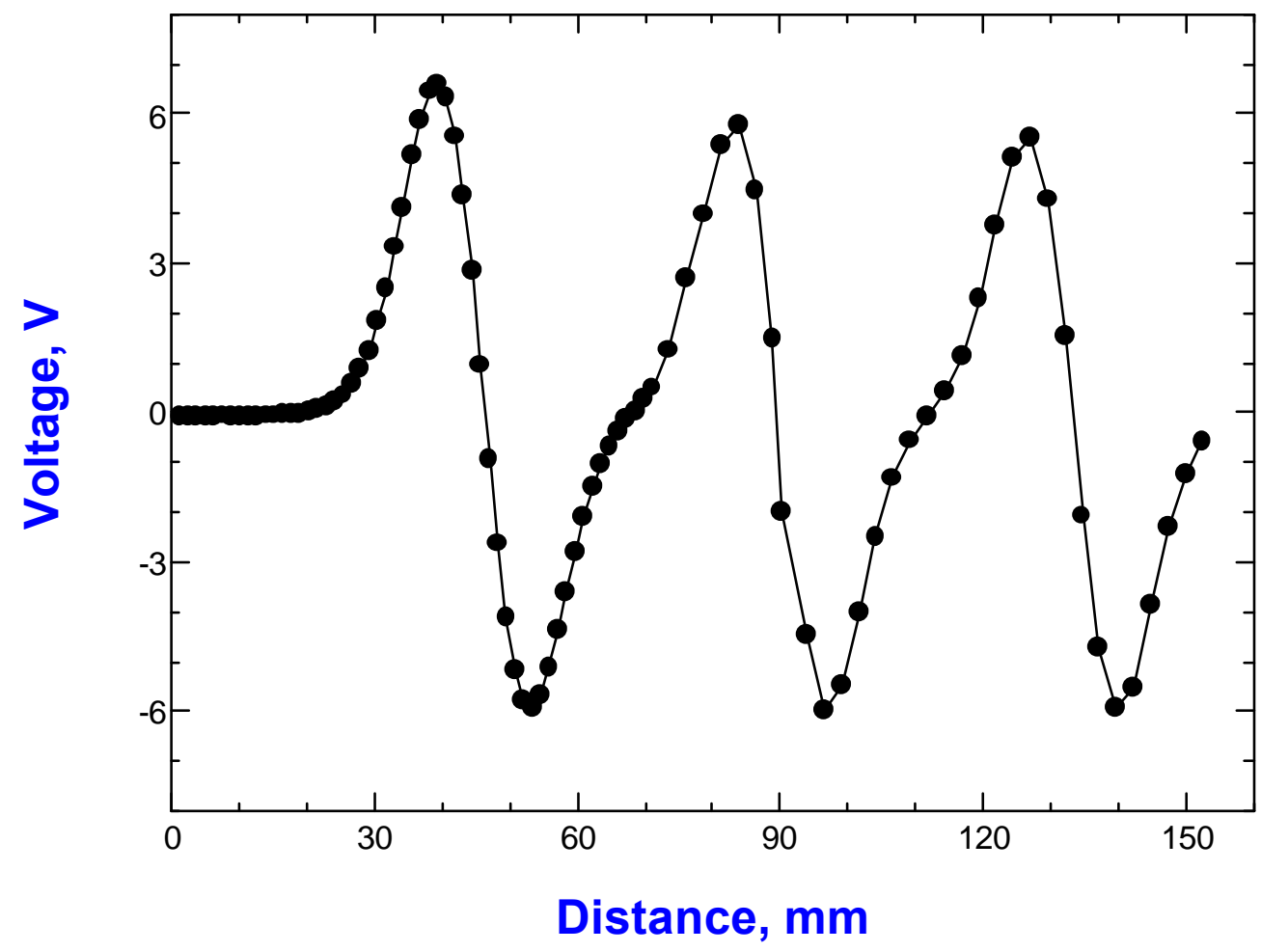

Figure 4.1. LVDT signal in volts vs sinker position in the fall tube. 
Once the system is loaded and thermal equilibrium is reached, several consecutive fall time measurements are taken at the desired pressures. Sufficient time, typically a period of $30 \mathrm{~min}$, is allowed between consecutive repeat measurements to achieve stability in the system and to prevent the pull-up magnet from overheating which may affect the temperature of the sample in the viscometer. After completing each measurement, voltage versus time information is obtained from the computer. Figure 3.4 is a typical computer output, which is obtained for pentane at $100{ }^{\circ} \mathrm{C}$ and $20.97 \mathrm{MPa}$.

There are three LVDT coils around the fall tube, and each curve in the Figure 3.4 represents one coil. If the numbering of the coils is done from top to bottom of the fall tube, then the last curve represents the third coil.

Distance versus time: The last step is to get Distance versus Time information. From the manual measurements, the voltage versus distance information is known, and this is used in all viscosity calculations as a basis. With each fall time measurement, voltage versus time information is obtained. In order to compare these two findings, the voltage readings are normalized. The normalization is done separately for each coil. All the positive voltage readings are divided by the maximum value and all the negative voltage readings are divided by the minimum value for each coil. Figure 4.2 shows the normalized voltage vs distance data, which is our basis plot. The next figure, Figure 4.3, shows the normalized voltage vs time data for npentane at the same conditions described above and shown in Figure 3.4.

Comparing these two plots, it is possible to obtain Distance versus Time information, the slope of which gives the velocity profile of the sinker during fall. For this specific case with pentane, the distance versus time data that has been generated is shown in Figure 4.4 . 


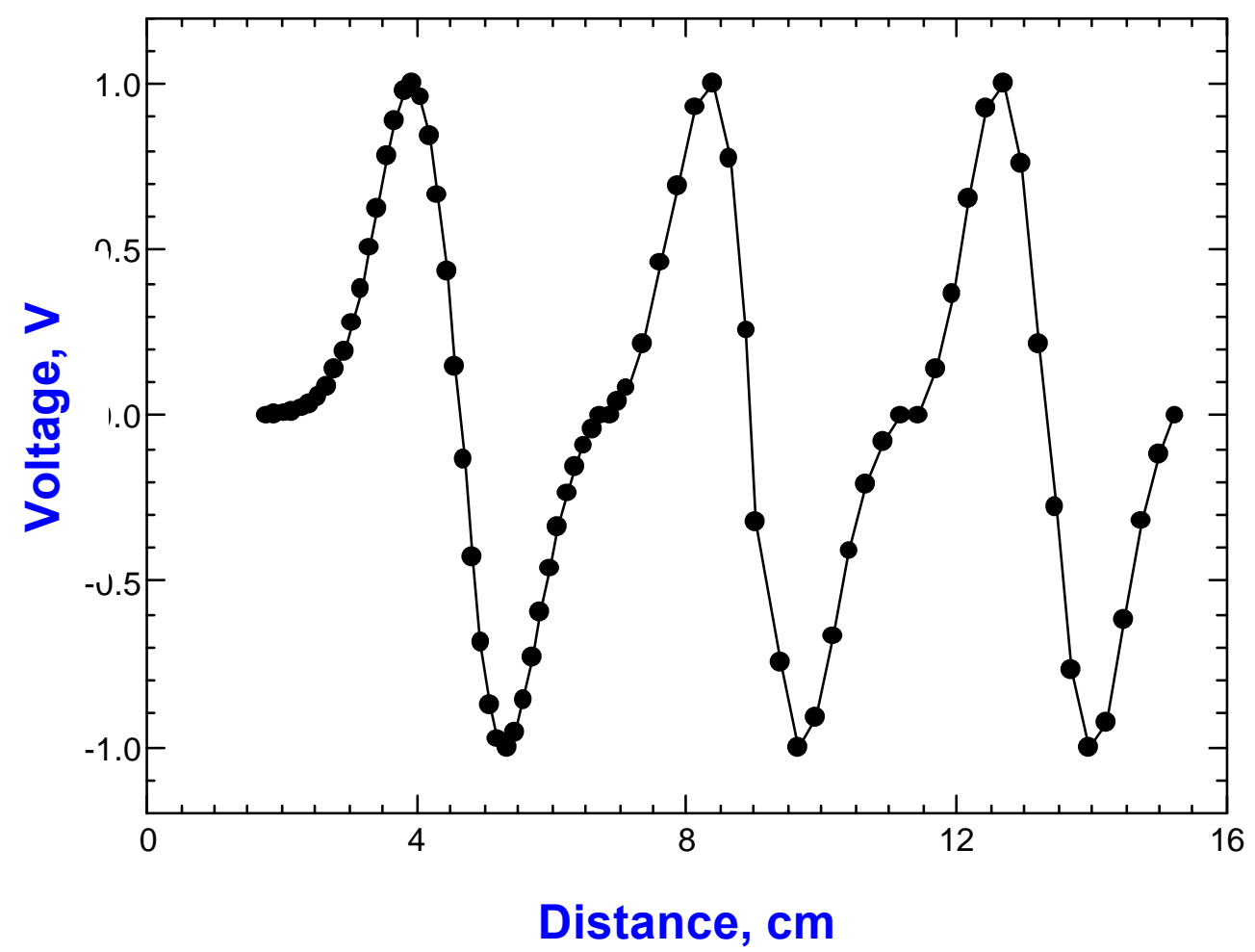

Figure 4.2. Normalized plot of LVDT response with sinker position. 


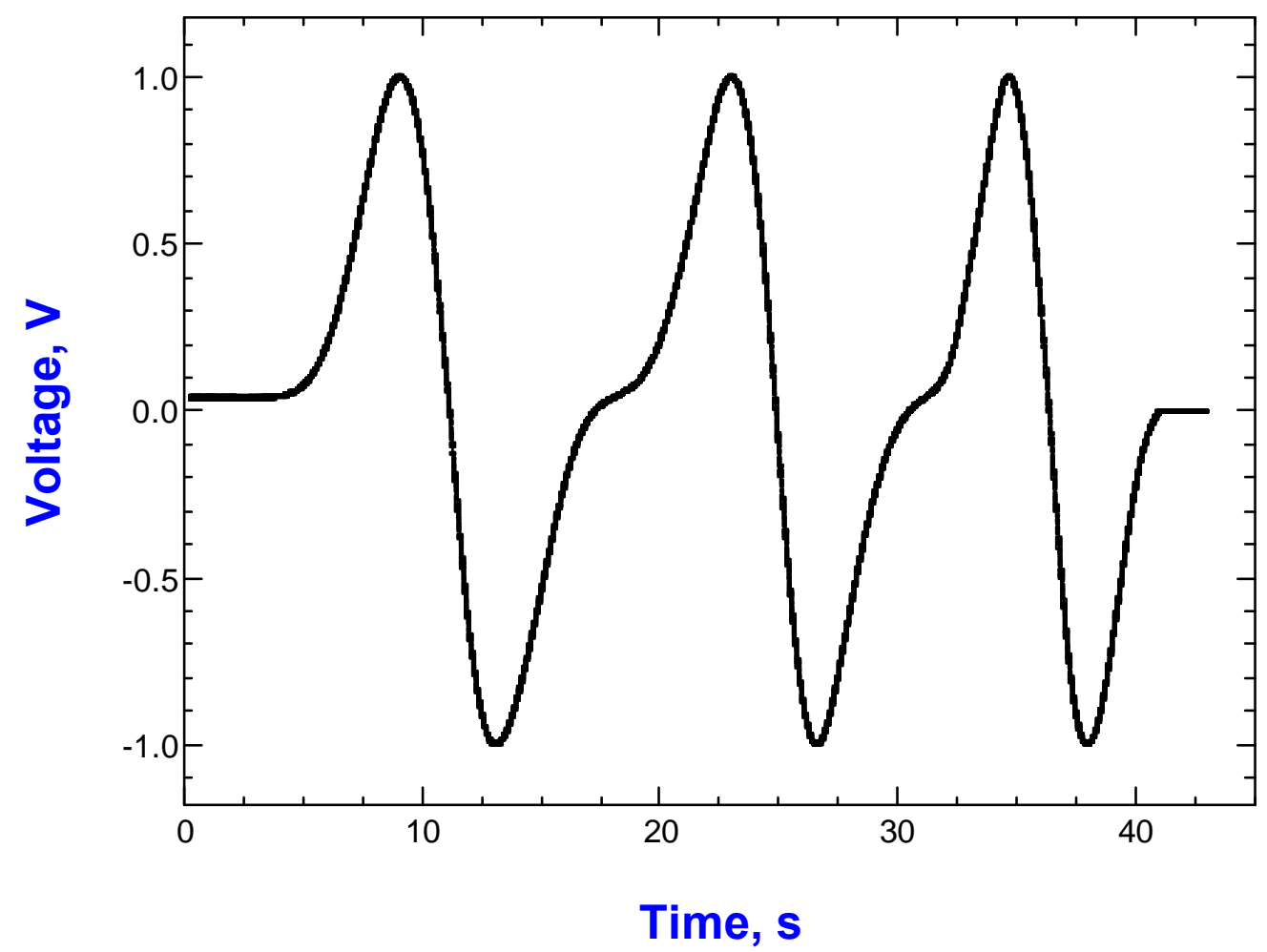

Figure 4.3. Normalized LVDT response versus fall time in n-pentane at $100^{\circ} \mathrm{C}$ and $20.97 \mathrm{MPa}$. 


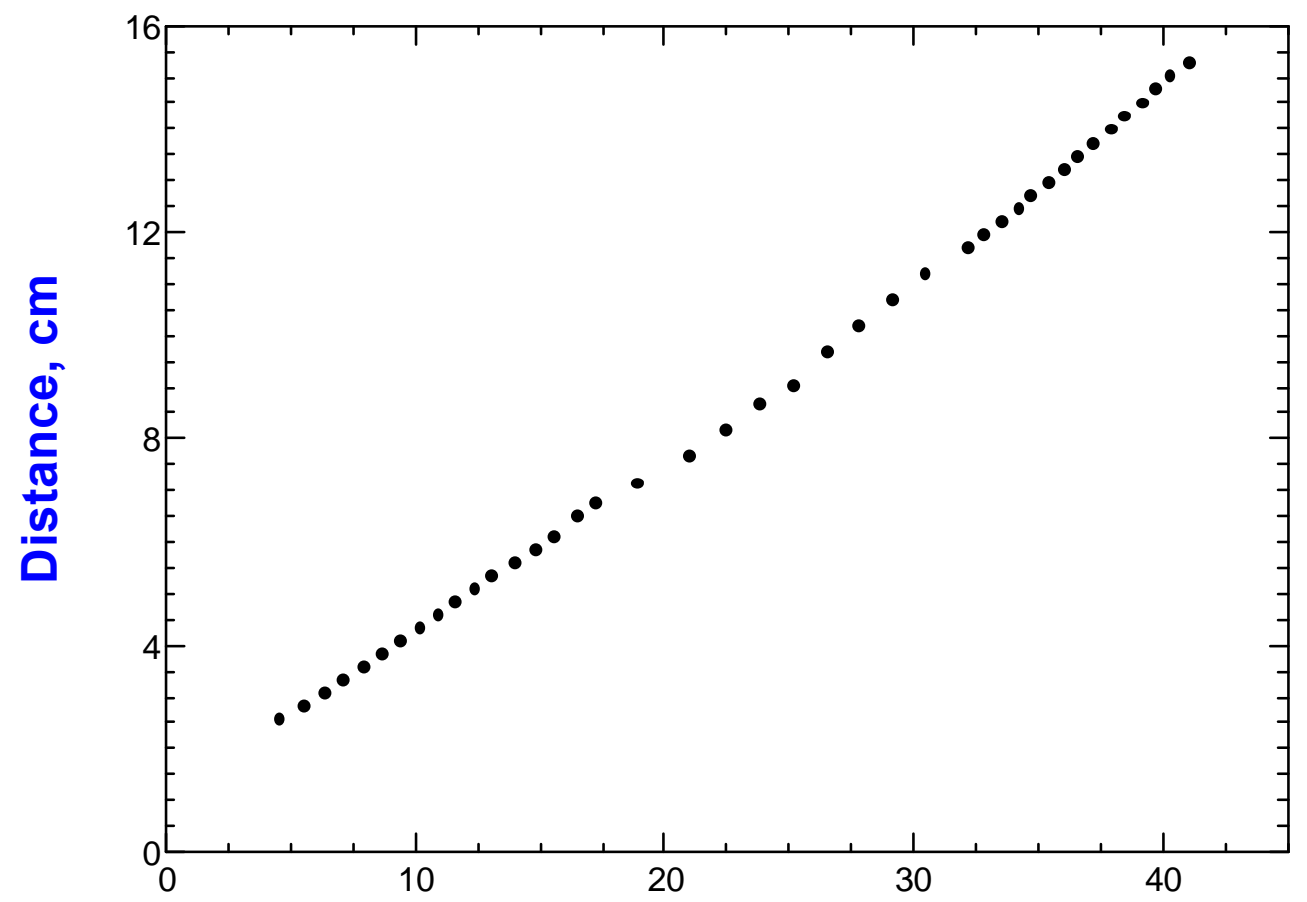

$\sigma$

ᄃ

Time, s

0

(1)

Figure 4.4. Sinker fall distance vs time in n-pentane at $100^{\circ} \mathrm{C}$ and 20.97

MPa. The slope is the fall velocity. 
Using the literature data for viscosity, the experimentally determined densities, and terminal velocities obtained from distance-time data as described above, the instrument constant, $\mathrm{K}$, is determined for each case.

\subsection{Materials}

Calibration was carried out using n-pentane purchased from Sigma-Aldrich with a stated minimum purity of $99+\%$, and $\mathrm{CO}_{2}$ purchased from Air Products and Chemical, Inc. with a minimum purity of $99.99 \%$. The substances were weighted using Mettler PM 6100 balance with an accuracy of $\pm 0.01 \mathrm{~g}$. The samples of $\mathrm{n}$ pentane and carbon dioxide were used without further purification.

\section{4. n-Pentane}

Measurements of terminal velocities, density and viscosity of n-pentane are carried out along four isotherms, 50, 75, 100 and $125{ }^{\circ} \mathrm{C}$, at pressures up to around $50 \mathrm{MPa}$. Literature data for n-pentane density and viscosity are taken from Kiran and Sen who reported data in the temperature range from 45 to $170{ }^{\circ} \mathrm{C}$ [15]. Densities for npentane were experimentally determined in the present study at each temperature and pressure along with the viscosity measurements. A specific advantage of our system is that density values can be directly measured and not extrapolated from the data available in literature or measured separately and then extrapolated to cover the range of the experiment.

\subsubsection{Density}

The densities of npentane measured in the present study were compared with the earlier data of Kiran and Sen [15]. As shown in Figure 4.5 and Table 4.1, the results are in excellent agreement with an error range of $1 \%$. 
Table 4.1. Density of n-pentane (Literature data from Kiran and Sen [15])

\begin{tabular}{|c|c|c|c|c|}
\hline $\begin{array}{c}\text { Temperature } \\
{ }^{\circ} \mathrm{C}\end{array}$ & $\begin{array}{c}\text { Pressure } \\
\text { MPa }\end{array}$ & $\begin{array}{l}\text { Literature value } \\
\qquad \rho / \mathrm{g} / \mathrm{cm}^{3}\end{array}$ & $\begin{array}{c}\text { Present study } \\
\rho / \mathrm{g} / \mathrm{cm}^{3}\end{array}$ & $\begin{array}{c}\text { Difference } \\
\%\end{array}$ \\
\hline \multirow[t]{6}{*}{50} & 44.76 & 0.6417 & 0.6358 & 0.91 \\
\hline & 34.41 & 0.6328 & 0.6262 & 1.05 \\
\hline & 27.75 & 0.6257 & 0.6200 & 0.91 \\
\hline & 20.70 & 0.6178 & 0.6125 & 0.87 \\
\hline & 15.39 & 0.6113 & 0.6075 & 0.61 \\
\hline & 10.23 & 0.6041 & 0.6009 & 0.53 \\
\hline \multirow[t]{7}{*}{75} & 45.75 & 0.6232 & 0.6210 & 0.35 \\
\hline & 44.92 & 0.6229 & 0.6313 & 1.35 \\
\hline & 36.45 & 0.6135 & 0.6122 & 0.21 \\
\hline & 28.39 & 0.6041 & 0.6042 & 0.01 \\
\hline & 27.62 & 0.6041 & 0.6027 & 0.23 \\
\hline & 20.72 & 0.5946 & 0.5934 & 0.21 \\
\hline & 15.45 & 0.5870 & 0.5864 & 0.11 \\
\hline \multirow[t]{4}{*}{100} & 45.69 & 0.6055 & 0.6042 & 0.22 \\
\hline & 38.21 & 0.5973 & 0.5956 & 0.17 \\
\hline & 20.85 & 0.5730 & 0.5730 & 0 \\
\hline & 15.90 & 0.5645 & 0.5647 & 0.03 \\
\hline \multirow[t]{7}{*}{125} & 45.08 & 0.5886 & 0.5883 & 0.06 \\
\hline & 42.03 & 0.5826 & 0.5847 & 0.28 \\
\hline & 34.61 & 0.5731 & 0.5736 & 0.10 \\
\hline & 29.97 & 0.5626 & 0.5666 & 0.70 \\
\hline & 24.47 & 0.5595 & 0.5607 & 0.22 \\
\hline & 17.08 & 0.5447 & 0.5440 & 0.13 \\
\hline & 10.85 & 0.5274 & 0.5308 & 0.64 \\
\hline
\end{tabular}




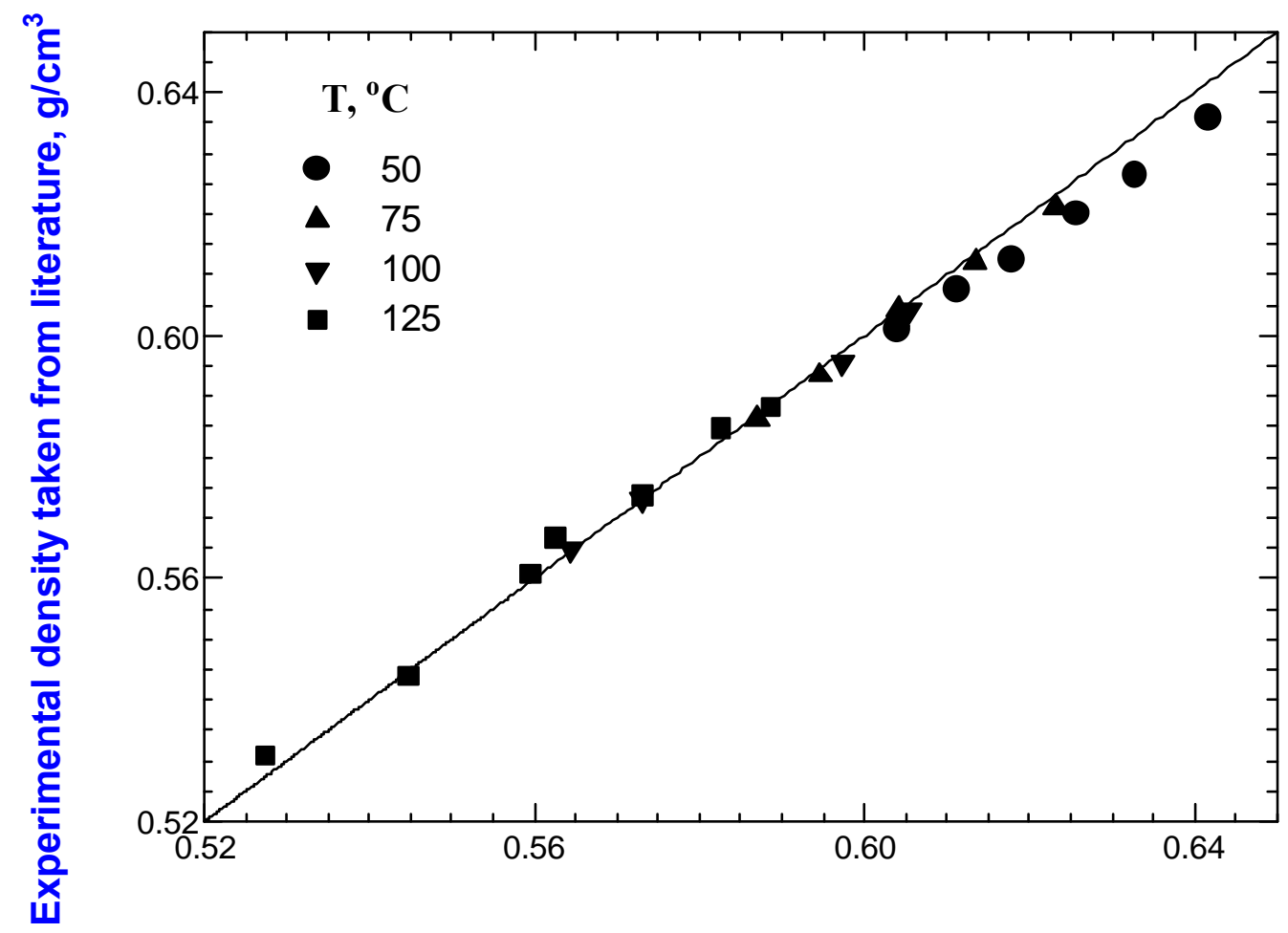

Experimental density from this study, $\mathrm{g} / \mathrm{cm}^{3}$

Figure 4.5. Comparison of experimental densities of n-pentane obtained in this study with the literature data taken from Kiran and Sen [15]. 


\subsubsection{Calibration Constant and Error Analysis}

The calibration constant was determined from Eqn. 4.1 for each measurement using the literature value of the viscosity, and experimentally determined density and the terminal velocity according to the procedure described above. The calibration constants are presented in Table A.1-A.4 in Appendix A.

Figure 4.6 shows the variation of calibration constants with pressure at different temperatures. As can be seen, pressure dependence of $\mathrm{K}$ is not very significant.

Table 4.2 summarizes the results for calibration constants found for each temperature, by arithmetic averaging the values obtained for each pressure (multiple runs at same pressures were also averaged). This calculation is based on the assumption that pressure does not have a significant effect on the calibration constant. Similar assumption is made for the effect of temperature and an overall average calibration constant with $\mathrm{K}=0.0199$ is assumed to be applicable in these P/T intervals.

Table 4.2. Average calibration constants obtained from calibrations with n-pentane

\begin{tabular}{|c|c|c|}
\hline$n$-Pentane & Temperature & $\mathbf{K}$ \\
\hline & $50{ }^{\circ} \mathrm{C}$ & 0.0202 \\
\hline & $75^{\circ} \mathrm{C}$ & 0.0205 \\
\hline & $100{ }^{\circ} \mathrm{C}$ & 0.0197 \\
\hline & $125^{\circ} \mathrm{C}$ & 0.0190 \\
\hline & $\mathrm{K}_{\mathrm{avg}}$ & 0.0199 \\
\hline
\end{tabular}




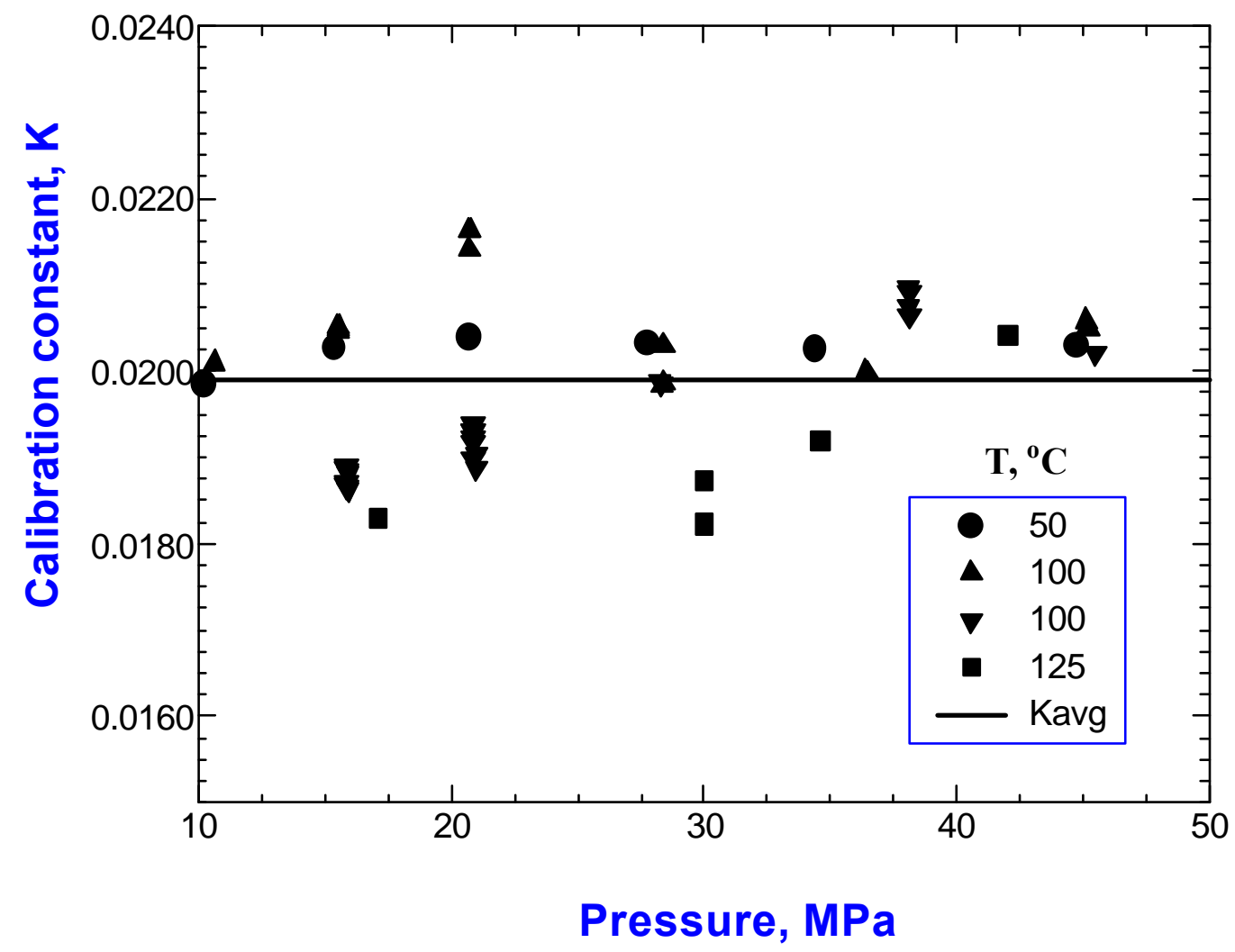

Figure 4.6 . Variation of calibration constants with pressure. Overall average calibration constant, $\mathrm{K}_{\mathrm{avg}}, 0.0199$, is shown as a straight line. 
In Figure 4.7, average calibration constants for each temperature are plotted with respect to temperature. It is observed that even though $\mathrm{K}$ appears to show a decrease above 70 ${ }^{\circ} \mathrm{C}$, the variation is not large. 


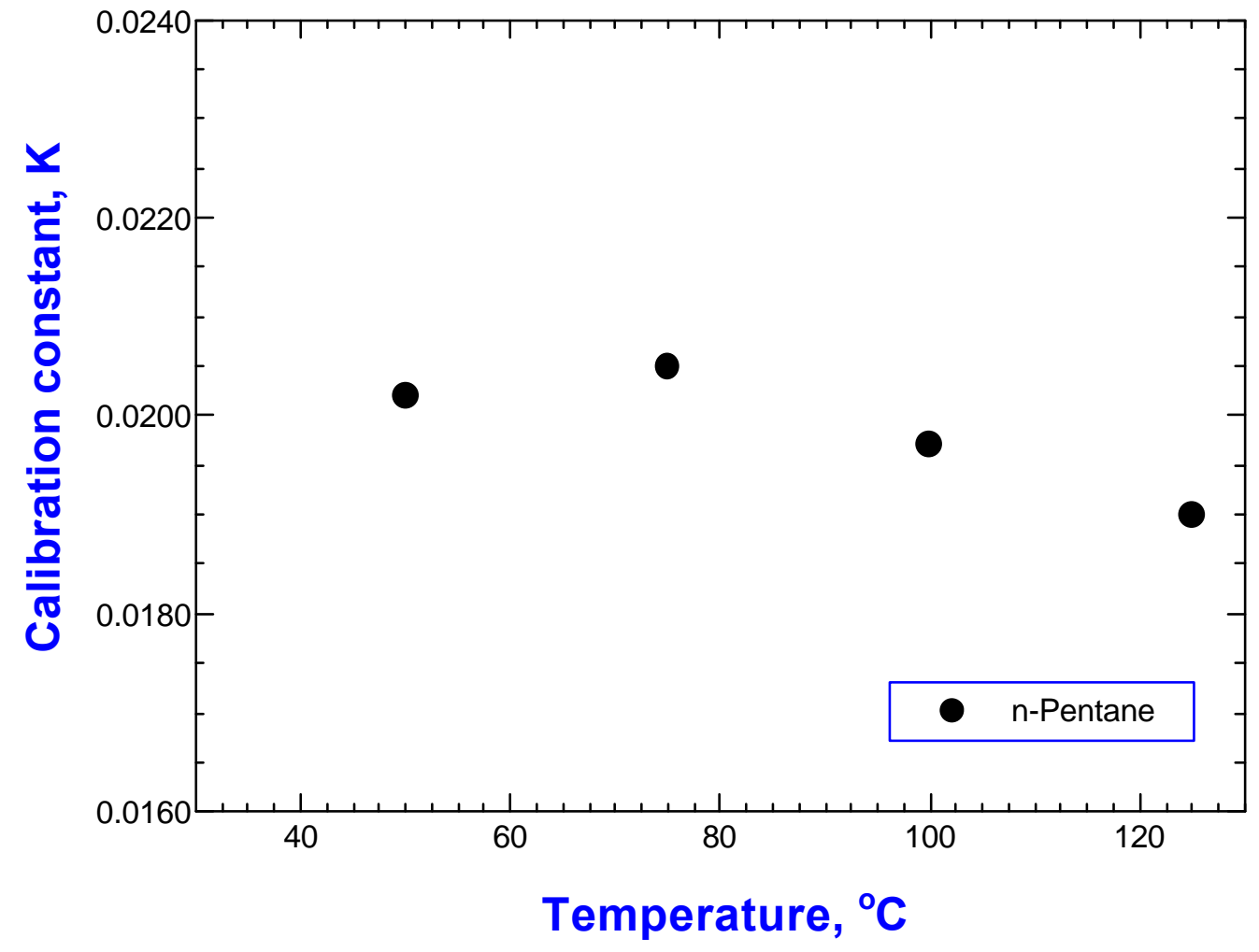

Figure 4.7. Variation of calibration constant obtained from n-pentane calibration with temperature 


\subsubsection{Viscosity}

In order to establish the accuracy of our results two other data sets for n-pentane from the literature were compared with our measurements. Figure 4.8 shows the variation of viscosity, calculated using $\mathrm{K}_{\mathrm{avg}}$, with pressure, where viscosity data at $50{ }^{\circ} \mathrm{C}$ are taken from Audonnet and Pádua [50] and data at $100{ }^{\circ} \mathrm{C}$ are taken from Estrada-Baltazar et al. [40]. Actual data from the present study are presented in the Table 4.3. Audonnet and Pádua [50] used vibrating-wire technique to determine the density and the viscosity values simultaneously and reported their accuracy as $2.5 \%$. Estrada-Baltazar et al. [40] used a rolling-ball viscometer for viscosity calculations where they report an average $3 \%$ error in the measurements. Our results are very consistent with Audonnet and Pádua, but show some minor deviation with the measurements of Estrada-Baltazar et al. One possible source of this small deviation is that Estrada-Baltazar et al. used a correlation suggested by Assael et. al [40] to calculate the densities, while both in our work and in Audonnet and Pádua's work densities are measured experimentally and simultaneously with the viscosities. 
Table 4.3. Measurements of density and viscosity of $n$-pentane from the present study

\begin{tabular}{|c|c|c|c|}
\hline Temperature, ${ }^{\circ} \mathrm{C}$ & Pressure, MPa & $\rho, g / \mathrm{cm}^{3}$ & $\eta$, mPa.s \\
\hline \multirow[t]{6}{*}{50} & 10.23 & 0.6009 & 0.1994 \\
\hline & 15.39 & 0.6075 & 0.2035 \\
\hline & 20.70 & 0.6125 & 0.2145 \\
\hline & 27.75 & 0.6200 & 0.2299 \\
\hline & 34.41 & 0.6262 & 0.2440 \\
\hline & 44.76 & 0.6358 & 0.2664 \\
\hline \multirow[t]{11}{*}{75} & 10.62 & 0.5790 & 0.1649 \\
\hline & 15.52 & 0.5854 & 0.1730 \\
\hline & 15.56 & 0.5929 & 0.1732 \\
\hline & 15.53 & 0.5864 & 0.1733 \\
\hline & 20.70 & 0.5864 & 0.1814 \\
\hline & 28.39 & 0.6041 & 0.2016 \\
\hline & 36.39 & 0.6152 & 0.2138 \\
\hline & 36.45 & 0.6152 & 0.2140 \\
\hline & 36.49 & 0.6152 & 0.2141 \\
\hline & 45.11 & 0.6310 & 0.2257 \\
\hline & 45.18 & 0.6314 & 0.2266 \\
\hline \multirow[t]{6}{*}{100} & 15.81 & 0.5645 & 0.1560 \\
\hline & 15.85 & 0.5647 & 0.1557 \\
\hline & 20.86 & 0.5724 & 0.1646 \\
\hline & 28.31 & 0.5835 & 0.1763 \\
\hline & 38.11 & 0.5973 & 0.1918 \\
\hline & 45.50 & 0.6041 & 0.2001 \\
\hline \multirow[t]{4}{*}{125} & 17.11 & 0.5440 & 0.1381 \\
\hline & 30.02 & 0.5666 & 0.1562 \\
\hline & 34.62 & 0.5737 & 0.1655 \\
\hline & 42.03 & 0.5843 & 0.1750 \\
\hline
\end{tabular}




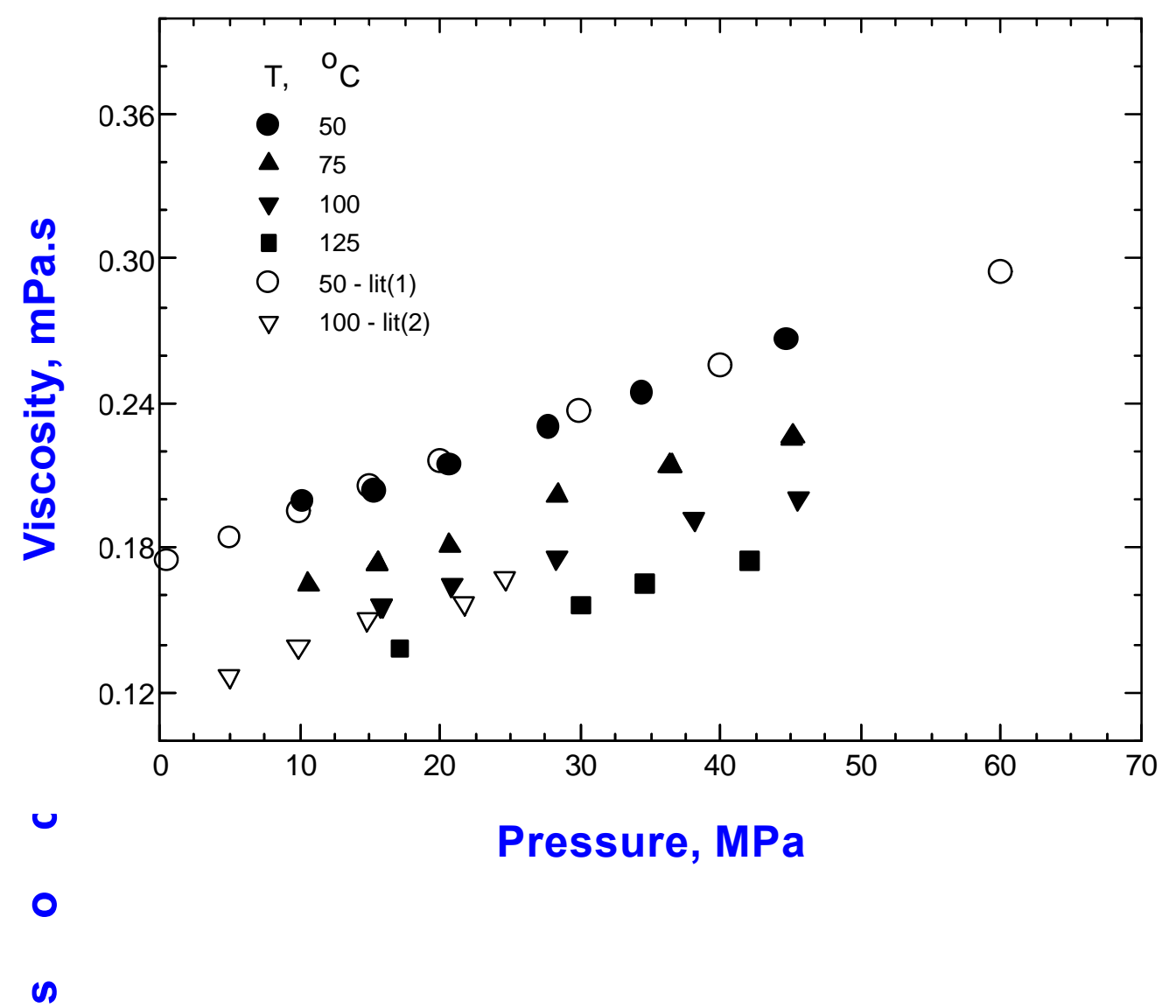

-- Figure 4. 8. Variation of viscosity, calculated using $\mathrm{K}_{\mathrm{avg}}$, with pressure. Literature viscosity data at $50{ }^{\circ} \mathrm{C}$ are taken from Audonnet and Pádua: lit(1)[50] and data at $100{ }^{\circ} \mathrm{C}$ - are taken from Estrada-Baltazar et al. : lit(2)[40].

$\lambda$ 


\subsection{Carbon dioxide}

In order to test the performance of the instrument on low viscosity fluids, some measurements were done with carbon dioxide. Terminal velocities were measured at 37 , 52, 77, and $90{ }^{\circ} \mathrm{C}$ (Selected examples are shown in Figure 4.9). Literature data for $\mathrm{CO}_{2}$ viscosity were taken from Stephen and Lucas who report data from $37{ }^{\circ} \mathrm{C}$ up to $627{ }^{\circ} \mathrm{C}$ with $\pm 5 \%$ accuracy [51]. We followed the same procedure used for n-pentane to calculate the instrument calibration constant for carbon dioxide as the calibration fluid. The results are presented in the Table 4.4.

Table 4.4. Calibration constants obtained from measurements with carbon dioxide

\begin{tabular}{ccc}
\hline $\mathbf{C O}_{2}$ & Temperature & $\mathbf{K}$ \\
\hline $37{ }^{\circ} \mathrm{C}$ & 0.0182 \\
$52{ }^{\circ} \mathrm{C}$ & 0.0187 \\
$77^{\circ} \mathrm{C}$ & 0.0184 \\
$97{ }^{\circ} \mathrm{C}$ & 0.0184 \\
\hline $\mathrm{K}_{\mathrm{avg}}$ & 0.0184 \\
\hline
\end{tabular}

For carbon dioxide the average calibration constant was found to be 0.0184 , which differ by $7.5 \%$ from the constant obtained using n-pentane as calibration fluid. The change in calibration constant with respect to pressure is plotted in Figure 4.10. As seen from the figure the pressure effect on the calibration constant is not large as in the case of npentane. Figure 4.11, is the variation of calibration constant with temperature based on the calculations with carbon dioxide and also with $\mathrm{n}$-pentane. $\mathrm{K}$ is less sensitive to temperature in the case of $\mathrm{CO}_{2}$. 

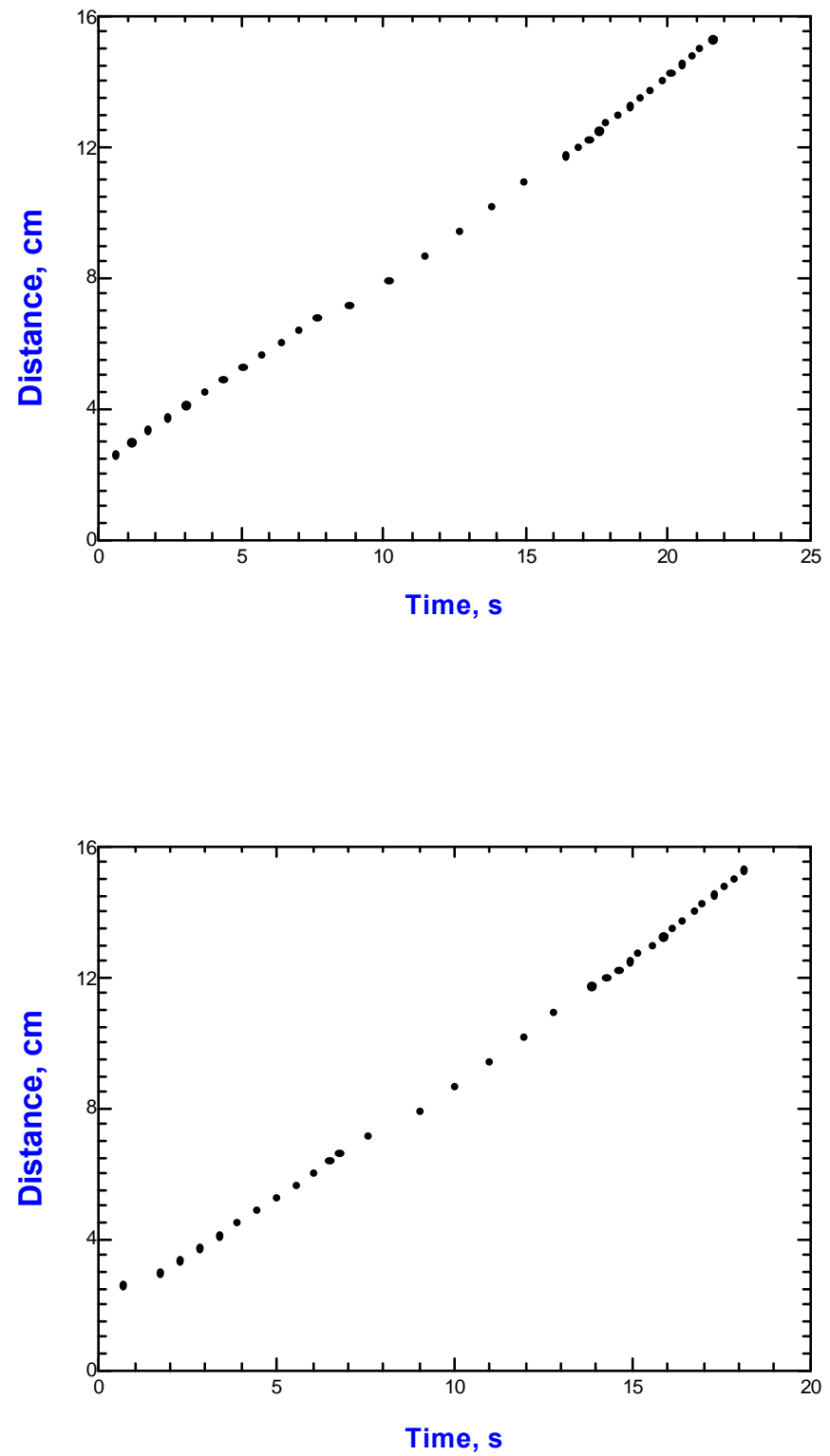

Figure 4.9. Examples "Distance versus Time" data obtained from measurements with $\mathrm{CO}_{2}$ (where slope $=\mathrm{V}_{\text {ter }}$ ). (a) at $37^{\circ} \mathrm{C}$ and $20 \mathrm{MPa}$; (b) at $97^{\circ} \mathrm{C}$ and $40 \mathrm{MPa}$ 


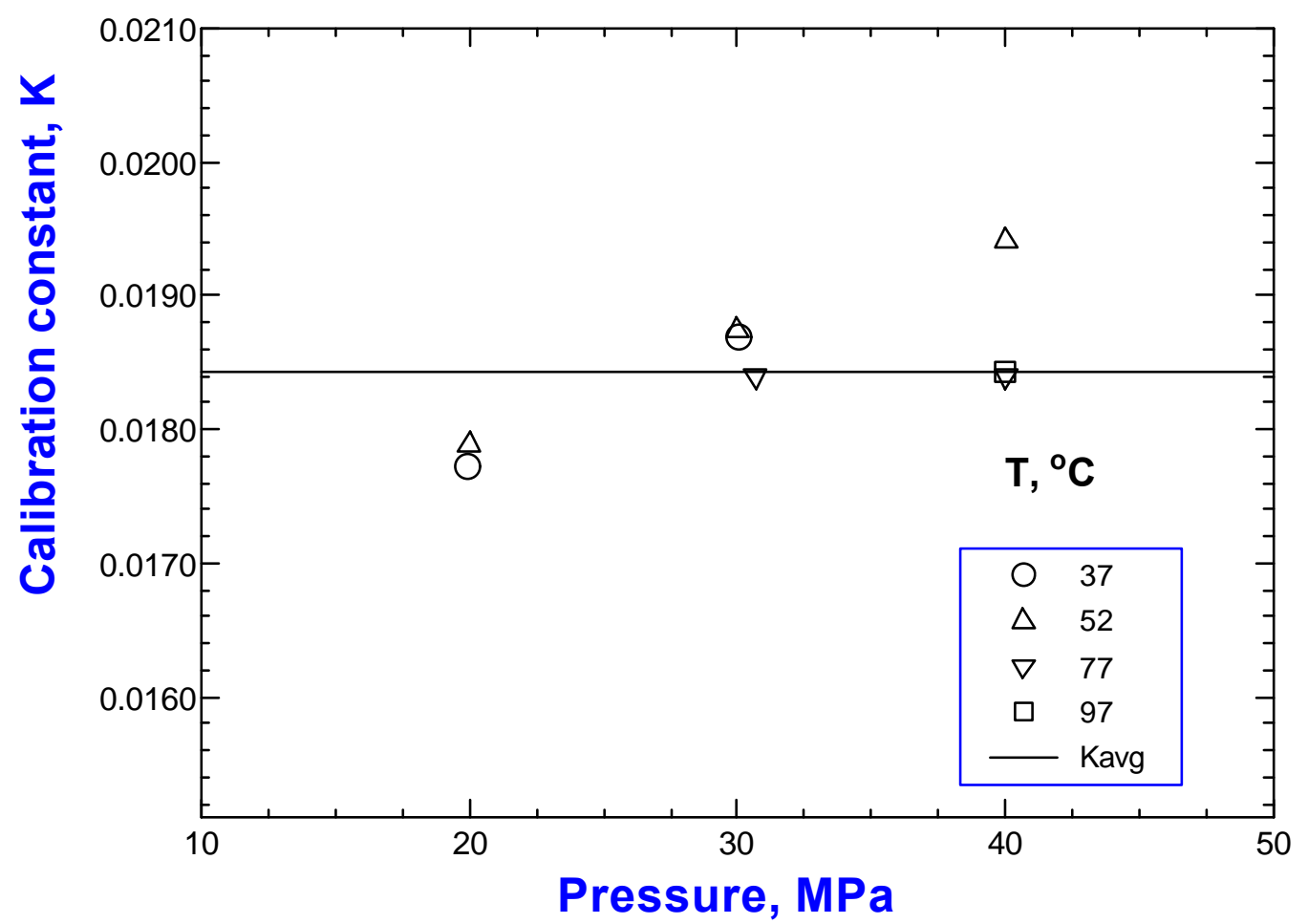

Figure 4.10. Variation of calibration constant calculated from carbon dioxide measurements with pressure. 


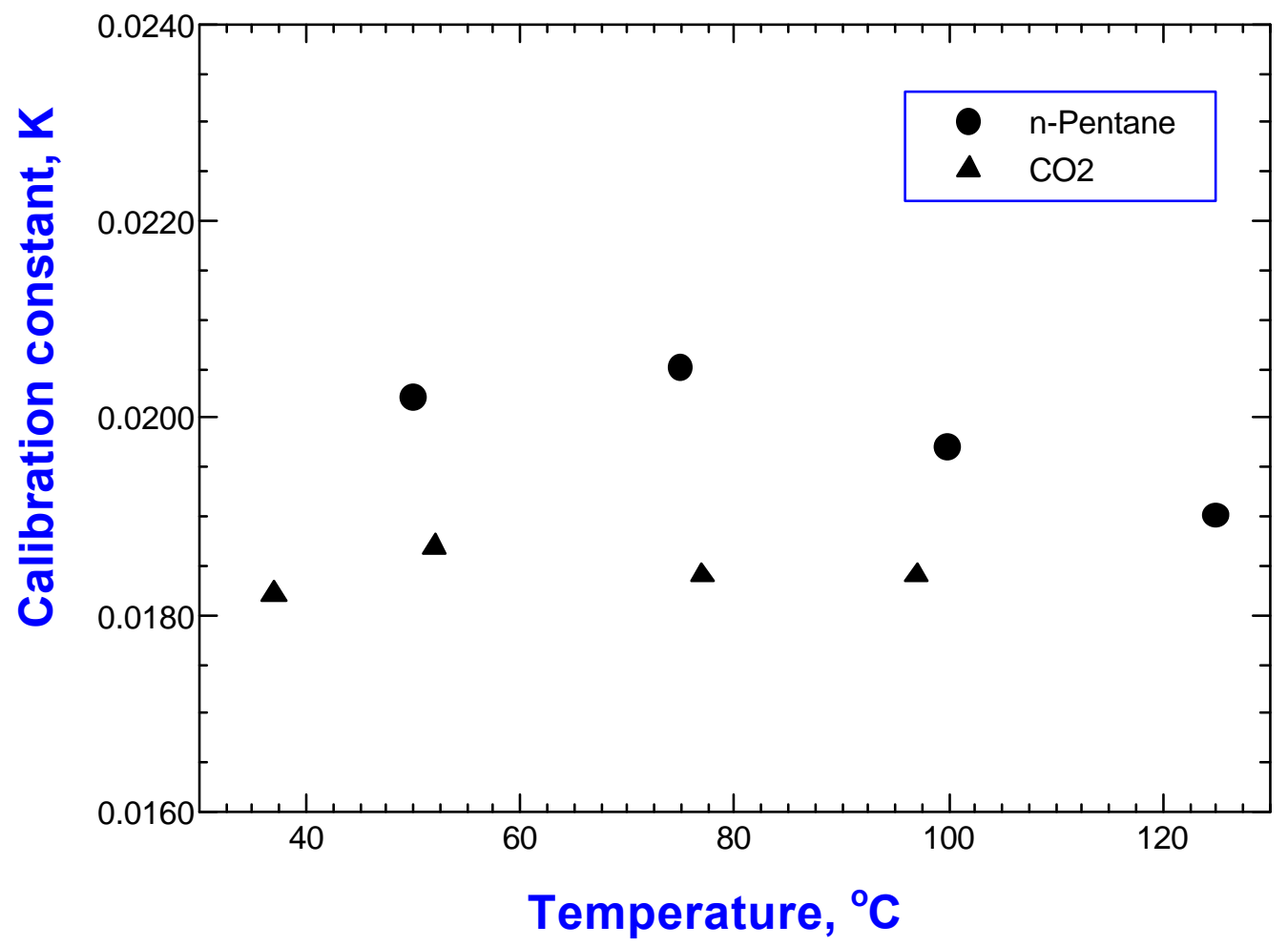

Figure 4.11. Variation of calibration constant calculated from carbon dioxide measurements with temperature. 
Experimentally determined viscosities of carbon dioxide using $K_{\mathrm{avg}}, 0.0199$, are compared with the data taken from literature $\left(\Delta \eta=\eta_{\text {Kavg }}-\eta_{\text {lit }}\right)$, and this difference with pressure is plotted in the Figure 4.12. It is observed that when the viscosities decrease below $0.09 \mathrm{mPa} \mathrm{s}$, the results are reliable with an accuracy of $10 \mu \mathrm{Pa} \mathrm{s}$, which is still very accurate in such low viscosity ranges.

Table 4.5. Measurements of density and viscosity of carbon dioxide (Literature data from Stephan and Lucas [51])

\begin{tabular}{ccccc}
\hline & & \multicolumn{2}{c}{ Present Study } & Literature \\
\hline Temperature, ${ }^{\mathbf{0}} \mathbf{C}$ & Pressure, $\mathbf{M P a}$ & $\boldsymbol{\rho}, \mathbf{g} / \mathbf{c m}^{\mathbf{3}}$ & $\boldsymbol{\eta}, \mathbf{m P a} . \mathbf{s}$ & $\boldsymbol{\eta}, \mathbf{m P a . s}$ \\
\hline 37 & 20.0 & 0.8696 & 0.0895 & 0.0796 \\
& 30.1 & 0.9264 & 0.1019 & 0.0956 \\
52 & 20.0 & 0.8821 & 0.0747 & 0.0671 \\
& 30.0 & 0.8855 & 0.0887 & 0.0835 \\
& 40.0 & 0.9397 & 0.0988 & 0.0963 \\
& 30.7 & 0.8809 & 0.0722 & 0.0667 \\
& 40.0 & 0.8584 & 0.0851 & 0.0787 \\
& 40.0 & 0.8875 & 0.0732 & 0.0678 \\
\hline
\end{tabular}




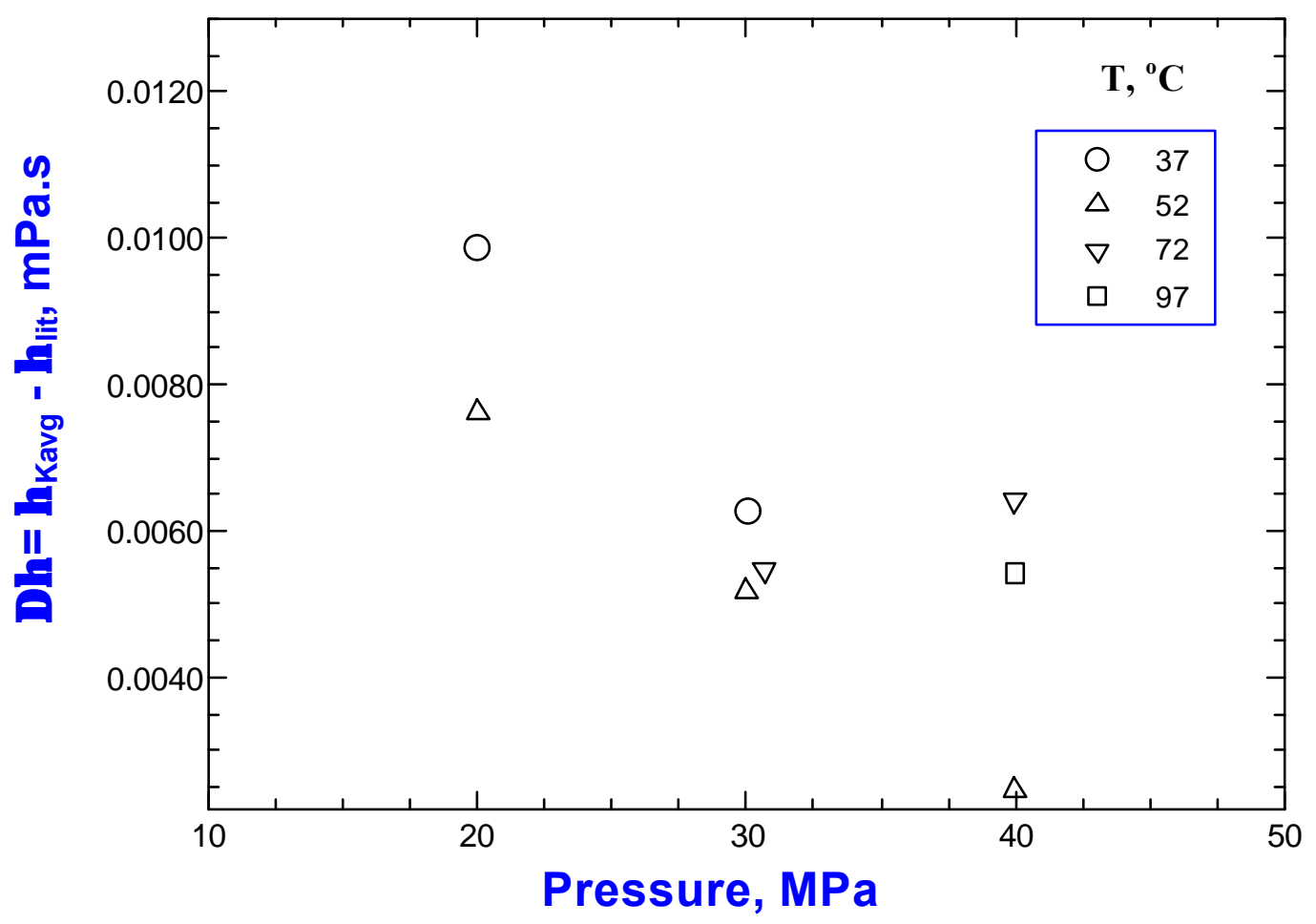

Figure 4.12. Difference in viscosities of carbon dioxide when experimentally determined viscosities, using $\mathrm{K}_{\mathrm{avg}}$, 0.0199, are compared with the data taken from literature $\left(\Delta \eta=\eta_{\text {Kavg }}-\eta_{\text {lit }}\right)$ with pressure (Literature data from Stephan and Lucas[51]). 


\section{CHAPTER 5}

\section{VISCOSITY AND DENSITY OF POLYMER SOLUTIONS AT THE CRITICAL POLYMER CONCENTRATION}

Information on high-pressure viscosity of polymer solutions is of special importance in a variety of applications such as high-pressure lubrication, enhanced oil recovery, and processing of polymers using near and supercritical fluids [52-55]. With the growing interest in using near-critical and supercritical fluids in polymer synthesis and modifications, there is a growing need for basic and applied data on both the thermodynamic and the transport properties of polymer solutions at high pressures for successful design and implementation of processes [53-57].

For single fluids, in the absence of the experimental data, there are models that can be used for prediction of viscosity using thermodynamic property data. However, for larger molecules, as the size difference between solvent and solute increases, the description of viscosity with thermodynamic parameters becomes complicated. Indeed, predictive methods for viscosity of polymer solutions are limited even at ambient pressures. Experimental data can however be effectively correlated with temperature, pressure and interaction parameters for a given solution [5, 58].

The viscosity of polymer solutions depends on the nature of the polymer and the solvent, concentration of the polymer, molecular weight and the molecular weight distribution of the polymer, temperature, pressure and the shear rate. In the following sections a brief review of literature on high-pressure viscosity of polymer solutions is first presented. 
Wolf and Jen were among the earliest authors who reported the thermodynamic properties of polymer solutions under pressure [59]. They stated that since the changes in the free volume of a liquid can be seen from its viscosity most easily; of all physicochemical properties, the viscosity shows the highest dependence on pressure. They determined the viscosity of trans-decahydro naphthalene + polystyrene solutions in the pressure range of $1-1000 \mathrm{bar}$ and the temperature range of $10-16{ }^{\circ} \mathrm{C}$ at $8-15$ weight $\%$ polymer concentrations using a rotating cylinder viscometer. Demixing conditions were observed as a sharp discontinuity in the logarithmic viscosity versus pressure curves. They correlated the variation of viscosity with pressure in terms of apparent volumes of activation, $\mathrm{V}^{\#}$.

$(\partial \ln \eta / \partial \mathrm{P})_{\mathrm{T}, \text { conc }}=\mathrm{V}^{\#} / \mathrm{RT}$

Eqn. 5.1

Variation of viscosity with temperature were correlated in terms of activation energy, $\mathrm{E}^{\#}$, according to the following relationship [59]:

$(\partial \ln \eta / \partial(1 / \mathrm{T}))_{\mathrm{P}, \mathrm{conc}}=\mathrm{E}^{\#} / \mathrm{R}$

Eqn. 5.2

In 1979, Kubota and Ogino measured the pressure dependence of the viscosity of the solutions of poly(dimethysiloxane) in cyclohexyl bromide at pressures up to $39 \mathrm{MPa}$ at 25 to $45{ }^{\circ} \mathrm{C}$ using a rolling-ball viscometer [60]. They reported that the intrinsic viscosity and the chain dimension increase with the increase of pressure.

Wolf and Geerissen investigated the factors governing the pressure dependence of the viscosity of polymer solutions and obtained information on the phase separation behavior of polystyrene solutions in cyclohexane, cyclopentane, diethylmalonate, and 1-phenyl decane at concentrations up to $12 \%$, temperatures from 32 to $102{ }^{\circ} \mathrm{C}$ and up to $1000 \mathrm{bar}$ [62]. Demixing points were determined form the sharp discontinuities in viscositypressure curves. Since pressure effects are particularly independent of polymer 
concentration only one solution of approximately critical composition was measured for each system [62].

In 1983, Claesson et al. studied the effect of pressure on the viscosity of dilute solutions of polystyrene in toluene using a falling body viscometer [63]. Measurements were performed in the concentration range from 0.0025 to $0.02 \mathrm{~g} / \mathrm{mL}$ and at temperatures from 25 to $45{ }^{\circ} \mathrm{C}$ at pressures up to 1057 bar. They found that the viscosity increases exponentially with pressure at a given temperature and concentration, while the apparent volume of activation $\mathrm{V}^{\#}$ decreases with increasing temperature. They showed that $\log \eta$ increases linearly with increasing concentration at given pressure and the intrinsic viscosity increases with increasing pressure, whereas the Huggins constant decreases.

Akki, Bair and Abhiraman measured low shear viscosities of dilute solutions of high molecular weight polyethylene in decalin and detected the phase transitions at high pressures. Viscosities were determined up to $0.6 \mathrm{GPa}$ and $150{ }^{\circ} \mathrm{C}$ [64].

Schott et al. performed viscometric measurements for the system isooctane/poly(decyl methacrylate) in the temperature range from $25{ }^{\circ} \mathrm{C}$ to $100{ }^{\circ} \mathrm{C}$ and pressure up to 3500 bar [37]. They observed a maximum in intrinsic viscosity at $75{ }^{\circ} \mathrm{C}$ at all pressures. They also reported that the free volume of the system increases with increasing temperature [37].

Viscosity measurements were carried out with solutions of $8 \mathrm{wt} \%$ poly(vinylchloride) in several good solvents at $25,40,60$ and $80{ }^{\circ} \mathrm{C}$ and up to 1000 bar [65]. The viscosities of pure solvents were obtained by rolling-ball viscometer whereas the viscosities of polymer solutions were obtained by using a Searle-type Haake viscometer. For constant temperature, the volumes of the activation for the viscous flow of the solutions, $\mathrm{V}^{\#}$, exceed that of the pure solvent by $25 \%$. It was reported that the dependence of $\mathrm{V}^{*}$ on temperature is not very pronounced and $\mathrm{V}$ decrease with increasing pressure. $\mathrm{E}^{\#}$ increases weakly as the pressure is raised. The pressure dependence of viscosity, expressed by $\mathrm{V}^{\#}$ 
passes a minimum at the temperature at which the solution becomes athermal and increases very strongly as the solvent power is reduced [65].

In 1992 Kiran and Sen investigated viscosity of polystyrene solutions in rpentane and in n-butane at temperatures from 125 to $170{ }^{\circ} \mathrm{C}$ and at pressures from demixing pressures up to $70 \mathrm{MPa}[5,15,56]$. All measurements were done using the falling sinker viscometer, used in the present thesis, that permits the simultaneous determination of viscosity, density and phase state of the solutions. They reported the temperature, pressure, solvent and molecular weight dependence of viscosity at moderate concentrations ranging between $4-12$ wt $\%$. They reported an exponential dependence of viscosity on density as well as on inverse temperature in the form of an Arrhenius type of equation,

$\eta=A \exp (B / T)$

Eqn. 5.3

In 1995, Kiran and Gokmenoglu using the same instrumental system studied the viscosity and density of homogenous one-phase solutions of (1 wt \%) polyethylenes with narrow molecular weight distributions $(\mathrm{Mw}=2150,15520,108,000,420,000)$ in $\mathrm{n}$-pentane at 125,140 and $155^{\circ} \mathrm{C}$ over a pressure range from 20 to $60 \mathrm{MPa}$ [54]. It was shown that the viscosities of these solutions can be correlated with density using the exponential relationship

$\eta=A \exp \left(B /\left(1-V_{o} \rho\right)\right)$

Eqn. 5.4

or

$\eta=\mathrm{C}_{1} \exp \left(\mathrm{C}_{2} \rho\right)$

Eqn. 5.5

which are based on free volume considerations. Temperature dependence of viscosity at fixed pressures and pressure dependence of viscosity at fixed temperatures were analyzed in terms of flow activation energies and apparent activation volumes, respectively. 
In 1994, Mertsch and Wolf studied homogenous mixtures of five poly(dimethysiloxane) fractions $(23-74 \mathrm{~kg} / \mathrm{mol})$ with carbon dioxide in the pressure range of 100-700 bars and temperatures between $30-70{ }^{\circ} \mathrm{C}$ [66]. Viscosities were measured in a rolling-ball and Searle-type pressure apparatus respectively, depending on the polymer content. They evaluated viscosity at constant pressure with respect to activation energies $E^{\#}$ and viscosities at constant temperature with respect to activation volumes $\mathrm{V}^{\#}$ and showed a pronounced sigmoidal dependence of these parameters on the composition of the mixtures. For the pure polymer they extrapolated these values in the limit of infinitely long chains and found $\mathrm{E}_{\infty}^{\#}=75 \mathrm{~kJ} / \mathrm{mol}$ at 300 bar and $\mathrm{V}_{\infty}^{\#}=43 \mathrm{~cm}^{3} / \mathrm{mol}$ at $30^{\circ} \mathrm{C}$.

In 1995, Xiong and Kiran determined the phase boundaries, densities and viscosities of solutions of poly(dimethylsiloxane)s (PDMS) in supercritical carbon dioxide [55]. The demixing pressures of $5 \mathrm{wt} \%$ solutions of PDMS with different molecular weights and molecular weight distributions were determined. Analyzing the density and viscosity data for solutions of PDMS with $\mathrm{M}_{\mathrm{w}}=38,900$ at 1,2 and $5 \mathrm{wt} \%$ concentrations they showed that results could be correlated with a free-volume based relationship of the form $\eta=A \exp \left(B /\left(1-V_{o} \rho\right)\right)$, Eqn. 5.4. Activation volumes at the pressure range of $40-70 \mathrm{MPa}$ are reported as $30-60 \mathrm{~cm}^{3} / \mathrm{mol}$ at the temperatures $107-147{ }^{\circ} \mathrm{C}$ for these solutions and activation energies for the same pressure and temperature range are reported as 7-10 $\mathrm{kJ} / \mathrm{mol}$, which are in the same order of magnitude with the data reported by Mertsch and Wolf.

In 1997, Xiong and Kiran determined the demixing pressures, densities and viscosities of solutions of nearly monodisperse polystyrene samples $\left(\mathrm{M}_{\mathrm{w}} / \mathrm{M}_{\mathrm{n}}<1.1\right)$ in $\mathrm{n}$-hexane [53]. Measurements were conducted with samples having different molecular weights $\left(\mathrm{M}_{\mathrm{w}}=\right.$ $4000-50,000)$ at concentrations up to 8 wt $\%$ over a pressure range from 5 to $70 \mathrm{MPa}$ and a temperature range from $50 \mathrm{~b} 150{ }^{\circ} \mathrm{C}$. It was reported that the demixing pressures were observed to increase with molecular weight and show high sensitivity to temperature. Density and viscosity data were collected in one-phase homogenous regions, 
and viscosity was correlated with density using Doolittle type of equation (Eqn. 5.4). It was concluded that at a fixed solution density, viscosity increases with polymer concentration or molecular weight. Flow activation volumes and flow activation energies were also calculated. The demixing data was compared with the results obtained in $n-$ butane and n-pentane for one sample, and it was reported that in going from nbutane to $\mathrm{n}$-hexane demixing pressures decrease while the viscosities become higher.

In 1999, Yeo and Kiran generated high-pressure density and viscosity data for polystyrene solutions in methylcyclohexane at $67,87,107$, and $127{ }^{\circ} \mathrm{C}$ using fallingcylinder type viscometer up to $35 \mathrm{MPa}$ [57]. Measurements were conducted with two different molecular weight samples $\left(\mathrm{M}_{\mathrm{w}}=50,000\right.$ and 700,000) in the concentration ranges of 3-14 wt $\%$ (for $\mathrm{M}_{\mathrm{w}}=50,000$ ) and $1-5 \mathrm{wt} \%$ (for $\mathrm{M}_{\mathrm{w}}=7000,000$ ). It was reported that density and viscosity of these solutions increased linearly with pressure in all the concentration ranges investigated. The flow activation volume and flow activation energy of the solutions were found to be in the range of $29-55 \mathrm{~cm}^{3} / \mathrm{mol}$ and $7-10 \mathrm{~kJ} / \mathrm{mol}$, respectively. It was found that the activation volume increased with temperature and the activation energy decreased with pressure. Viscosity was correlated with density employing Doolittle type of equation, and the close packed volumes were found to be in the range of $0.66-0.72 \mathrm{~cm}^{3} / \mathrm{g}$.

In 1999, Lee et. al., measured and modeled the solution viscosities of polystyrenesupercritical carbon dioxide using a linear capillary tube die mounted on a foaming extruder [67]. Carbon dioxide contents in the measurements were varied between 0 to 4 wt \%. They indicated that the $\mathrm{PS} / \mathrm{CO}_{2}$ solution viscosity is a sensitive function of shear rate, temperature, pressure and $\mathrm{CO}_{2}$ content. The zero shear viscosity was modeled using a generalized Arrhenius equation. 


\section{Present Study: Viscosity of Polymer Solutions at Critical Polymer Concentration}

In the present thesis we have measured the densities and viscosities of solutions of polyethylene $\left(\mathrm{M}_{\mathrm{w}}=121,000, \mathrm{M}_{\mathrm{w}} / \mathrm{M}_{\mathrm{n}}=4.3\right)$ in $\mathrm{n}$-pentane and poly(dimethylsiloxane) $\left(M_{w}=93,700, M_{w} / M_{n}=2.99\right)$ in carbon dioxide. The concentrations of the solutions were chosen to correspond to the critical polymer concentration, which is $5.75 \mathrm{wt} \%$ for solution of $\mathrm{PE}$ in n-pentane, and $5.5 \mathrm{wt} \%$ for solution of PDMS in $\mathrm{CO}_{2}$. Critical concentrations for these systems were already determined earlier [68-70] in our laboratory as part of an investigation on the kinetics of phase separation.

Viscosity is an important factor that influences the time-scale of new phase development in systems undergoing phase separation. Solutions at the critical polymer concentrations undergo phase separation by spinodal decomposition. Two different polymer + solvent systems that undergo spinodal decomposition at the critical polymer concentration may exhibit different kinetics. It was therefore of interest to determine the viscosity of these two inherently different polymer solutions at their critical polymer concentrations.

\subsection{Viscosity of PDMS $+\mathrm{CO}_{2}$ Solutions}

Viscosity measurements were conducted at $55,70,85$ and $100{ }^{\circ} \mathrm{C}$ and pressures up to 50 MPa. The viscosities are calculated from the general equation 4.1 (Chapter 4),

$\eta=K\left(\rho_{s}-\rho\right) / V_{t}$ Eqn. 4.1

using the $\mathrm{K}_{\mathrm{avg}}=0.0199$, as the value for the calibration constant, while the terminal velocities were determined from the distance versus time data. Figure 5.1 is an example of the 'voltage versus time' and 'distance versus time' plots generated at $70{ }^{\circ} \mathrm{C}$ and 48.5 $\mathrm{MPa}$ for the solution of $5.5 \mathrm{wt} \%$ PDMS in $\mathrm{CO}_{2}$. The data at different temperatures and pressures are presented in Table 5.1. Figure 5.2 shows the variation of viscosity with pressure at different temperatures. As shown in the figure, viscosities increase with 
pressure but decrease with temperature. At these conditions the viscosities are still relatively low, being less than $0.22 \mathrm{cP}$.

\subsection{Viscosity of PE + n-Pentane Solutions}

Viscosity measurements were conducted at 140 and $150{ }^{\circ} \mathrm{C}$. Figure 5.3 shows the 'voltage versus time' and 'distance versus time' plots generated at $150{ }^{\circ} \mathrm{C}$ and $30.2 \mathrm{MPa}$. The data at different temperatures and pressures are presented in Table 5.2. Figure 5.4 shows the variation of viscosity with pressure at these temperatures. Here also viscosity increases with pressure and decreases with temperature as expected. In contrast to PDMS $+\mathrm{CO}_{2}$ system, the viscosities for these solutions are much higher (nearly ten times), ranging from about 2 to $4.5 \mathrm{cP}$. 
Table 5.1. Density and viscosity of $5.5 \mathrm{wt} \% \mathrm{PDMS}\left(\mathrm{M}_{\mathrm{w}}=93,700\right)$ in $\mathrm{CO}_{2}$

\begin{tabular}{|c|c|c|c|c|}
\hline $\mathbf{T}$ & $\mathbf{P}, \mathbf{M P a}$ & $\rho, g / \mathrm{cm}^{3}$ & $\mathrm{Vt}, \mathrm{cm} / \mathrm{s}$ & $\eta, \mathbf{m P a} . \mathrm{s}$ \\
\hline \multirow[t]{9}{*}{$55^{\circ} \mathrm{C}$} & 48.70 & 0.9801 & 0.2785 & 0.2158 \\
\hline & 44.93 & 0.9663 & 0.3008 & 0.2007 \\
\hline & 41.74 & 0.9534 & 0.3182 & 0.1905 \\
\hline & 39.29 & 0.9420 & 0.3282 & 0.1854 \\
\hline & 34.72 & 0.9189 & 0.3508 & 0.1749 \\
\hline & 33.19 & 0.9090 & 0.3603 & 0.1707 \\
\hline & 33.19 & 0.9090 & 0.3708 & 0.1659 \\
\hline & 30.78 & 0.8959 & 0.3834 & 0.1611 \\
\hline & 28.04 & 0.8765 & 0.3922 & 0.1585 \\
\hline \multirow[t]{10}{*}{$70{ }^{\circ} \mathrm{C}$} & 48.45 & 0.9349 & 0.3161 & 0.1930 \\
\hline & 46.38 & 0.9349 & 0.3284 & 0.1857 \\
\hline & 44.90 & 0.9222 & 0.3334 & 0.1837 \\
\hline & 43.38 & 0.9203 & 0.3414 & 0.1795 \\
\hline & 41.54 & 0.9064 & 0.3578 & 0.1721 \\
\hline & 40.07 & 0.9030 & 0.4021 & 0.1533 \\
\hline & 38.17 & 0.8887 & 0.3858 & 0.1605 \\
\hline & 35.86 & 0.8759 & 0.4030 & 0.1543 \\
\hline & 35.59 & 0.8761 & 0.3964 & 0.1568 \\
\hline & 35.16 & 0.8723 & 0.4169 & 0.1493 \\
\hline \multirow[t]{5}{*}{$85^{\circ} \mathrm{C}$} & 48.28 & 0.9054 & 0.3531 & 0.1744 \\
\hline & 44.83 & 0.8901 & 0.3707 & 0.1670 \\
\hline & 41.59 & 0.8734 & 0.4039 & 0.1541 \\
\hline & 39.41 & 0.8548 & 0.4341 & 0.1442 \\
\hline & 37.75 & 0.8476 & 0.4388 & 0.1430 \\
\hline
\end{tabular}


Table 5.1. Cont'd

\begin{tabular}{ccccc}
\hline $\mathbf{T}$ & $\mathbf{P}, \mathbf{M P a}$ & $\boldsymbol{\rho}, \mathbf{g} / \mathbf{c m}^{\mathbf{3}}$ & $\mathbf{V t}, \mathbf{c m} / \mathbf{s}$ & $\boldsymbol{\eta}, \mathbf{m P a . s}$ \\
\hline $100{ }^{\circ} \mathrm{C}$ & 48.21 & 0.8610 & 0.4035 & 0.1548 \\
& 46.55 & 0.8503 & 0.4158 & 0.1507 \\
& 44.83 & 0.8396 & 0.4311 & 0.1459 \\
& 43.79 & 0.8325 & 0.4475 & 0.1409 \\
\hline
\end{tabular}

Table 5.2. Density and viscosity of 5.74 wt $\% \mathrm{PE}(\mathrm{Mw}=121,000)$ in n-pentane

\begin{tabular}{|c|c|c|c|c|}
\hline $\mathbf{T}$ & $\mathbf{P}, \mathbf{M P a}$ & $\boldsymbol{\rho}, \mathbf{g} / \mathrm{cm}^{3}$ & $\mathrm{Vt}, \mathrm{cm} / \mathrm{s}$ & $\boldsymbol{\eta}, \mathbf{m P a} . \mathbf{s}$ \\
\hline \multirow[t]{7}{*}{$140{ }^{\circ} \mathrm{C}$} & 48.51 & 0.5751 & 0.0162 & 4.1986 \\
\hline & 41.81 & 0.5623 & 0.0170 & 4.0180 \\
\hline & 34.40 & 0.5511 & 0.0192 & 3.5771 \\
\hline & 24.26 & 0.5346 & 0.0234 & 2.9509 \\
\hline & 21.55 & 0.5296 & 0.0251 & 2.7548 \\
\hline & 18.62 & 0.5296 & 0.0273 & 2.5288 \\
\hline & 17.59 & 0.5255 & 0.0299 & 2.3113 \\
\hline \multirow[t]{9}{*}{$150{ }^{\circ} \mathrm{C}$} & 48.29 & 0.5819 & 0.0147 & 4.6239 \\
\hline & 44.86 & 0.5780 & 0.0149 & 4.5605 \\
\hline & 41.65 & 0.5737 & 0.0154 & 4.4368 \\
\hline & 34.88 & 0.5648 & 0.0165 & 4.1549 \\
\hline & 31.34 & 0.5597 & 0.0178 & 3.8521 \\
\hline & 27.76 & 0.5538 & 0.0186 & 3.6805 \\
\hline & 20.83 & 0.5411 & 0.0221 & 3.1193 \\
\hline & 15.52 & 0.5310 & 0.0246 & 2.8007 \\
\hline & 12.97 & 0.5255 & 0.0261 & 2.6496 \\
\hline
\end{tabular}



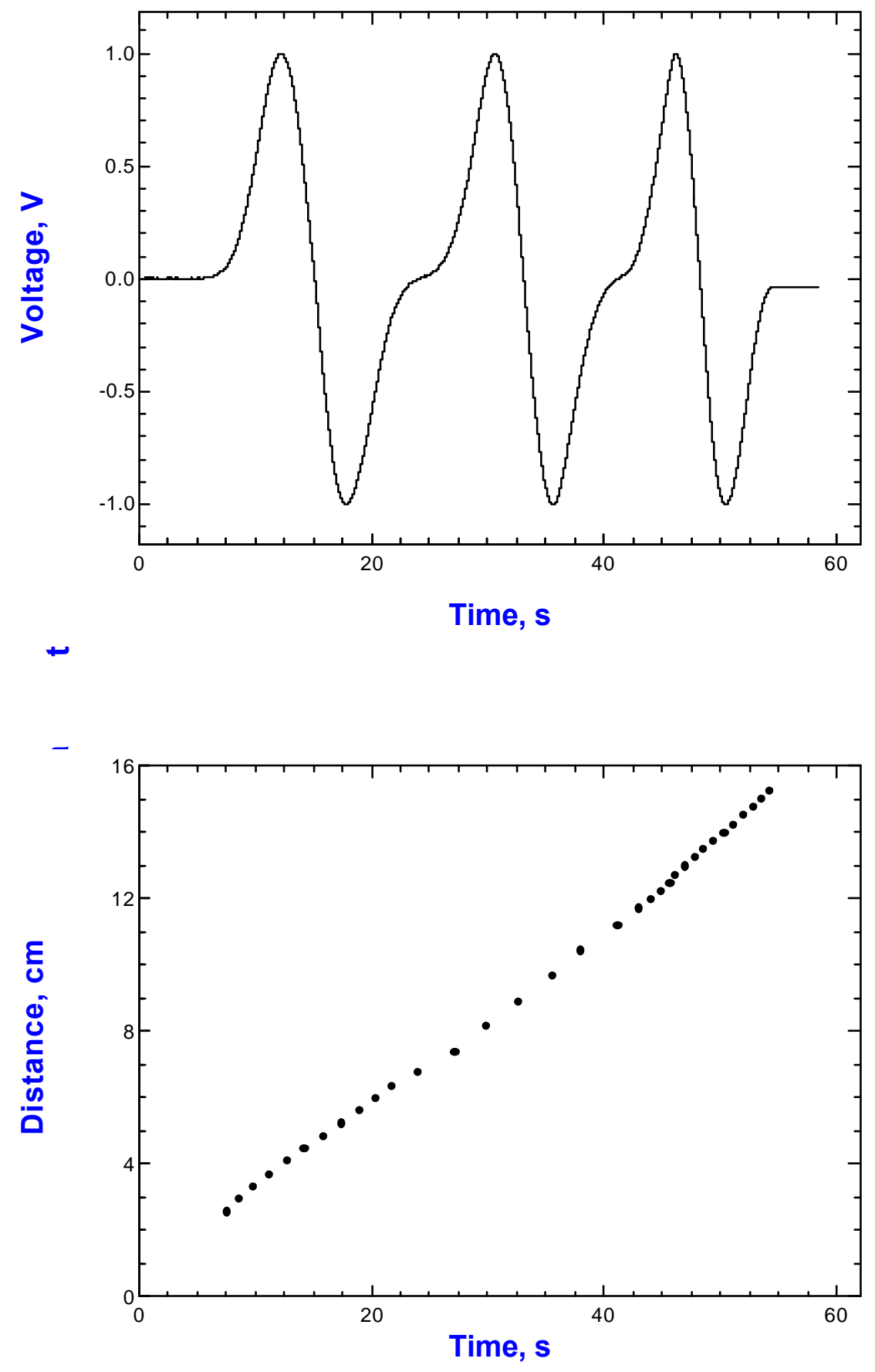

Figure 5.1. 5.5 wt $\%$ PDMS $\left(\mathrm{M}_{\mathrm{w}}=93,700 ; \mathrm{M}_{\mathrm{w}} / \mathrm{M}_{\mathrm{n}}=2.99\right)$ in $\mathrm{CO}_{2}$ at $70{ }^{\circ} \mathrm{C}$ and $48.5 \mathrm{MPa}$. 


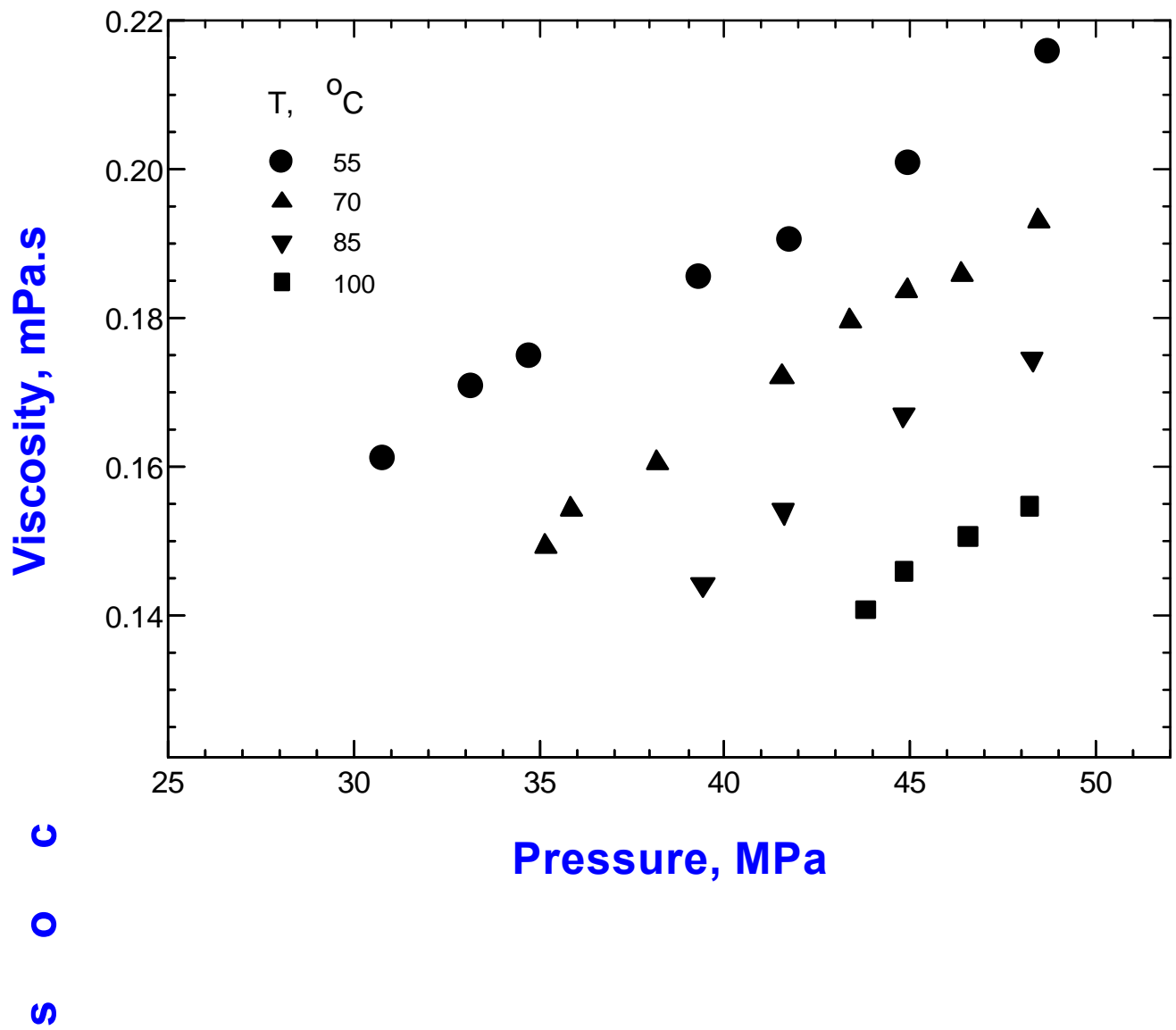

Figure 5.2. Variation of viscosity with pressure for $5.5 \mathrm{wt} \%$ solution of PDMS $\leftarrow\left(\mathrm{M}_{\mathrm{w}}=93,700\right)$ in carbon dioxide at different temperatures.

$\lambda$ 


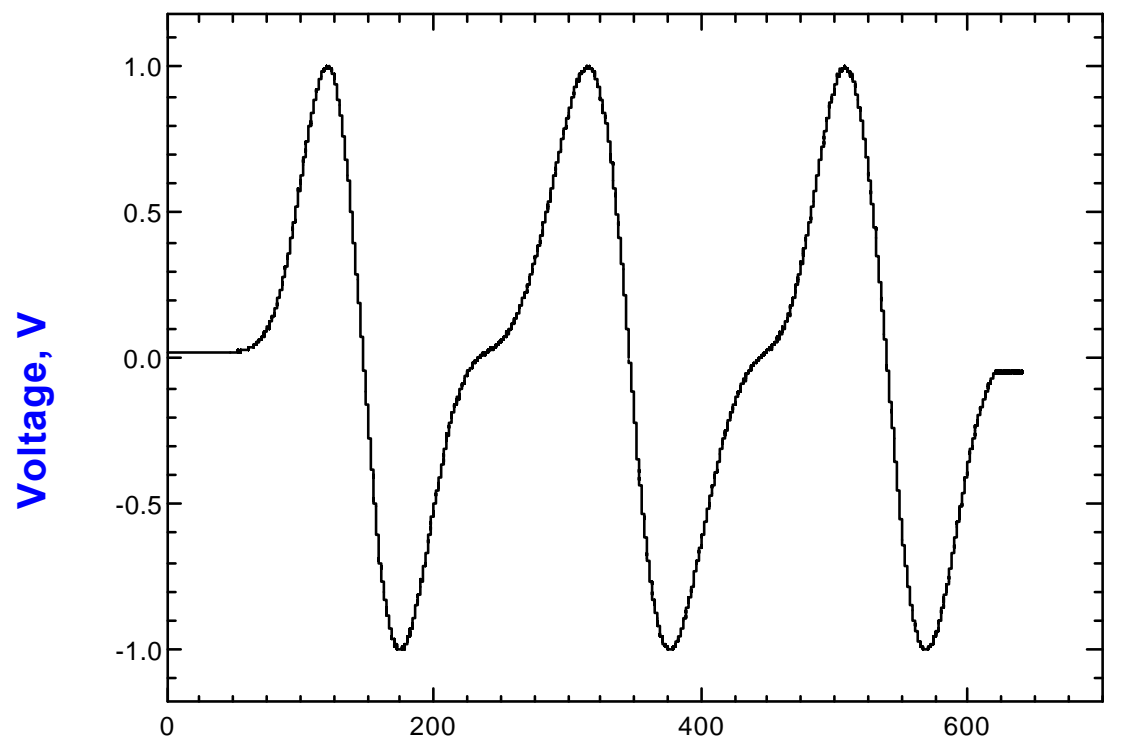

Time, $\mathbf{s}$

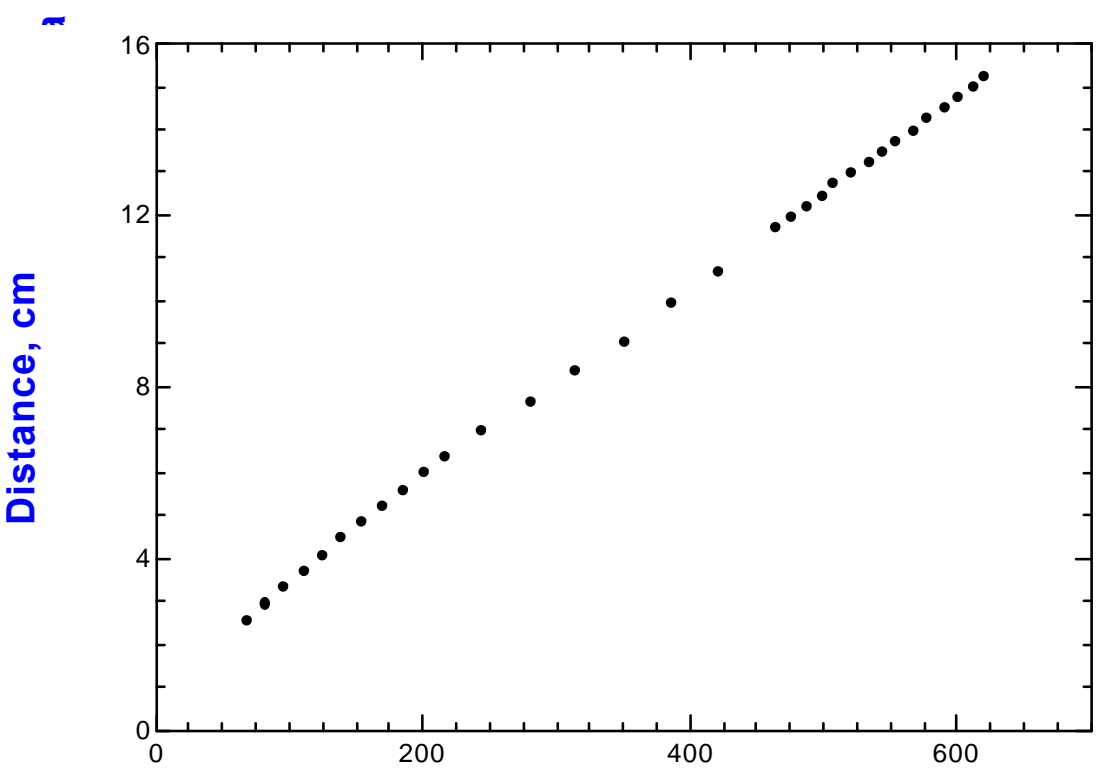

Time, s

Figure 5.3. 5.74 wt \% PE $\left(\mathrm{M}_{\mathrm{w}}=121,000 ; \mathrm{M}_{\mathrm{w}} / \mathrm{M}_{\mathrm{n}}=4.3\right)$ in $\mathrm{n}$-pentane at $150{ }^{\circ} \mathrm{C}$ and $30.2 \mathrm{MPa}$. 


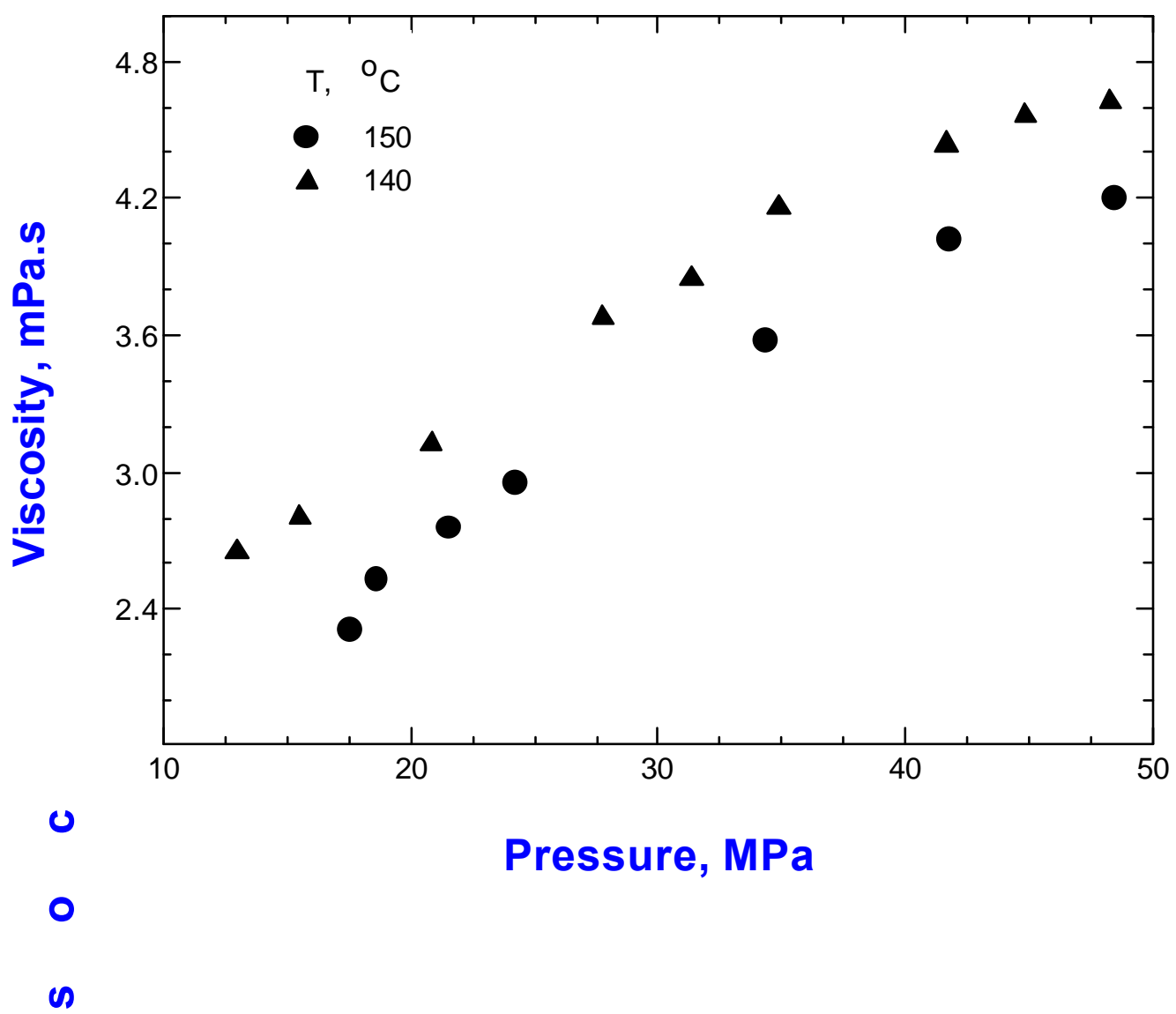

- Figure 5.4. Variation of viscosity with pressure for $5.74 \mathrm{wt} \%$ solution of $\mathrm{PE}\left(\mathrm{M}_{\mathrm{w}}=\right.$ $\leftarrow 121,000)$ in n-pentane at different temperatures.

$>$ 


\subsection{Analysis of Viscosity Data}

\subsubsection{Temperature Dependence of Viscosity}

The apparent energy of activation, $E^{\#}$, for the viscous flow can be described by an Arrhenius equation obtained from the plots [61],

$\eta=\mathrm{A} \exp \left(\mathrm{E}^{\#} / \mathrm{RT}\right)$

Eqn. 5.6

or

$(\partial \ln \eta / \partial(1 / \mathrm{T}))_{\mathrm{P}, \mathrm{conc}}=\mathrm{E}^{\#} / \mathrm{R}$

Eqn. 5.2

where $\eta$ is the viscosity, $E^{\#}$ is the activation energy of viscous flow, $R$ is the ideal gas constant, and $\mathrm{T}$ is the absolute temperature. This relationship is based upon a lattice structure for a solution containing some unoccupied sites or holes [57]. The quantity of flow activation energy is an energy barrier for the movement of a molecule, and expected to be related to the latent heat of vaporization of the solution which defines the flow activation energy obtained by fitting logarithmic viscosity versus inverse temperature at different pressures. The slope of the fitted equation, $E^{\#} / R$, is used to calculate flow activation energies.

\section{a. $\mathrm{PDMS}+\mathrm{CO}_{2}$}

Figure 5.5 shows the logarithmic viscosity versus inverse temperature at different pressures $(42,45,48 \mathrm{MPa})$ for $5.5 \mathrm{wt} \% \mathrm{PDMS}$ in $\mathrm{CO}_{2}$. The slope of the fitted equation, $E^{\#} / R$, is used to calculate flow activation energies. The results are presented in Table 5.3.

The calculated activation energy is around $7 \mathrm{~kJ} / \mathrm{mol}$. It is observed that flow activation energies show a small increase with increasing pressure which has also been observed by others $[54,55]$ showing that at higher pressure the viscosity becomes more temperature dependent for this system. Table 5.3 shows the activation energy values reported for 1,2 


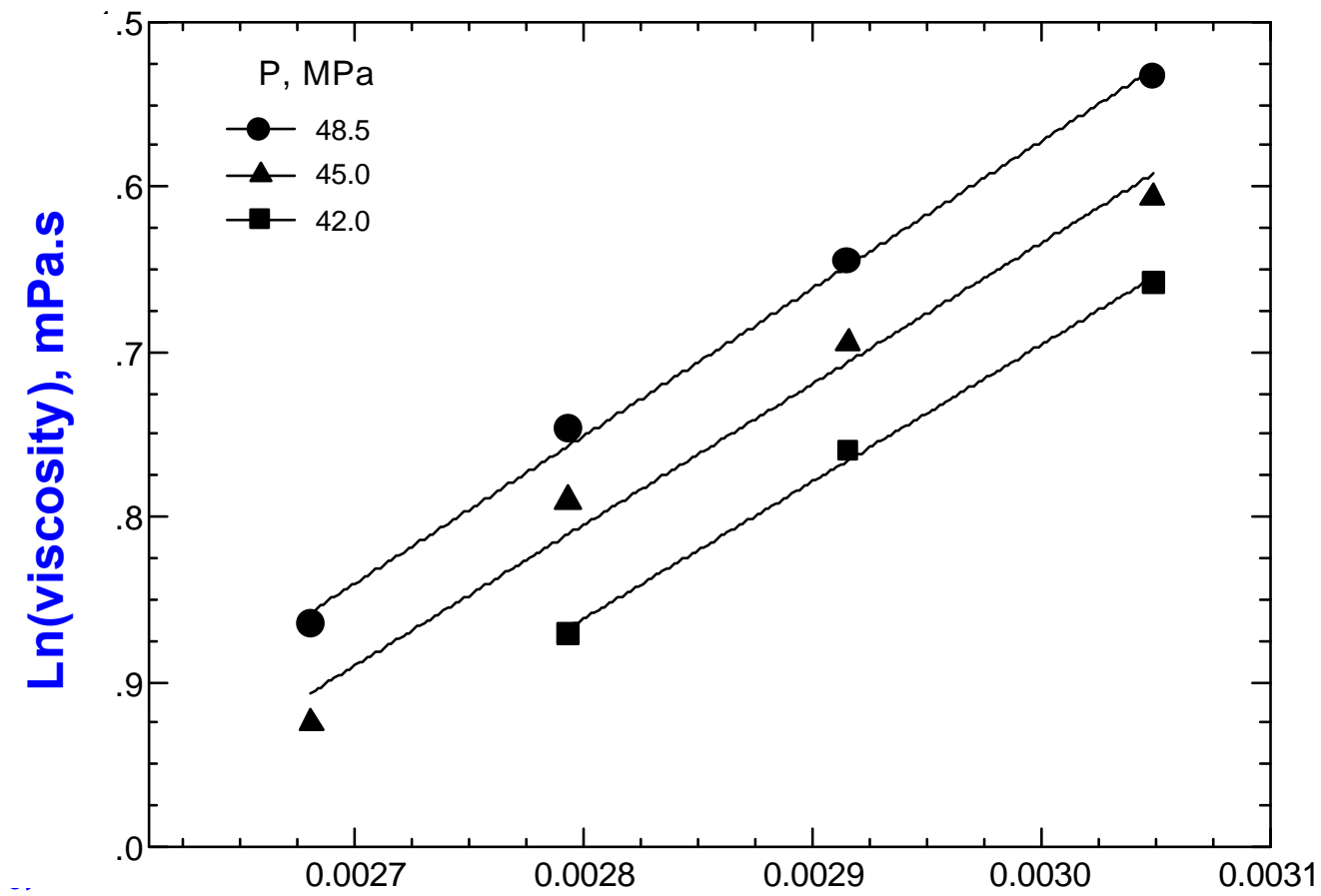

0

@

-

$\leftarrow$

$\lambda$

-

Figure 5.5. Variation of $\operatorname{lm} \eta$ with reciprocal temperature, $1 / \mathrm{T}$, for $5.5 \mathrm{wt} \%$ solution of PDMS $\left(M_{w}=93,700\right)$ in carbon dioxide at different pressures. 
and 5 wt \% solutions of PDMS of lower molecular weight (with $\mathrm{M}_{\mathrm{w}}=38,900$ ) in $\mathrm{CO}_{2}$ determined earlier by Xiong and Kiran [55].

Comparison with the present data suggests that the activation energy values are of similar magnitude suggesting that $\mathrm{E}^{\#}$ values are not affected significantly by concentration and molecular weight in the range investigated.

Table 5.3. Activation energy, $\mathrm{E}^{\#}$, for $5.5 \mathrm{wt} \%$ solution of PDMS $\left(\mathrm{M}_{\mathrm{w}}=93,700\right)$ in $\mathrm{CO}_{2}$

\begin{tabular}{ccc}
\hline Pressure(MPa) & Slope $=\mathbf{\partial} \mathbf{l n \eta} / \mathbf{\partial}(\mathbf{1} / \mathbf{T})$ & $\mathbf{E}^{\#}(\mathbf{k J} / \mathbf{m o l})$ \\
\hline 42 & 893 & 6.9 \\
45 & 854 & 7.1 \\
48 & 831 & 7.4 \\
\hline
\end{tabular}

Table 5.4 Activation energy, $E^{\#}$, for 1,2 and 5 wt \% solutions of PDMS $\left(M_{w}=38,900\right)$ in $\mathrm{CO}_{2}$ (From ref. [55])

\begin{tabular}{cccc}
\hline Pressure (MPa) & & $\mathbf{E}^{\#}(\mathbf{k J} / \mathbf{m o l})$ & \\
\hline & $\mathbf{1} \mathbf{~ w t} \%$ & $\mathbf{2} \mathbf{~ w t} \%$ & $\mathbf{5} \mathbf{~ w t} \%$ \\
\hline 45 & 7.0 & 7.4 & 8.1 \\
50 & 7.4 & 8.1 & 8.8 \\
\hline
\end{tabular}

Stein et al. determined the activation energy for the bulk viscosity of PDMS $\left(\mathrm{M}_{\mathrm{w}}=28\right.$, 000) as $16 \mathrm{~kJ} / \mathrm{mol}$ [75]. The bulk activation energy is greater that the activation energy for the solution of PDMS in $\mathrm{CO}_{2}$. Since activation energy is the energy required to create a hole big enough for a molecule to jump into, when compared to bulk, creating this hole becomes easier in solution, and activation energies are lower when compared to bulk 
polymer. They measured the viscosity of PDMS over the range of -13 to $82{ }^{\circ} \mathrm{C}$ and similarly described viscosity by the linear plot of $\ln \eta$ versus $1 / T$ [71].

\section{b. PE + n-Pentane}

Figure 5.6 shows the variation of $1 \mathrm{n \eta}$ with $1 / \mathrm{T}$ at $21,34.5,48.4 \mathrm{MPa}$. The activation energies determined from the slopes of these plots are given in Table 5.5. The activation energy shows a maximum at $34.5 \mathrm{MPa}$, which has been observed for some other systems at critical polymer concentrations [62]. Table 5.6 shows the activation energies reported for 1 wt \% solutions of PE (with $\mathrm{M}_{v}=2150,15,520,108,000$ ) in npentane earlier by Kiran and Gokmenoglu [54]. The present values are higher as shown in Table 5.6.

The activation energies obtained for $\mathrm{PE}+\mathrm{n}$-pentane system are higher than the values obtained for PDMS $+\mathrm{CO}_{2}$ system. This may be related to the greater backbone flexibility with PDMS. With larger, irregularly shaped or stiff backbone molecules, the deformation is slower as the molecules restrict the easy translation of one past the other [58]. This results in high values of activation energy as well as a high viscosity. PDMS is known for its extremely low glass transition temperature $\left(\mathrm{T}_{\mathrm{g}}=-123^{\circ} \mathrm{C}\right)$ and extraordinary flexibility of the chain back bone which are due to the long $\mathrm{Si}-\mathrm{O}$ bond lengths, partial ionic character of the silicon -oxygen bond, and small methyl substituents [71].

Table 5.5 Activation energy, $E^{\#}$, for 5.74 wt \% solution of PE $\left(M_{w}=121,000\right)$ in $n-$ Pentane

\begin{tabular}{ccc}
\hline Pressure(MPa) & Slope $=\partial \ln \eta / \partial(\mathbf{1} / \mathbf{T})$ & $\mathbf{E}^{\#}(\mathbf{k J} / \mathbf{m o l})$ \\
\hline 21.0 & 2172 & 18.1 \\
34.5 & 2617 & 21.8 \\
48.4 & 1686 & 14.0 \\
\hline
\end{tabular}


Table 5.6 Activation energy, $E^{\#}$, for 1 wt \% solutions of PE in n-Pentane (From ref. [54])

\begin{tabular}{cccc}
\hline Pressure (MPa) & & $\mathbf{E}^{\#}(\mathbf{k J} / \mathbf{m o l})$ & \\
\hline & $\boldsymbol{M w}=\mathbf{2 1 5 0}$ & $\boldsymbol{M w}=\mathbf{1 5 , 5 2 0}$ & $\boldsymbol{M w}=\mathbf{1 0 8 , 0 0 0}$ \\
\hline 30 & 9.3 & 8.1 & 12.2 \\
40 & 8.6 & 8.8 & 11.2 \\
50 & 8.0 & 9.4 & 10.1 \\
\hline
\end{tabular}

\subsubsection{Pressure Dependence of Viscosity}

The apparent volume of activation for the viscous flow can be determined according to $[61,72]$

$\eta=\mathrm{A} \exp \left[\left(\mathrm{V}^{\#} / \mathrm{RT}\right) / \mathrm{P}\right]$

Eqn. 5.7

or

$(\partial \ln \eta / \partial \mathrm{P})_{\mathrm{T}, \text { conc }}=\mathrm{V}^{\#} / \mathrm{RT}$

Eqn. 5.1

Where $\mathrm{R}$ is the gas constant, $\mathrm{T}$ is the temperature in $\mathrm{K}$. For low molecular weight liquids it is reported that $\mathrm{V}^{\#}$ amounts to $1 / 4$ to $1 / 3$ of the molar volume, in the case of high molecular weight liquids $\mathrm{V}^{\#}$ has been considered as a similar portion of the volume of the flow unit, i.e. of the independently moving part of a macromolecule. For polymer solutions $\mathrm{V}^{\#}$ is a composite quantity lies close to the corresponding value of the solvent [61].

\section{a. $\mathrm{PDMS}+\mathrm{CO}_{2}$}

Activation volumes of solution of $5.5 \mathrm{wt} \% \mathrm{PDMS}\left(\mathrm{M}_{\mathrm{w}}=94,700\right)$ in $\mathrm{CO}_{2}$ were calculated from the slopes of $\ln \eta$ versus $P$ plots at $55,70,85$ and $100{ }^{\circ} \mathrm{C}$ as shown in Figure 5.7. The results are presented in Table 5.7. The evaluated activation volumes range from 40 to 64 $\mathrm{cm}^{3} / \mathrm{mol}$. Table 5.8 shows the data for 1,2 and $5 \mathrm{wt} \%$ solutions of a lower molecular weight PDMS $\left(\mathrm{M}_{\mathrm{w}}=38,900\right)$ in $\mathrm{CO}_{2}[55]$. 

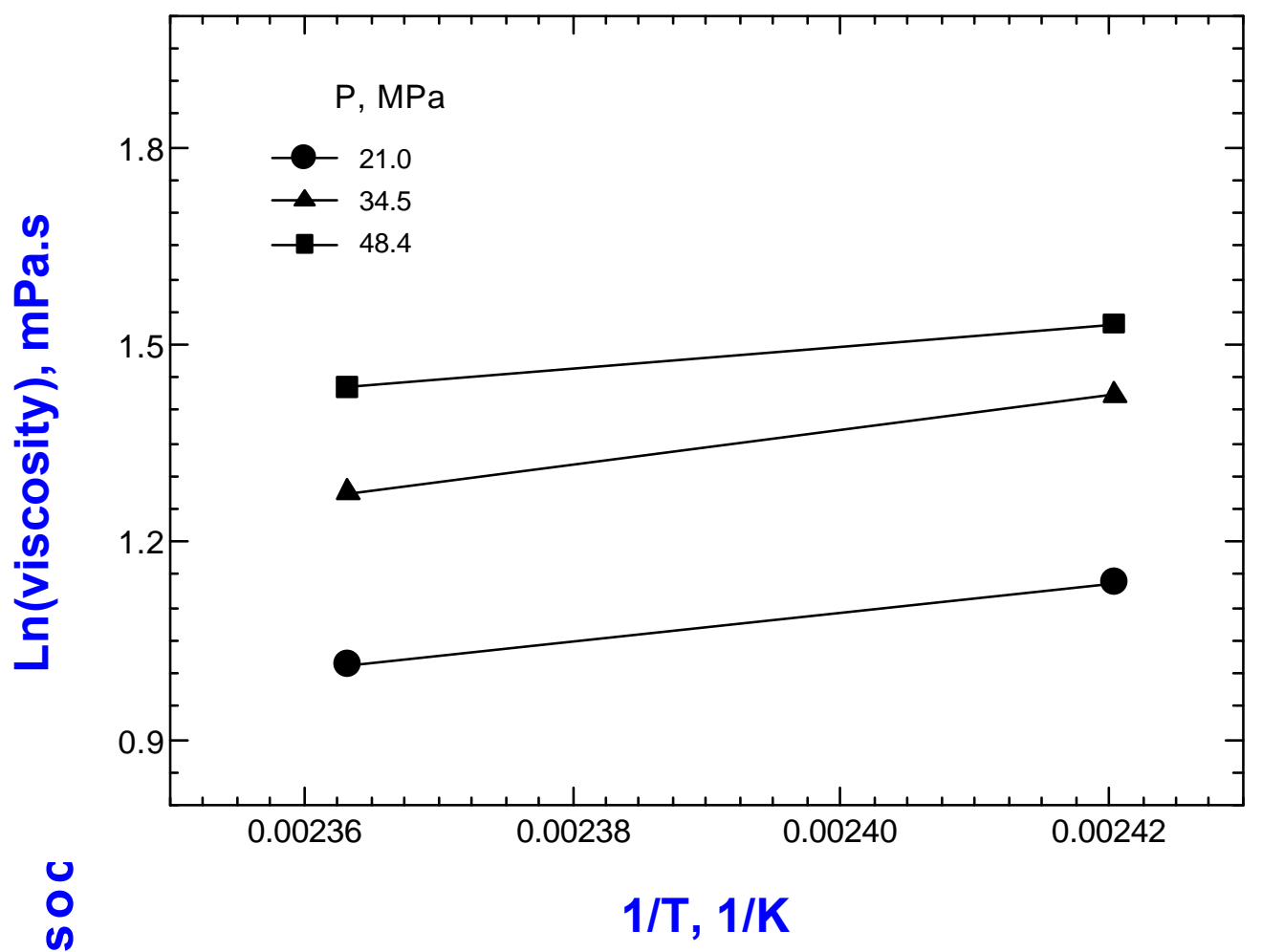

-

$\lambda$

Figure 5.6. Variation of $\ln \eta$ with reciprocal temperature, $1 / \mathrm{T}$, for $5.74 \mathrm{wt} \%$ solution of $\mathrm{PE}\left(\mathrm{M}_{\mathrm{w}}=121,000\right)$ in n-pentane at different pressures. 


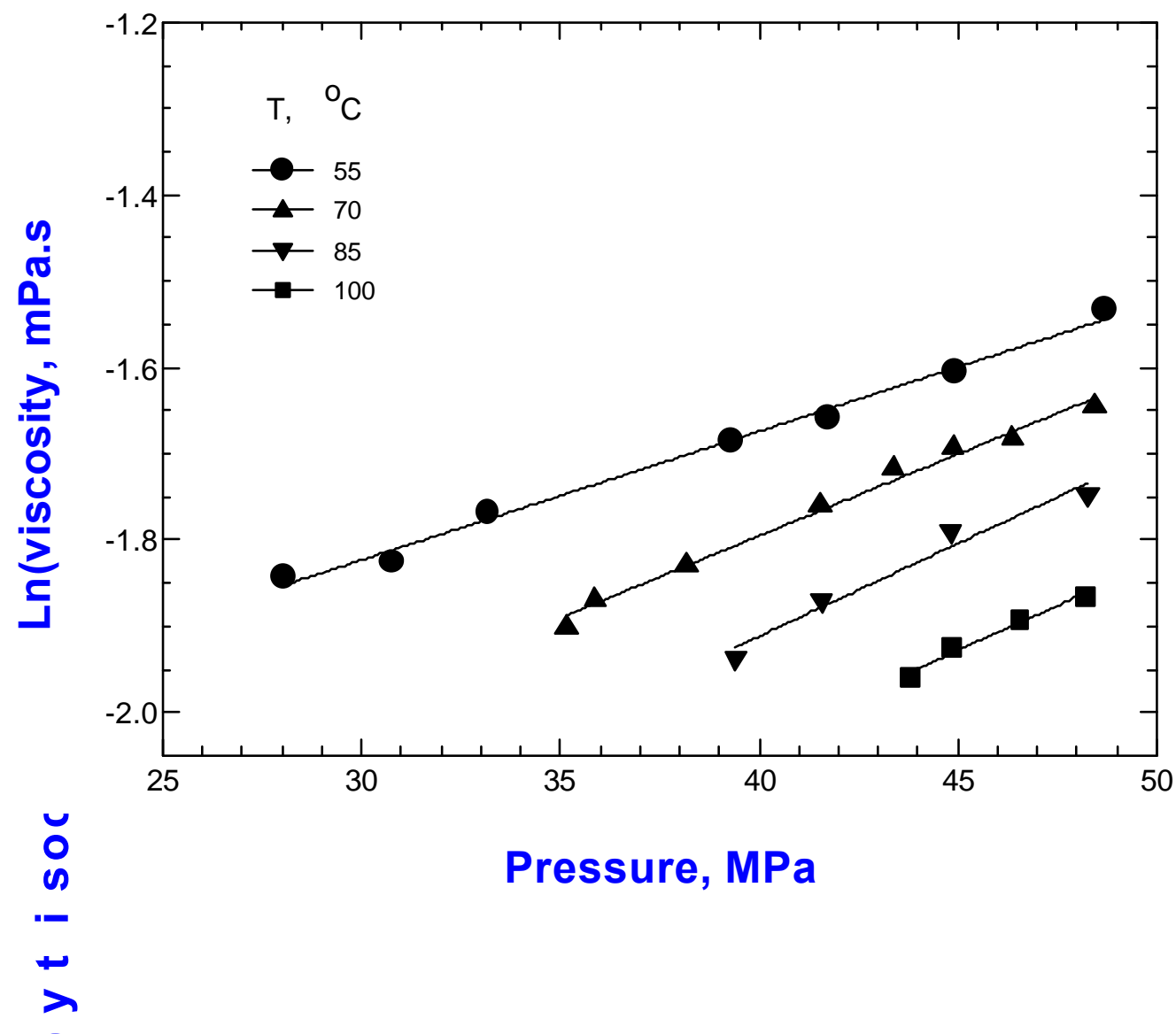

Figure 5.7. Variation of $\ln \eta$ with pressure for $5.5 \mathrm{wt} \%$ solution of PDMS $\left(\mathrm{M}_{\mathrm{w}}\right.$ $=93,700)$ in carbon dioxide at different temperatures. 
The activation volumes for the 5.5 wt \% PDMS $\left(\mathrm{M}_{\mathrm{w}}=94,3000\right)$ in $\mathrm{CO}_{2}$ are larger in the present study which may be due to the higher molecular weight of PDMS or the higher concentration of the solution.

Table 5.7 Activation volume, $\mathrm{V}^{\#}$, for $5.5 \mathrm{wt} \%$ solution of PDMS $(\mathrm{Mw}=94,700)$ in $\mathrm{CO}_{2}$

\begin{tabular}{ccc}
\hline Temperature $\left({ }^{\mathbf{0}} \mathbf{C}\right)$ & $\mathbf{S l o p e}=\boldsymbol{\partial} \mathbf{l n} \boldsymbol{\eta} / \mathbf{P}$ & $\mathbf{V}^{\#}\left(\mathbf{c m}^{\mathbf{3}} / \mathbf{m o l}\right)$ \\
\hline 55 & 0.015 & 40.7 \\
70 & 0.019 & 54.1 \\
85 & 0.022 & 64.0 \\
100 & 0.021 & 64.4 \\
\hline
\end{tabular}

Table 5.8 Activation volume, $\mathrm{V}^{\#}$, for 1, 2 and $5 \mathrm{wt} \%$ solutions of PDMS (Mw =38,900) in $\mathrm{CO}_{2}$ (From ref. [55])

\begin{tabular}{cccc}
\hline Temperature $\left({ }^{\mathbf{0}} \mathbf{C}\right)$ & & $\mathbf{V}^{\#}\left(\mathbf{c m}^{\mathbf{3}} / \mathbf{m o l}\right)$ & \\
\hline & $\mathbf{1} \mathbf{~ w t} \%$ & $\mathbf{2} \mathbf{~ w t} \%$ & $\mathbf{5} \mathbf{~ w t} \%$ \\
\hline 107 & 38.0 & 32.6 & 39.2 \\
127 & 44.8 & 40.7 & 49.9 \\
147 & 49.3 & 50.1 & 58.7 \\
\hline
\end{tabular}

\section{b. PE + n-Pentane}

Figure 5.8 shows the variation of $\ln \eta$ with pressure at 140 and $150{ }^{\circ} \mathrm{C}$. Because of the nonlinear nature of the data, the slopes were calculated for two pressure ranges, one for pressures up to $41 \mathrm{MPa}$, and the other for pressures above $41 \mathrm{MPa}$. The results are presented in Table 5.9. The activation volumes increase with temperature but observed to 
decrease with pressure. Activation volumes are higher when compared with values reported for 1 wt \% solutions of different molecular weight PE samples in npentane [54] that are shown in Table 5.10, which may be due to the higher concentration of the polymer.

Table 5.9 Activation volume, $V^{\#}$, for $5.74 \mathrm{wt} \%$ solution of $\mathrm{PE}\left(\mathrm{M}_{\mathrm{w}}=121,000\right)$ in $\mathrm{n}$ Pentane

\begin{tabular}{cccc}
\hline Pressure(MPa) & Temperature, ${ }^{\mathbf{0}} \mathbf{C}$ & Slope $=(\boldsymbol{\partial} \mathbf{l n} \boldsymbol{\eta} / \partial \mathbf{P})$ & $\mathbf{V}^{\#}\left(\mathbf{c m}^{\mathbf{3}} \mathbf{\mathbf { m o l }}\right)$ \\
\hline Up to 41.8 & 150 & 0.021 & 75.1 \\
Above 41.8 & 150 & 0.007 & 23.1 \\
Up to 41.6 & 140 & 0.019 & 64.6 \\
Above 41.6 & 140 & 0.006 & 21.3 \\
\hline
\end{tabular}

Table 5.10 Activation volume, $\mathrm{V}^{\#}$, for $1 \mathrm{wt} \%$ solutions of PE in n-Pentane (From ref. [54])

\begin{tabular}{cccc}
\hline Temperature, ${ }^{\mathbf{0}} \mathbf{C}$ & \multicolumn{3}{c}{$\mathbf{V}^{\#}\left(\mathbf{c m}^{\mathbf{3}} \mathbf{m o l}\right)$} \\
\hline \multirow{2}{*}{140} & $\boldsymbol{M w}=\mathbf{2 1 5 0}$ & $\boldsymbol{M w}=\mathbf{1 5 , 5 2 0}$ & $\boldsymbol{M w}=\mathbf{1 0 8 , 0 0 0}$ \\
155 & 34.1 & 32.5 & 43.5 \\
& 38.5 & 31.0 & 44.5 \\
\hline
\end{tabular}




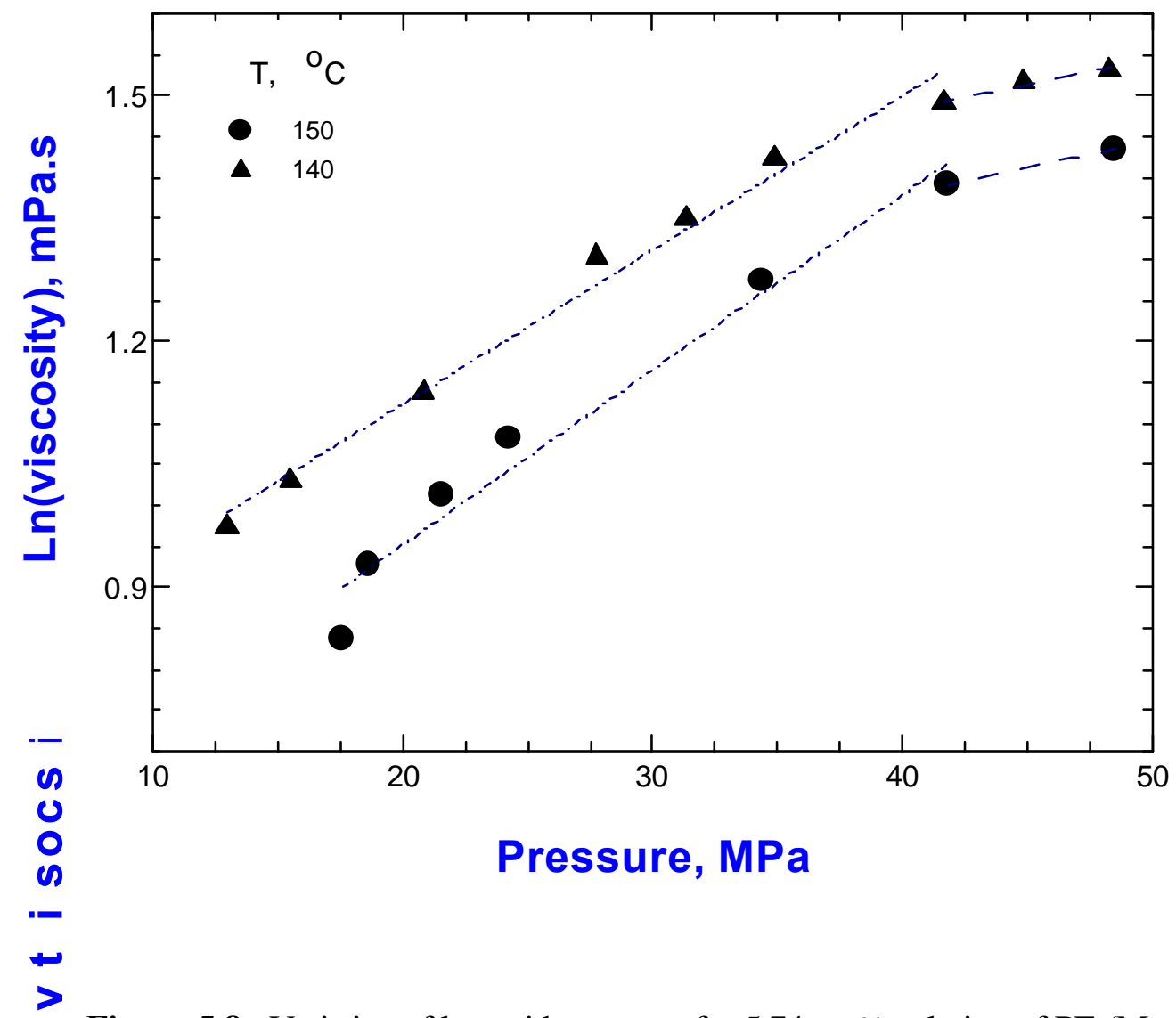

- Figure 5.8. Variation of $\ln \eta$ with pressure for $5.74 \mathrm{wt} \%$ solution of $\mathrm{PE}\left(\mathrm{M}_{\mathrm{w}}=\right.$

- 121,000) in n-Pentane at different temperatures. 


\subsubsection{Density Dependence of Viscosity}

The free volume concept in polymer science is well known. Generally free volume can be specified as the volume of a given system at the temperature of study minus the volume of the same system at $0 \mathrm{~K}$. The free volume is contributed by all the species present in the system [78].

A convenient way to interpret the effect of temperature on the viscosity of a polymeric system is the relative increase in the free volume. According to the free volume concept, the viscous flow of a low molar mass liquid at low shear stresses is connected with the jumps of flow units, in this case molecules, to voids between them. The molecular transport depends on the critical free volume, $V^{*}$, necessary for the displacement of a flow unit. In other words, molecular transport can only occur when voids, whose volume is greater than $\mathrm{V}^{*}$, exist in the system. Based on this assumption, Cohen and Turnbull (1959) obtained a relationship between the viscosity and the fractional free volume f, [73]

$\operatorname{lm}=\ln \mathrm{A}+\mathrm{B} / \mathrm{f}$ with

Eqn. 5.8

$\mathrm{f}=\left(\mathrm{V}_{\mathrm{p}}-\mathrm{V}_{\mathrm{o}}\right) / \mathrm{V}_{\mathrm{p}}$

where $\mathrm{A}$ is a constant independent of the temperature, $\mathrm{V}_{\mathrm{o}}$ the specific volume occupied by the molecules, and $\mathrm{B}$ is proportional to the fractional void volume required for a jump, $B \propto V^{*} / V_{p}$. This equation is identical with the Doolittle equation obtained empirically (1951) as

$\eta=A \exp \left[B /\left(1-V_{o} \rho\right)\right]$

Eqn. 5.4 
where $A$ and $B$ are constants, $\rho$ is the density and $V_{o}$ is the closed pack volume. The freevolume concept had originally been developed for low molar mass fluids in which the flow units are identical [58, 72]. Kelley and Bueche (1961) suggested this approach for polymers, assuming that the flow unit can be identified with a segment of the chain which can move into neighboring voids independently of the motions adjacent segments of the same chain [73]. This is possible only if the segment consists of sufficient number of monomer units.

The Doolittle equation is an effective correlative relationship to describe viscosity data in terms of density. We have conducted such analysis with the present data sets. These are described below.

\section{a. $\mathrm{PDMS}+\mathrm{CO}_{2}$}

The experimentally determined densities for the solution of $5.5 \mathrm{wt} \%$ PDMS $\left(\mathrm{M}_{\mathrm{w}}=\right.$ $93,700, \mathrm{Mw} / \mathrm{Mn}=2.99)$ in $\mathrm{CO}_{2}$ as a function of pressure at four different temperatures is shown in Figure 5.9. These density values are used to show the variation of viscosity for PDMS $+\mathrm{CO}_{2}$ as a function of density of the solutions in Figure 5.10. The data correspond to a temperature range of $55-100{ }^{\circ} \mathrm{C}$ and a pressure range of 25 to $50 \mathrm{MPa}$. The viscosity increases with increasing density, with a small positive curvature. In the figure, viscosity data at different pressures and temperatures tend to collapse to a single curve, suggesting that density can be an effective scaling factor for the viscosity. This type of density scaling has been also observed in other systems [53-55]. Doolittle type of equation, mentioned earlier, is adapted to correlate the present data (Eqn. 5.4).

The experimental data are used to calculate the optimal values for the three parameters in equation 5.3 by non-linear regression method using Levenberg-Marquart type of iteration method. The obtained parameters are summarized in Table 5.11. A significant temperature dependence has not been observed and all data were represented by an overall equation with a standard error of $4.334 \mathrm{E}-3$ in viscosity (Table 5.11). The 


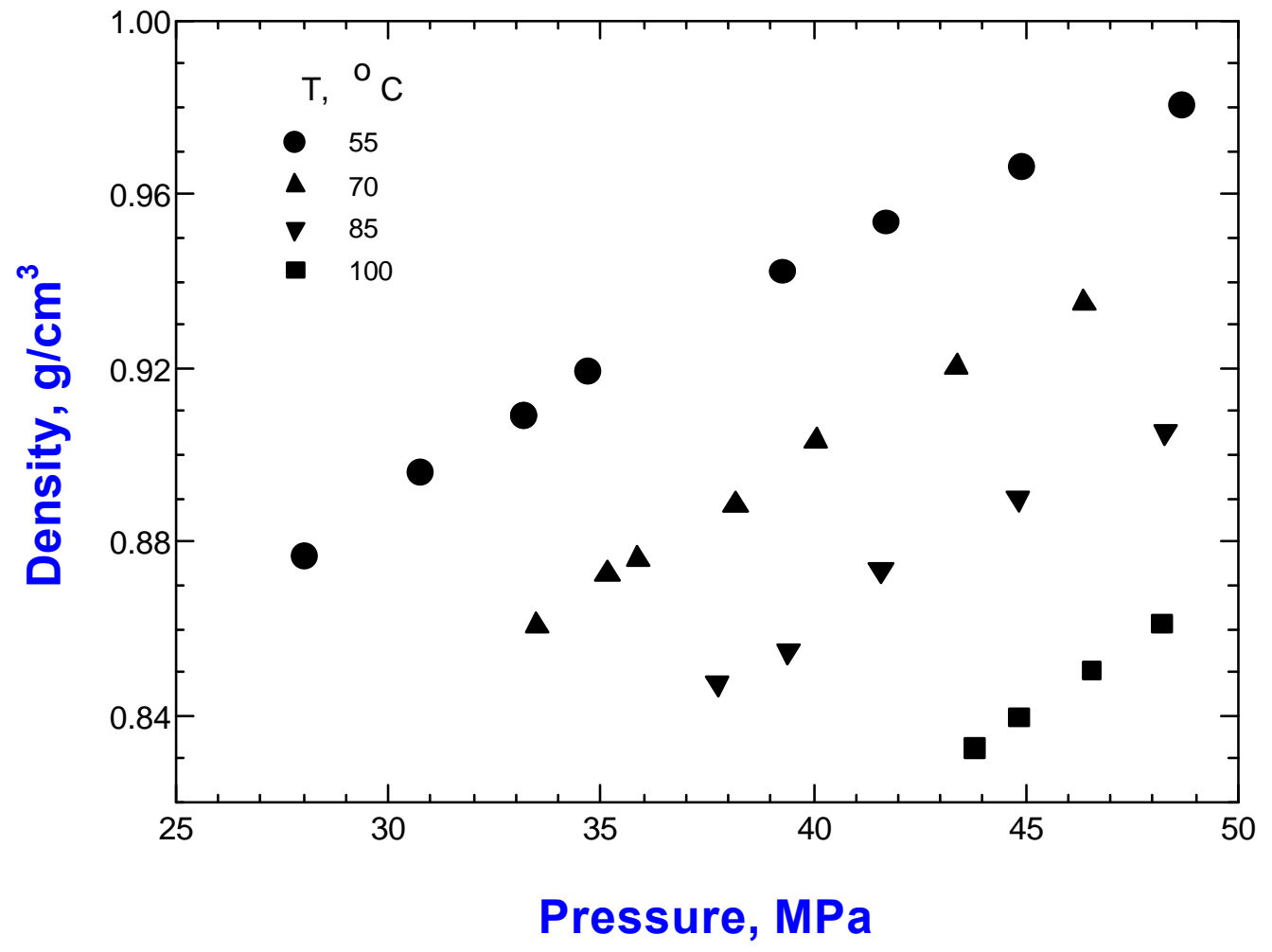

Figure 5.9. Variation of density with pressure for $5.5 \mathrm{wt} \%$ solution of PDMS $\left(\mathrm{M}_{\mathrm{w}}\right.$ $=93,700)$ in carbon dioxide at different temperatures. 


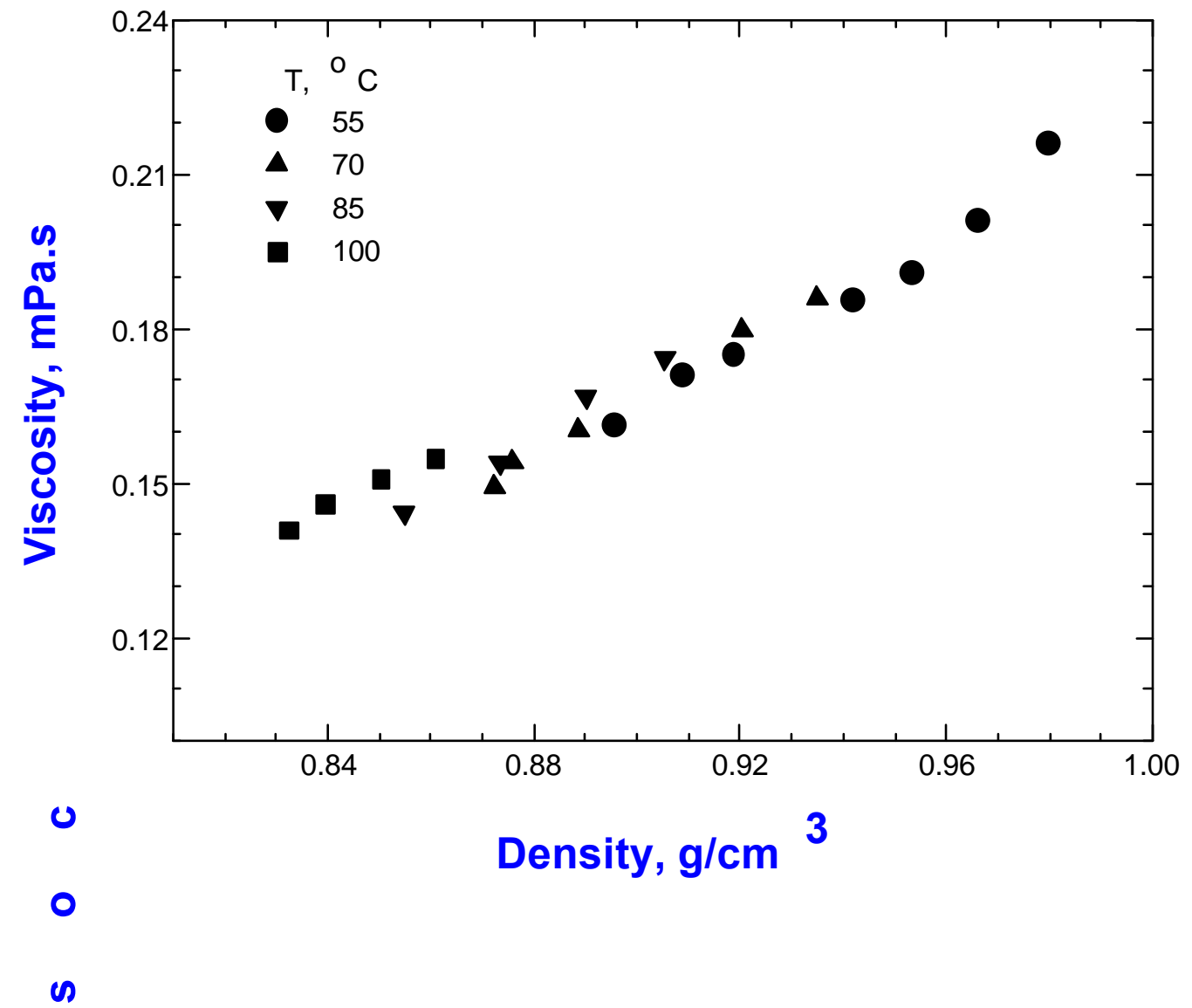

Figure 5.10. Variation of viscosity with density for $5.5 \mathrm{wt} \%$ solution of PDMS $\left(\mathrm{M}_{\mathrm{w}}=93,700\right)$ in carbon dioxide.

$+$

$>$ 


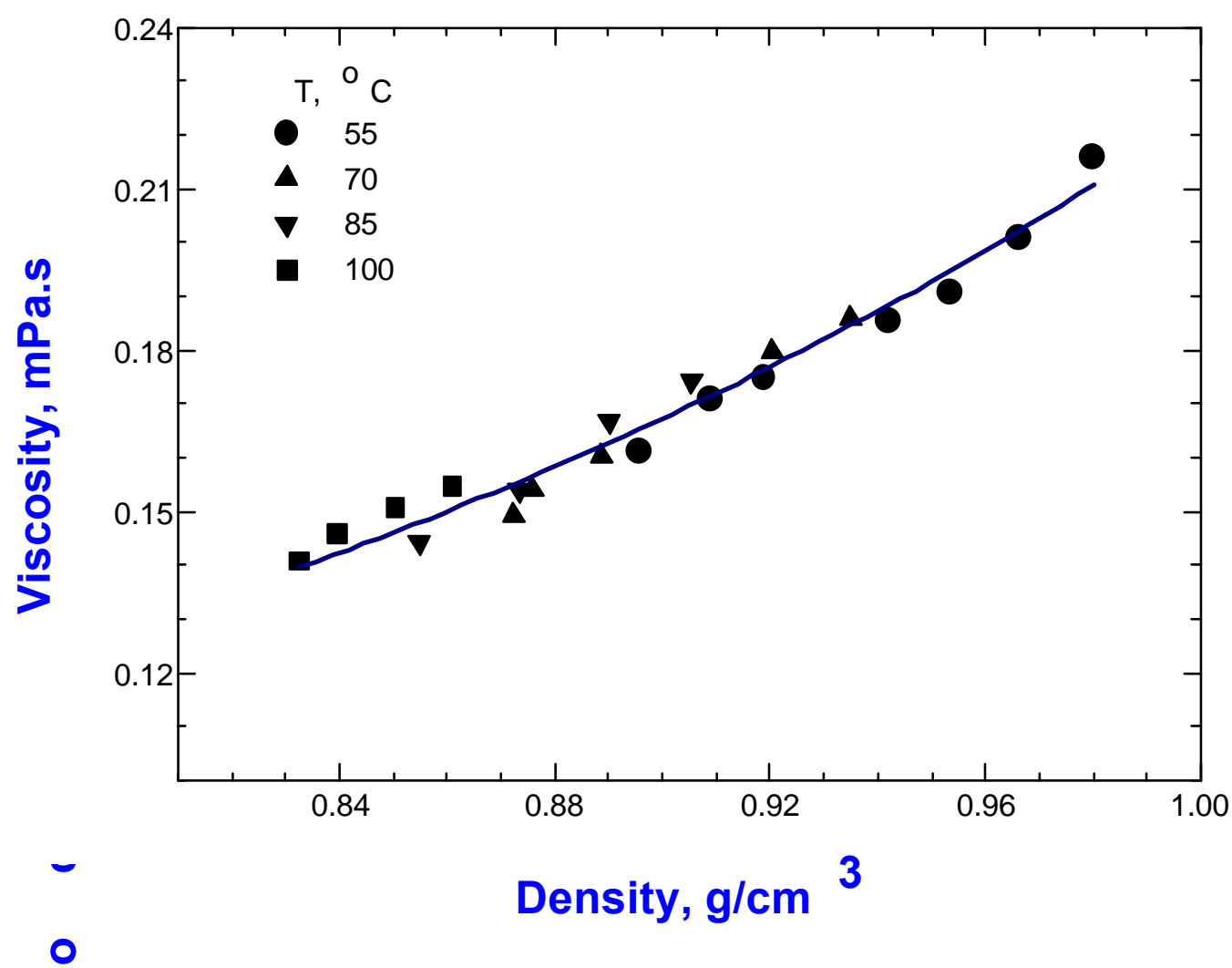

$\infty$

- Figure 5.11. Variation of viscosity with density for $5.5 \mathrm{wt} \%$ solution of PDMS in

$\leftarrow$ carbon dioxide and fitted Doolittle type of equation for this system.

Fitted Equation: $\mathrm{Y}=0.000454 * \operatorname{EXP}(4.156 /(1-0.3297 * \mathrm{X}))$

$\lambda$ 
correlative equation is shown as solid curve in Figure 5.11. The estimated closed packed volume is $0.33 \mathrm{~cm}^{3} / \mathrm{g}$ which is a little higher than the values obtained for 1,2 and $5 \mathrm{wt} \%$ PDMS $\left(\mathrm{M}_{\mathrm{w}}=38,900\right)$ in $\mathrm{CO}_{2}$ determined in an earlier study [55](Table 5.12). The closed packed volumes for the solutions of PDMS in $\mathrm{CO}_{2}$ does not appear to change significantly with polymer concentration and with molecular weight in the range studied.

Table 5.11. Coefficients for the exponential equation $\eta=A \exp \left[B /\left(1-V_{o} \rho\right)\right]$ for the density dependence of viscosity for 5.5 wt \% PDMS solution $\left(\mathrm{Mw}=93,700, \mathrm{M}_{\mathrm{w}} / \mathrm{M}_{\mathrm{n}}=\right.$ 2.99) in $\mathrm{CO}_{2}$

\begin{tabular}{ccccc}
\hline $\mathbf{T},{ }^{\mathbf{0}} \mathbf{C}$ & $\mathbf{A}$ & $\mathbf{B}$ & $\mathbf{V}_{\mathbf{0}}$ & $\mathbf{S E}^{\mathbf{a}}$ \\
\hline 55 & $4.51 \mathrm{E}-4$ & 4.16 & 0.3312 & \\
70 & $4.53 \mathrm{E}-4$ & 4.15 & 0.3300 & \\
85 & $4.45 \mathrm{E}-4$ & 4.17 & 0.3319 & \\
100 & $4.55 \mathrm{E}-4$ & 4.15 & 0.3347 & \\
& & & 0.3297 & $4.33 \mathrm{E}-3$ \\
\hline
\end{tabular}

${ }^{a}$ Standard error of estimating $\eta$ values using the given coefficients. It is calculated according to the following equation,

$\mathrm{SE}=\left(\sum\left[\mathrm{y}_{\mathrm{i}}-\mathrm{y}_{\text {cali }}\right]^{2} / \mathrm{n}\right)^{1 / 2}$

Where $y_{i}$ are the experimental values of a given property, $y_{\text {cali }}$ are the calculated values after regression, and $\mathrm{n}$ is the number of data points. 
Table 5.12. Coefficients for the exponential equation $\eta=A \exp \left[B /\left(1-V_{o} \rho\right)\right]$ for the density dependence of viscosity for 1, 2 and 5 wt \% PDMS solutions $\left(M_{w}=38,900\right)$ in $\mathrm{CO}_{2}$ (Data from ref. [55])

\begin{tabular}{ccccc}
\hline Concentration & $\boldsymbol{A}$ & B & Vo & SE \\
\hline $\mathbf{0}$ & $1.12 \mathrm{E}-4$ & 4.95 & 0.2960 & $1.74 \mathrm{E}-3$ \\
$\mathbf{1} \mathbf{w t} \%$ & $1.23 \mathrm{E}-4$ & 4.96 & 0.2890 & $6.00 \mathrm{E}-4$ \\
$\mathbf{2} \mathbf{w t} \%$ & $1.34 \mathrm{E}-4$ & 4.96 & 0.2840 & $2.51 \mathrm{E}-3$ \\
$\mathbf{5} \mathbf{w t} \%$ & $1.43 \mathrm{E}-4$ & 4.95 & 0.3050 & $3.02 \mathrm{E}-3$ \\
\hline
\end{tabular}

\section{b. PE + n-Pentane}

Figure 5.12 shows the experimentally determined densities for the solution of $5.74 \mathrm{wt} \%$ PE $\left(M_{w}=121,000, \quad M_{w} / M_{n}=4.3\right)$ in $n$-pentane as a function of pressure. Figure 5.13 shows the variation of viscosity as a function of density for this system. The data correspond to temperatures of 140 and $150{ }^{\circ} \mathrm{C}$ and pressures up to about $50 \mathrm{MPa}$. Viscosity was correlated with density using Doolittle type of equation, Eqn. 5.3, and the parameters were calculated by nonlinear regression method. The optimum parameters are presented in Table 5.13 and the corresponding curve is displayed in Figure 5.14. The estimated closed packed volume is found as $0.48 \mathrm{~cm}^{3} / \mathrm{g}$ for this solution, which is comparable with the previous work done for $1 \mathrm{wt} \%$ solutions of PE but of different molecular weight also in n-pentane [54] (See Table 5.14. ).

Table 5.13. Coefficients for the exponential equation $\eta=A \exp \left[B /\left(1-V_{o} \rho\right)\right]$ for the density dependence of viscosity of $5.74 \mathrm{wt} \% \mathrm{PE}\left(\mathrm{M}_{\mathrm{w}}=121,000, \mathrm{M}_{\mathrm{w}} / \mathrm{M}_{\mathrm{n}}=4.3\right)$ solution in $n$-Pentane

\begin{tabular}{cccc}
\hline $\mathbf{A}$ & $\mathbf{B}$ & $\mathbf{V}_{\mathbf{0}}$ & $\mathbf{S E}$ \\
\hline $6.37 \mathrm{E}-07$ & 11.44 & 0.4772 & $3.799 \mathrm{E}-0.3$ \\
\hline
\end{tabular}




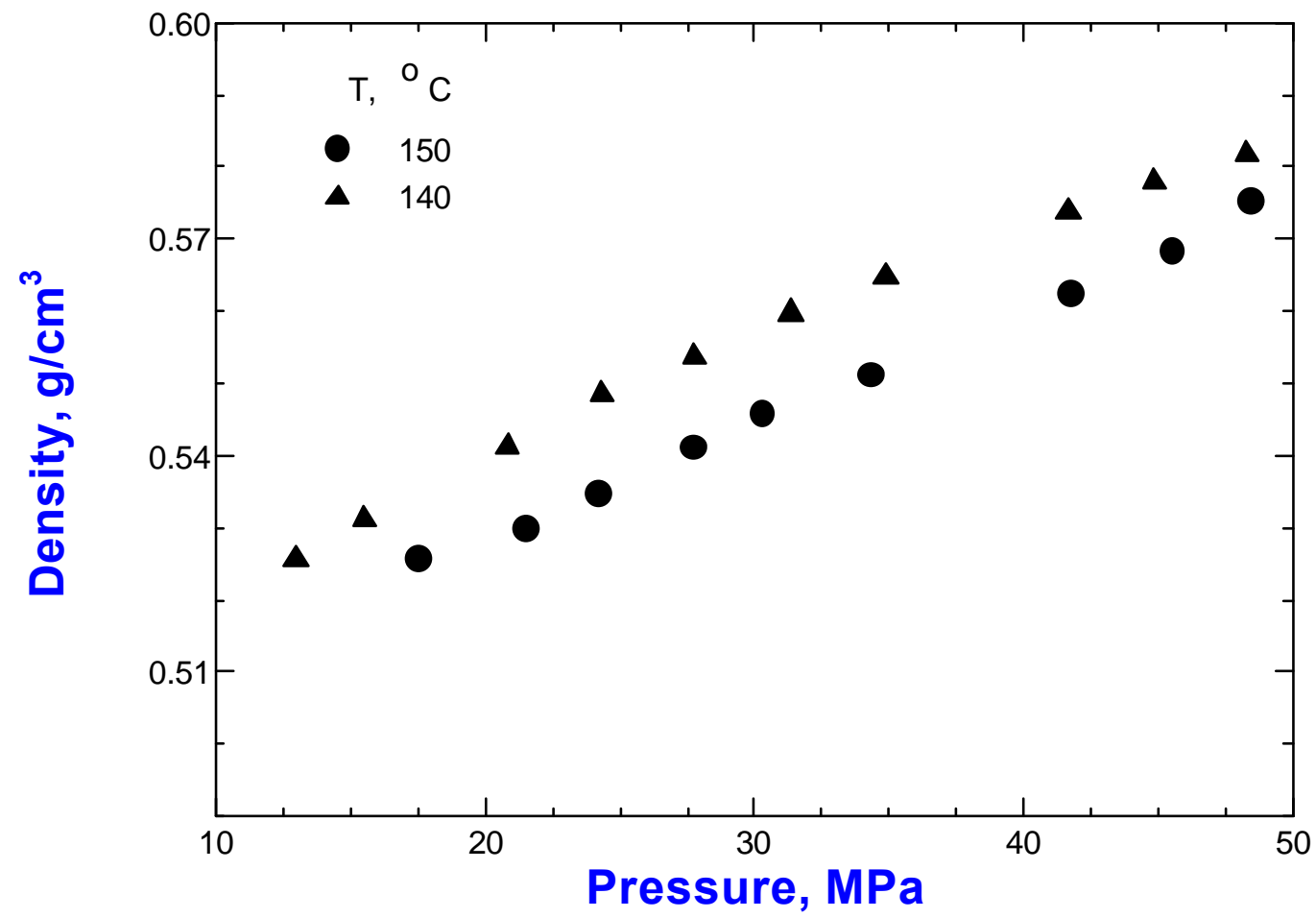

Figure 5.12. Variation of density with pressure for $5.74 \mathrm{wt} \%$ solution of $\mathrm{PE}\left(\mathrm{M}_{\mathrm{w}}=\right.$ $121,000)$ in n-Pentane at different temperatures. 


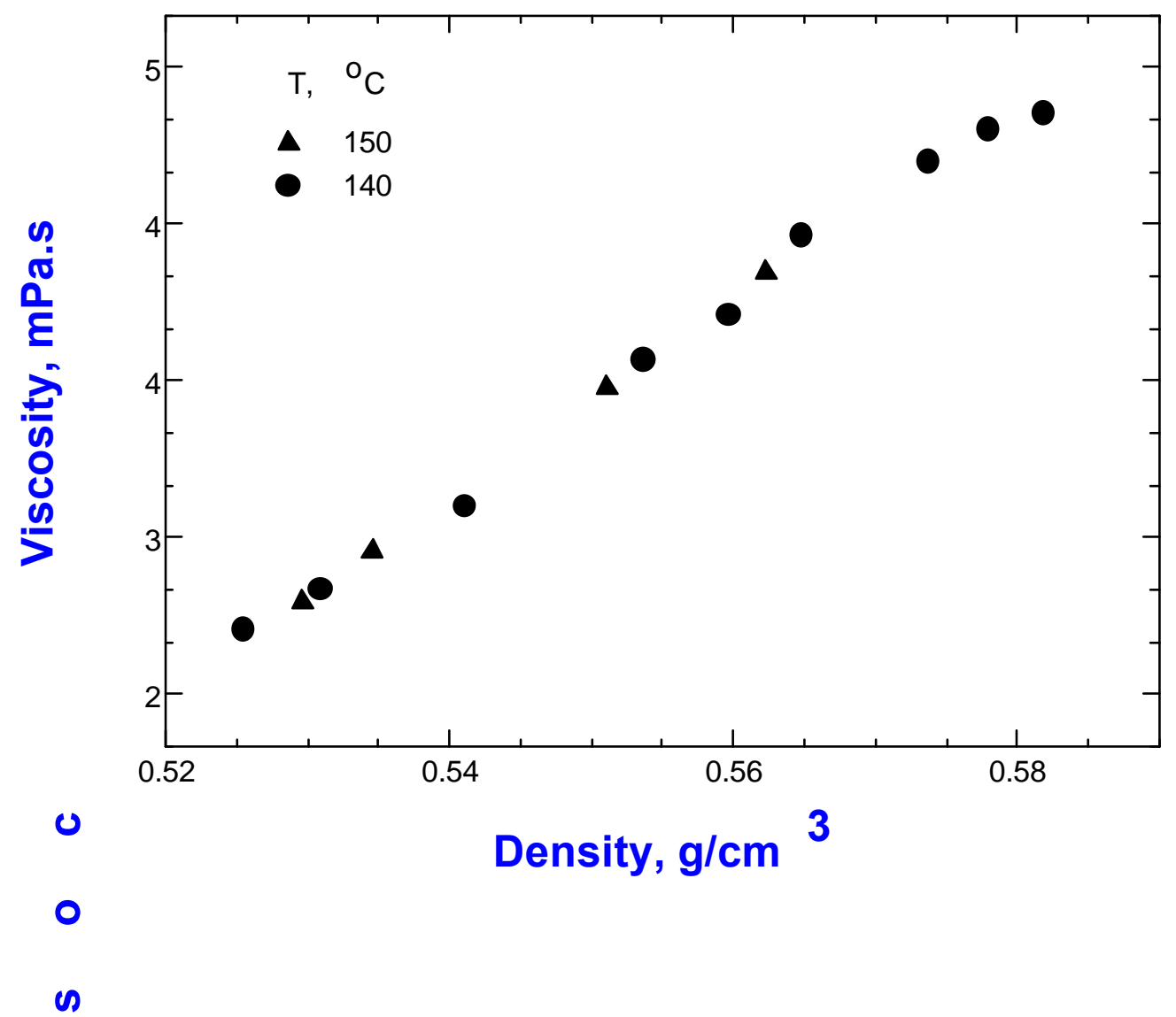

Figure 5.13. Variation of viscosity with density for 5.74 wt $\%$ solution of $\mathrm{PE}\left(\mathrm{M}_{\mathrm{w}}=\right.$ 121,000) in n-Pentane.

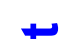




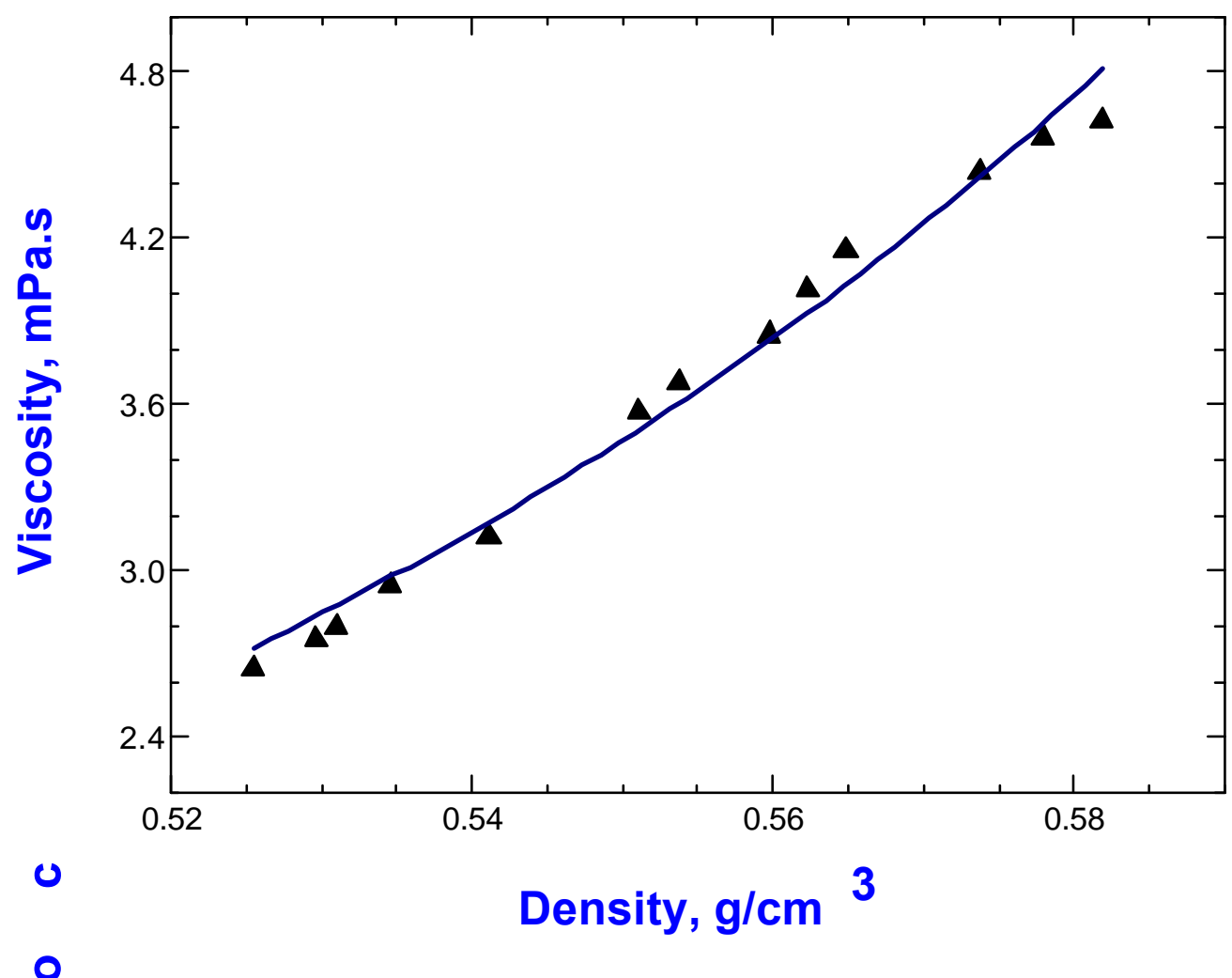

$\infty$

Figure 5.14. Variation of viscosity with density for 5.74 wt $\%$ solution of PE in n- pentane and fitted Doolittle type of equation for this system.

Fitted Equation: $\mathrm{Y}=6.369 * \operatorname{EXP}(11.44 /(1-0.4772 * \mathrm{X}))$

$>$ 
Table 5.14. Coefficients for the exponential equation $\eta=A \exp \left[B /\left(1-V_{o} \rho\right)\right]$ for the density dependence of viscosity of 1 wt \% PE solutions in $n$-Pentane (From ref. [54])

\begin{tabular}{lcccc} 
& $\mathbf{A}$ & $\mathbf{B}$ & $\mathbf{V}_{\mathbf{o}}$ & $\mathbf{S E}$ \\
\hline$n$-Pentane & $3.40 \mathrm{E}-07$ & 9.90 & 0.4232 & $9.717 \mathrm{E}-0.3$ \\
$\mathrm{Mw}=2150$ & $3.10 \mathrm{E}-07$ & 9.85 & 0.4443 & $5.256 \mathrm{E}-0.3$ \\
$\mathrm{Mw}=15,520$ & $2.92 \mathrm{E}-07$ & 9.93 & 0.4519 & $2.933 \mathrm{E}-0.3$ \\
$\mathrm{Mw}=108,000$ & $3.22 \mathrm{E}-07$ & 9.94 & 0.4853 & $9.220 \mathrm{E}-0.3$ \\
$\mathrm{Mw}=420,000$ & $5.35 \mathrm{E}-07$ & 9.94 & 0.4839 & $1.540 \mathrm{E}-0.3$ \\
\hline
\end{tabular}

Doolittle type relationships have also been found effective by other researchers in describing the effect of pressure on viscosity [54]. Values for parameter B has been reported to be in the range from 1 to 10 for various fluids, which are similar to present observations. Doolittle considered the parameter B to be related to the cohesive forces, or the force field intensity resisting flow, and for parrafins he found the parameter to increase with molecular weight which is observed for $\mathrm{PE}+\mathrm{n}$-pentane system. The parameter A was also found to show an increase with molecular weight.

For relatively dilute polymer solutions, $\mathrm{V}_{\mathrm{o}}$ values should be of similar magnitude and be representative of the closed-packed volume of the solvent [54]. A value of $0.42 \mathrm{~cm}^{3} / \mathrm{g}$ is suggested for n-pentane [54], where $0.48 \mathrm{~cm}^{3} / \mathrm{g}$ was found for the solution of $\mathrm{PE}+\mathrm{n}$ pentane. Similar analysis with viscosity of carbon dioxide results in a $V_{o}$ value of about $0.30 \mathrm{~cm}^{3} / \mathrm{g}$ [55], where $0.33 \mathrm{~cm}^{3} / \mathrm{g}$ was determined for the solution of PDMS $+\mathrm{CO}_{2}$ in the present study. 


\subsubsection{Significance of Viscosity in Phase Separation}

Phase separation phenomena are encountered in many applications of polymer industries including polymer formation, fractionation, modification and post processing [75]. For the design and operation of these application processes, the information on both thermodynamic and dynamic aspects of the phase separation is of great importance. One area that thermodynamic aspects of the phase separation are of special importance is material formation from polymer solutions or blends [75, 76]. Since the time-dependent morphology during phase separation can be locked in by measures of vitrification, gelation or crosslinking, materials with different microstructure can be obtained. Single component polymer matrix with suitable pore size and connectivity can be used as membranes for the separation of gas or liquid mixtures. In other applications, composite materials of two or multiple components can be fabricated. Examples of these types of materials include polymer/drug composite spheres, electrically conducting polymer films and polymer-dispersed liquid crystals [75]. Since the morphology of these materials has direct impact on their effectiveness in corresponding applications, it is crucial to understand the time evolution and morphology development of a phase-separating material.

The general approach to study the kinetics of phase separation is called "quench" method. A quench can be a sudden change in temperature, pressure, or composition which includes the phase separation by transferring the material from a thermodynamically stable state into a thermodynamically unstable state [75].

Among the various phase separation techniques, there is now common interest in pressure as a parameter in phase separation from polymer solutions for the formation of microstructured materials due to the growing interest in supercritical fluid-based processes [68, 69]. This technique allows formation of microstructured materials with potentially more uniform morphologies [76]. 
There are many routes to form solid phases from a supercritical medium, but they all involve one of two fundamental mechanisms of phase separation, nucleation and growth or spinodal decomposition. For systems undergoing phase separation from high pressure solutions by pressure quench or temperature quench, in addition to quench-depth and the rate of penetration into the two-phase regions, viscosity, along with interfacial tension is an important parameter influencing the progress of phase separation since these factors are crucial in the later stages of phase separation and coarsening of the domain structure $[53,76]$. It is therefore of interest to obtain viscosity information.

Figure 5.15 represents the pressure composition phase diagram of a polymer solution at constant temperature.

The region above the binodal curve corresponds to the homogenous one phase region. Between the binodal and spinodal, system is metastable. The region inside the spinodal

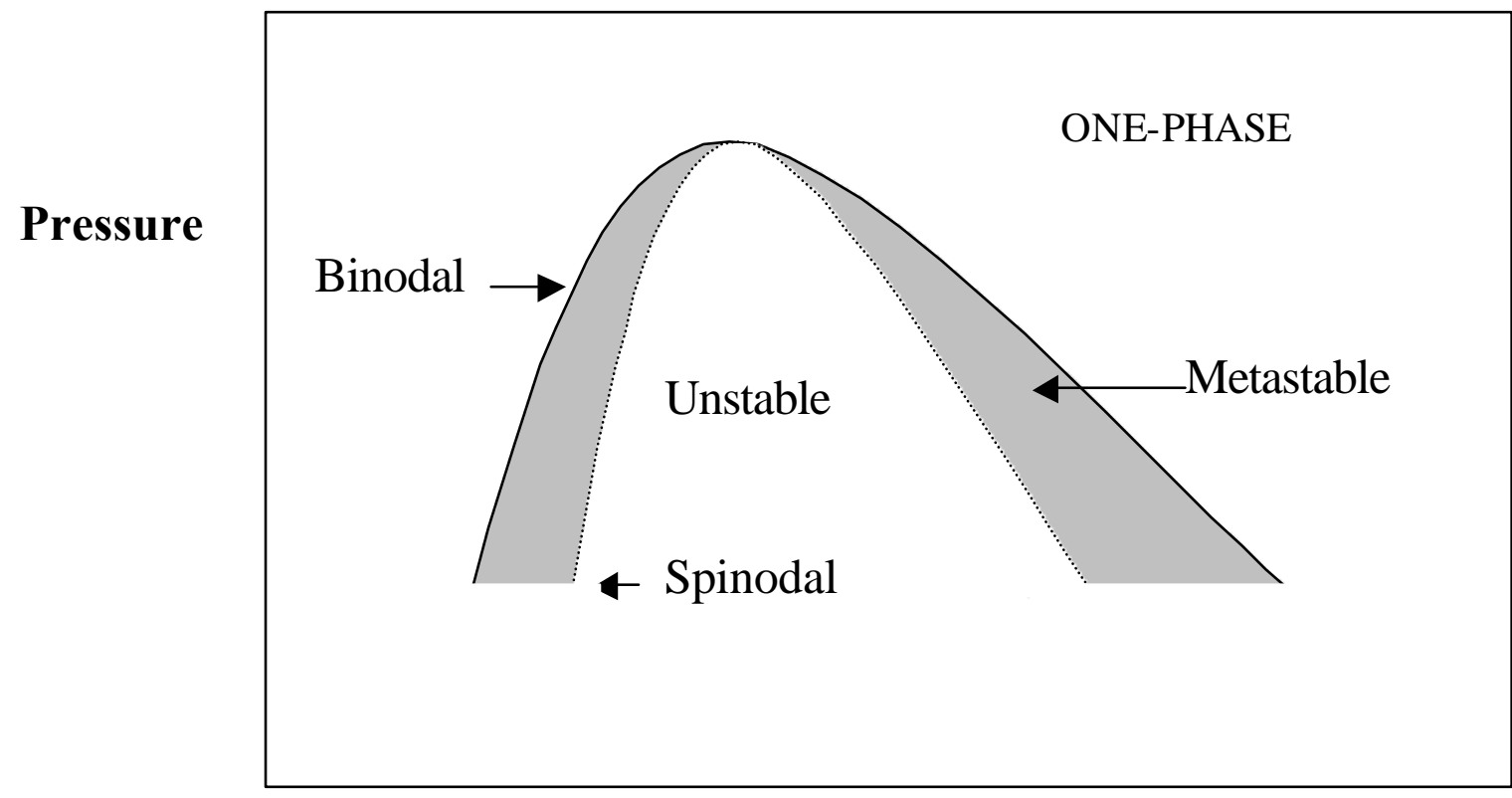

\section{Polymer concentration}

Figure 5.15. Pressure-composition phase diagram of a polymer solution at constant temperature 
envelope represents the thermodynamically unstable region where all concentration fluctuations result in a decrease of free energy and lead to a spontaneous phase separation $[68,70]$.The point where binodal and spinodal envelopes merge is defined as the critical polymer concentration which is at the apex for monodisperse systems, as displayed in the figure above. For broader molecular weight distribution samples (such as PDMS, $\mathrm{M}_{\mathrm{w}}=$ 93,700, and PE, $\mathrm{M}_{\mathrm{v}}=121,000$, used in the present study with polydispersities of 2.99 and 4.3, respectively) the location shifts to higher concentrations. Thermodynamically, the critical polymer concentration corresponds to the condition where the third derivative of Gibbs free energy with respect to composition at constant temperature and pressure is equal to zero [76], i.e., $\left[\partial^{3} \Delta \mathrm{G} / \partial \varphi^{3}\right]_{\mathrm{T}, \mathrm{P}}=0$.

Earlier in our laboratory, kinetics of pressure-induced phase separation (PIPS) in solutions of poly(dimethylsiloxane) in supercritical carbon dioxide, and solutions of polyethylene in near critical n-pentane had been studied using time- and angle-resolved light scattering $[68,69]$. Controlled pressure quench experiments were conducted at different polymer concentrations to determine both the binodal and spinodal envelopes, and the critical polymer concentration.

From Figure 5.15 it is clear that except at critical polymer concentration, whether the phase separation should proceed by nucleation or growth or by spinodal decomposition will depend on the depth of penetration (magnitude of pressure quench) into the region of immiscibility [70]. For solutions at critical concentrations the phase separation proceeds exclusively via spinodal decomposition irrespective of the depth of penetration. Early stage of spinodal decomposition is characterized by formation of a co-continuous phase structure which in time undergoes changes $[68,75,76]$. For off-critical solutions different mechanism governing phase separation are observed: for shallower quenches, phase separation proceeds by nucleation and growth, while for deep quenches, phase separation could proceed by spinodal decomposition $[68,70,75]$. 
It was found that metastable region becomes very narrow at about $5.5 \mathrm{wt} \%$ PDMS solution in $\mathrm{CO}_{2}$ which showed that this was the critical polymer concentration of this system [68]. This concentration is higher than the concentration corresponding the apex of the binodal envelop due to the polydispersity of the polymer sample. In the pressure quench experiments done for $\mathrm{PE}$ in n-pentane at a concentration of $5.75 \mathrm{wt} \%$ spinodal decomposition was observed even for very small pressures, which suggested that this must be the critical polymer concentration for this system [68-70].

In order to relate the rate of phase separation with the viscosity of the system, the present study has been carried out at the critical polymer concentrations, both for $\mathrm{PDMS}+\mathrm{CO}_{2}$ and PE + n-Pentane systems.

It is known that for the solutions with the same polymer molecular weight, the higher temperatures leads to faster rates of phase separation [75]. This can be explained by decrease in viscosity with increasing temperature, which is also observed in this study (Figure 5.2 and Figure 5.4). At high viscosities, the typical hydrodynamic effects encountered in fluid mixtures involving small molecules may be suppressed and phase separation may be retarded [53]. That is why slower kinetics is observed for higher molecular weight polymer solutions. Indeed, for $\mathrm{PE}+\mathrm{n}$-pentane the spinodal decomposition is almost completed at $24 \mathrm{sec}$, Figure 5.16, whereas for PDMS $+\mathrm{CO}_{2}$ the completion of the spinodal decomposition takes less than $14 \mathrm{sec}$, Figure 5.17, [68, 69]. As shown in the previous sections, the viscosity of PDMS $+\mathrm{CO}_{2}$ system is about 10 times lower than the viscosity of $\mathrm{PE}+\mathrm{n}$-pentane systems. The polymers are of comparable molecular weight, and polymer concentrations are also comparable, yet phase separation kinetics are significantly different which stem from the viscosity differences. 


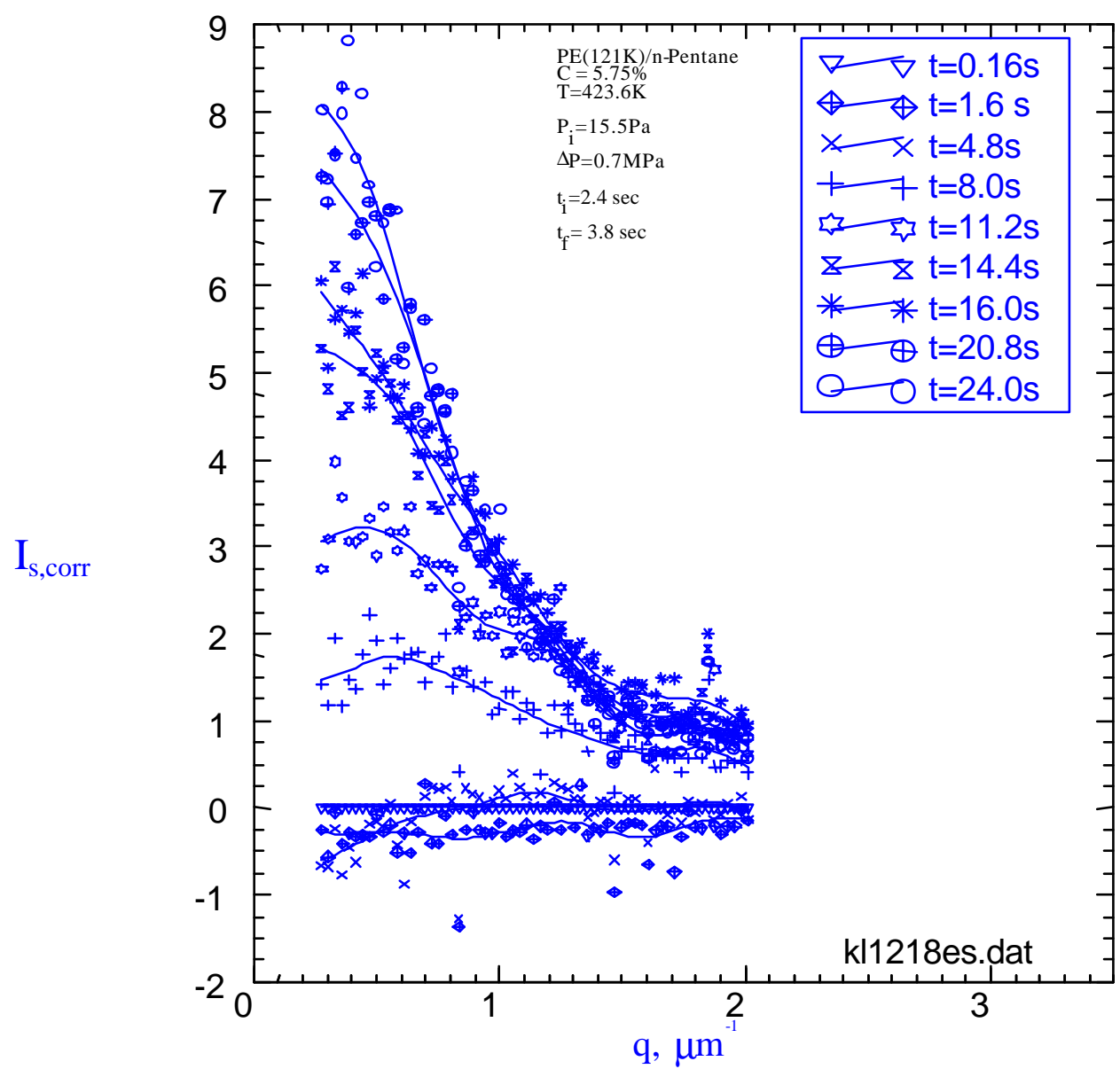

Figure 5.16. The evolution of the scattered light intensities with time as a function of the wave number $\mathrm{q}$ after a pressure quench $\Delta \mathrm{P}=0.7 \mathrm{MPa}$ in $5.75 \%$ by mass solution of $\mathrm{n}$-PE $(121,000)$ in pentane at $150{ }^{\circ} \mathrm{C}$. The total observation time is $24.0 \mathrm{~s}$. (From ref. [69]) 


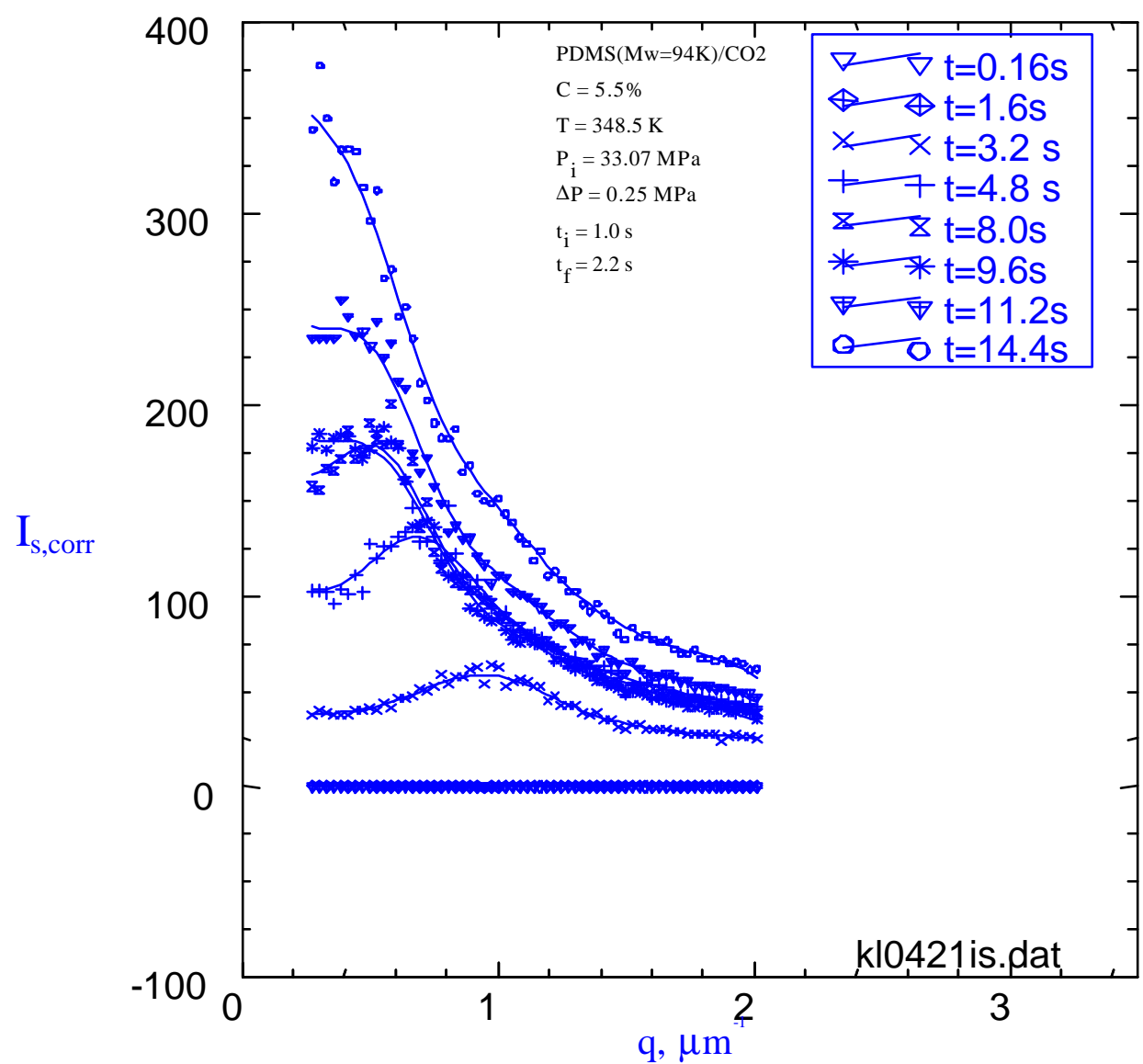

Figure 5.17. The evolution of the scattered light intensities with time as a function of the wave number $\mathrm{q}$ after a pressure quench of $\Delta \mathrm{P}=0.25 \mathrm{MPa}$ in $5.5 \%$ by mass solution of PDMS in $\mathrm{CO}_{2}$ at $75{ }^{\circ} \mathrm{C}$. The total observation time is $14.4 \mathrm{~s}$ (From ref. [68, 69]). 


\section{CHAPTER 6}

\section{CONCLUSIONS AND RECOMMENDATIONS}

The high-temperature high-pressure falling cylinder type viscometer that permits simultaneous determination of viscosity, density and phase state of the solutions has been improved. The modification involved changing the design of the LVDT coils that are placed along the viscometer fall tube. These LVDT coils are used to determine the fall time and the terminal velocity of the sinker that is used in viscosity determination. The new design and data reduction procedure are implemented to develop a more reliable procedure for determining the terminal velocity of the sinker and thus improve the accuracy of the viscosity measurements.

In this procedure, we have combined time versus voltage reading, that is stored in a computer file with the distance versus voltage reading, that has been generated by $a$ priori calibration by changing the position of the sinker, to get the time versus distance data for any specific measurement after normalizing the voltage readings. Terminal velocity is calculated from the slope of the distance versus time plot.

Terminal sinker velocities that were generated for npentane were used along with known viscosity values from literature for $\mathrm{n}$-pentane, an instrument constant $\mathrm{K}_{\mathrm{avg}}=0.0199$ was generated and could be used in all the viscosity calculations in this study. 
Generating complete position versus time history cleared the ambiguity related with the terminal velocity determinations in the previous procedure which was based on the zero voltage reading. This procedure validates that earlier measurements were also done when the sinker reached the terminal velocity and therefore the viscosity measurements were reliable.

The calibration procedure was also validated using carbon dioxide as test fluid. With the present system, viscosity determinations have been found to be accurate to $\pm 5 \%$ for over a wide range from about 0.1 to $5 \mathrm{mPa} . \mathrm{s}$.

Densities and viscosities of solutions of poly(dimethylsiloxane) $\left(\mathrm{M}_{\mathrm{w}}=93,700, \mathrm{M}_{\mathrm{w}} / \mathrm{M}_{\mathrm{n}}=\right.$ $2.99)$ in carbon dioxide and polyethylene $\left(\mathrm{M}_{\mathrm{w}}=121,000, \mathrm{M}_{\mathrm{w}} / \mathrm{M}_{\mathrm{n}}=4.3\right)$ in nentane have been determined at their critical polymer concentration, which is $5.5 \mathrm{wt} \%$ for solution of PDMS in $\mathrm{CO}_{2}$ and 5.75 wt \% for solution of PE in n-pentane.

For PDMS $+\mathrm{CO}_{2}$ system, viscosity measurements are conducted at $55,70,85$ and $100{ }^{\circ} \mathrm{C}$ and pressures up to $50 \mathrm{MPa}$. At these conditions the viscosities are relatively low, being less than $0.22 \mathrm{cP}$. For $\mathrm{PE}+n$-pentane system, viscosity measurements are conducted at 140 and $150{ }^{\circ} \mathrm{C}$ and again up to $50 \mathrm{MPa}$. In contrast to $\mathrm{PDMS}+\mathrm{CO}_{2}$ system, the viscosities for these solutions are much higher (nearly ten times), ranging from about 2 to $4.5 \mathrm{cP}$.

As would be expected, viscosities increase with pressure, and decrease with temperature for a given system. Density and viscosity data were generated in the one-phase homogenous regions, and viscosities were correlated with density according to,

$\eta=0.000454 \exp (4.156 /(1-0.3297 \rho))$, and 
$\eta=6.369 \exp (11.44 /(1-0.4772 \rho))$

for PDMS and PE solutions, respectively, confirming that free-volume is a key parameter that influences viscosity.

The temperature dependence of viscosity has been analyzed for these solutions using an Arrhenius-type equation given by

$(\partial \ln \eta / \partial(1 / \mathrm{T}))_{\mathrm{P}, \text { conc }}=\mathrm{E}^{\#} / \mathrm{R}$.

The activation energies are obtained from the plots of logarithmic viscosity versus inverse temperature. It is observed that for PDMS $+\mathrm{CO}_{2}$ system, flow activation energies show a small increase with increasing pressure showing that at higher pressures the viscosity becomes more temperature dependent for this system. In PE + n-pentane system, the activation energy shows a maximum at $34.5 \mathrm{MPa}$ and are higher than the values obtained for $\mathrm{PDMS}+\mathrm{CO}_{2}$ system.

The pressure dependence of viscosity has been shown to follow

$(\partial \ln / \partial \mathrm{P})_{\mathrm{T}, \mathrm{conc}}=\mathrm{V}^{\#} / \mathrm{RT}$

type dependence and has been analyzed by plotting logarithmic viscosity versus pressure. From the slopes of these plots activation volumes of the solutions are calculated. For PDMS $+\mathrm{CO}_{2}$, the variation was found to be linear, whereas for PE $+\mathrm{n}$-pentane linearity was not displayed in the full pressure range. The activation volumes were therefore assigned for two different pressure ranges, one for pressures up to $41 \mathrm{MPa}$ and one for pressures below $41 \mathrm{MPa}$. 
The viscosity data for these systems at the critical polymer concentrations were consistent with the kinetics of pressure-induced phase separation. The viscosity of PDMS $+\mathrm{CO}_{2}$ system is about 10 times lower than the viscosity of $\mathrm{PE}+\mathrm{n}$-pentane system. Phase separation process in PDMS $+\mathrm{CO}_{2}$ system subjected to a pressure quench is much faster (more than twice as much) than the phase separation process in $\mathrm{PE}+\mathrm{n}$-pentane system to which the viscosity differences contribute greater even though the polymers are of comparable molecular weight, and polymer concentrations are also comparable.

The viscosities of $\mathrm{PE}+\mathrm{npentane}$ system are found to be almost 10 times greater than the viscosities of PDMS $+\mathrm{CO}_{2}$ system at the regions investigated, but these viscosities are still not very high, being less than $5 \mathrm{mPa}$.s. In order to examine the performance of the instrument at high viscosities, polymer solutions of higher concentrations can be studied provided good circulation can be achieved. The usefulness of the present method of fall time generation and analysis of terminal velocities can be better demonstrated in viscous systems since fall time measurements can be made in any segment of the fall tube.

A statistical analysis of our data is made by using Stat-Ease DESIGN-EXPERT ${ }^{\circledR}$ software. The analysis led to a model equation in terms of temperature and pressure. When this temperature and pressure dependent calibration constant is used to determine the viscosity instead of $K_{a v g}$ greater accuracy can be obtained in the viscosity measurements. The reliability of the model equation at high viscosities can be further evaluated. Using the simple $\mathrm{K}_{\mathrm{avg}}$ permits easy analysis of the data if as in the presents study error margins are not excessive.

Although present study provides some data to relate viscosity with the kinetics of phase separation for the first time, more experiments can be conducted for broader investigation of this phenomena. 


\section{REFERENCES}

1. H. E. King, J., E. Herbolzheimer, R. L. Cook "The diamond-anvil cell as a high pressure viscometer." J. Appl. Phys 71(5): 2071-2081 (1992).

2. G. A. Iglesias-Silva, A. Estrada-Baltazar, K. R. Hall, M. A. Barrufet "Experimental liquid viscosity of pentane + octane + decane mixtures from 298.15 to $373.15 \mathrm{~K}$ up to 25 MPa." J. Chem. Eng. Data 44: 1304-1309 (1999).

3. S. Sawamura, N. Takeuchi,K. Kitamura, Y. Taniguchi "High pressure rolling-ball viscometer of a corrosion-resistant type." Rev. Sci. Instrum. 62(2): 871-873 (1990).

4. E. Kiran "Polymer formation, modifications and processing in or with supercritical fluids. " Supercritical Fluids: Fundamentals and Applications E. Kiran, J.H.M. L. Sengers, Editors, 541-588. Kluwer Academic Publishers, Netherlands (1994).

5. Y. L. Sen PhD Thesis: "The density and viscosity of polymer solutions at high pressures and temperatures." Department of Chemical Engineering, University of Maine, (1991) (E. Kiran, Advisor).

6. H. P. Mattischek, R. Sobczak. "A new cell for measurement of viscosity under high pressure." Meas. Sci. Technol. 5: 782-785 (1994).

7. K. D. Knudsen, A. Mikkelsen, A. Elgsaeter. "An automated high-pressure, hightemperature, low-frequency viscometer." Rheol. Acta 34: 248-258 (1995).

8. J. R. Van Wazer, J. W. Lyons, K. Y. Kim, R. E. Colwell Viscosity and Flow 
Measurement. Interscience Publication, New York (1963).

9. K. Kobayashi, A. Nagashima "Measurement of the viscosity of trifluoroethanol and its aqueous solutions under pressure. " Bulletin of JSME 28: 1453-1458 (1985).

10. D. Q. Tuan, J. A. Zollweg, P. Harriott, S. S. H. Rizvi "Measurement and modeling of viscosity of supercritical carbon dioxide/biomaterial(s) mixtures." Ind. Eng. Chem. Res. 38(5): 2129-2136 (1999).

11. M. E. Yener, P. Kashulines, S. S. H. Rizvi, P. Harriot "Viscosity measurement and modeling of lipid-supercrtical carbon dioxide mixtures." J. Supercritical Fluids 11: 151-162 (1998).

12. M. J. Assael, M. Papadaki, M. Dix, S. M. Richardson, W. A. Wakeham "An absolute vibrating-wire viscometer for liquids at high pressures." Int. J. Thermophys. 12(2): 231-244 (1990).

13. B. A. Wolf "Thermodynamics and rheology of polymer solutions." Chemistry and Physics of Macromolecules. E.W. Fischer, R.C. Schulz, H. Sillescu, Editors, 273-294. Sonderforschungsbereiche, Weinheim (1991).

14. U. Sulzner, G. Luft "Viscosity of alcohol-ethene mixtures pressures up to $195 \mathrm{MPa} . "$ Int. J. Thermophys. 19(1): 43-69 (1998).

15. E. Kiran, Y. L. Sen "High-pressure viscosity and density of n-alkanes." Int. J. Thermophys. 13(3): 411-442 (1992).

16. M. R. Khadilkar M.Sc.Thesis: Viscosity of polymer solutions in supercritical fluid solvents. Department of Chemical Engineering, University of Maine (1993) (E. 
Kiran, Advisor).

17. R. Malhotra, W. E. Price, L. A. Woolf, and A. J. Easteal "Thermodynamic and Transport properties of 1,2-dichloroethane." Int. J. Thermophys. 11(5): 835-861 (1990).

18. B. J. Briscoe, P. F. Luckham, S. R. Renn "An assessment of a rolling-ball viscometer for studying non-Newtonian fluids." Colloids and Surfaces 62: 153-162 (1992).

19. G. E. LeBlanc, R A. Secco "High pressure Stoke's viscometry: A new in situ technique for sphere velocity determination." Rev. Sci. Instrum. 66(10): 5015-5018 (1995).

20. A. F. Collings, E. McLaughlin " Torsional crystal technique for the measurement of viscosities of liquids at high-pressure. " Trans. Faraday Soc. 67: 340 -352 (1971).

21. M. Kanzaki, K. K. T Fujiti, T. Kato, O. Shimomura, S. Akimoto High Pressure Research In Mineral Physics, Terrapub, Tokyo (1987).

22. F. J. V. Santos, C. A. Nieto de Castro "New accurate data on the viscosity of toluene under high pressure." High Temp. - High Press. 25: 465-469 (1993).

23. C. A. Nieto de Castro, F. J. Vieira dos Santos "Viscosity of toluene and benzene under high pressure." Int. J. Thermophys. 18(2): 367-378 (1997).

24. K. R. Harris, L. A. Woolf "Temperature and density dependence of the viscosity of octane and toluene. " J. Chem. Eng. Data 42: 1254-1260 (1997).

25. P. S. van der Gulik "Viscosity of carbon dioxide in liquid phase." Physica A 238: 81- 
112 (1997).

26. A. A. H. Pádua, J. M. N. A. Fareleria, J. C. G. Calado, W. A. Wakeham "Electromechanical model for vibrating-wire instruments." Rev. Sci. Instrum. 69(6): 2392-2399 (1998).

27. M. J. Assael, N. K. Dalaouti, S. Polimatidou "The viscosity of toluene in the temperature range from 210 to $370 \mathrm{~K}$ at pressures up to $30 \mathrm{MPa}$." Int. J. Thermophys. 20(5): 1367-1377 (1999).

28. R. L. Cook, H. E. King Jr., D. G. Peiffer "High pressure viscosity of dilute polymer solutions in good solvents." Macromolecules 25: 2928-2934 (1992).

29. R. L. Cook, H. E. King Jr., Dennis G. Peiffer "High pressure viscosity of and associating polymer system: Zinc sulfonated polystyrene/poly(styrene - 4vinylpyridine) copolymer solution." Macromolecules 25: 629-635 (1992).

30. S. Bair "Pressure-viscosity behavior of lubricants to $1.4 \mathrm{GPa}$ and its relation to EHD traction." Tribol. Transactions 43(1): $91-99$ (2000).

31. J. A. Jimenez, M. Kostic "A novel computerized viscometer/rheometer." Rev. Sci. Instrum. 65(1): 229-241 (1994).

32. S. Bair, W. O. Winer "A new high-pressure high-shear stress viscometer and results for lubricants." Tribol. Transactions 36(3) (1993).

33. S. Bair "The high-pressure rheology of a soap-thickened grease." Tribol. Transactions 37(3): 646-650 (1994). 
34. R. L. Cook, C. A. Herbst, and H. E. King Jr. "High pressure viscosity of glass forming liquids measured by the centrifugal force diamond anvil cell viscometer." $J$. Phys. Chem. 97: 2355-2361 (1993).

35. C. A. Herbst, R. L. Cook, and H. E. King Jr. "Density-mediated transport and the glass transition: high pressure viscosity measurements in the diamond anvil cell." $J$. of Non-Crystalline Solids 172-174: 256-271 (1994).

36. K. Linliu, F. Yeh, J. W. Shook, W. H. Turninello, B. Chu "Development of a centrifuge ball viscometer for polymer melts." Rev. Sci. Instrum. 65(12): 3823-3828 (1994).

37. N. Schott, B. Will, B. A. Wolf "Thermodynamics and high pressure viscosity of dilute solutions of poly(decyl methacrylate) and how the free volume influences them." Makromol. Chem. 189: 2067-2075 (1988).

38. Y. Yoshimura, S. Sawamura, and Y. Taniguchi "Effects of pressure, temperature, and concentration on the viscosity of aqueous ammonium bromide solution." $Z$. Naturforsch 50a: 316-322 (1995).

39. A. Estrada-Baltazar, G. A. Iglesias-Silva, M. A. Barrufet "Liquid viscosities of pentane and pentane + decane from 298.15 to $373.15 \mathrm{~K}$ up to $25 \mathrm{MPa}$." J. Chem. Eng. Data 43: 601-604 (1998).

40. A. Estrada-Baltazar, J. F. J. Alvarado, G. A. Iglesias-Silva, M. A. Barrufet "Experimental liquid viscosities of decane and octane + decane from 298.15 to 373.15 K up to 25 MPa." J. Chem. Eng. Data 43: 441-446 (1998).

41. M. A. Barrufet, K. R. Hall, A. Estrada-Baltazar, G. A. Iglesias-Silva "Liquid 
viscosities of octane and pentane + octane from 298.15 to $373.15 \mathrm{~K}$ up to $25 \mathrm{MPa}$." $J$. Chem. Eng. Data 44: 1310-1314 (1999).

42. J. R. Schmidt, B. A. Wolf "Pressure dependence of intrinsic viscosities and Huggins constants for polystyrene in tert-butyl acetate." Macromolecules 15: 1192-1195 (1982).

43. K. R. Harris "The temperature and density dependences of the self diffusion coefficient and the shear viscosity of liquid trichloromethane. "Molecular Physics 71(6): 1205-1211 (1990).

44. J. H. Dymond, M. A. Awan, N. F. Glen, J. D. Isdale "Transport properties of nonelectrolyte mixtures. IX. viscosity coefficients for acetonitrile and for three mixtures of toluene + acetonitrile from 25 to $100{ }^{\circ} \mathrm{C}$ at pressures up to $500 \mathrm{MPa}$." Int. J. Thermophys. 12(3): 433-447 (1991).

45. J. H. Dymond, M. A. Awan, N. F. Glen, J. D. Isdale "Transport properties of nonelectrolyte mixtures. IIIV. viscosity coefficients for toluene and for three mixtures of toluene + hexane from 25 to $100{ }^{\circ} \mathrm{C}$ at pressures up to $500 \mathrm{MPa}$."Int. J. Thermophys. 12(2): 275-287 (1991).

46. J. H. Dymond, N. F. Glen, J. D. Isdale, M. Pyda "The viscosity of liquid toluene at elevated pressure." Int. J. Thermophys. 16(4): 877-882 (1995).

47. G. E. Leblanc, R. A. Secco, M. Kostic Engineering Handbook CRC Press LLC London (1999).

48. K. R. Harris "Temperature and density dependence of the viscosity of toluene." $J$. Chem. Eng. Data 45: 893-897 (2000). 
49. J. L. Sutterby "Laminar converging flow of dilute polymer solutions in conical sections. "AIChE J 12: 63-68 (1966).

50. F. Audonnet, A. A. H. Padua "Simultaneous measurement of density and viscosity of n-pentane from 298 to $383 \mathrm{~K}$ and up to $100 \mathrm{MPa}$ using a vibrating-wire instrument." Fluid Phase Equilibria 181: 147-161(2001).

51. K. Stephan, K. Lucas Viscosity of Dense Fluids, Plenum Press, New York and London (1979).

52. J. Vladimir Oliveira, C. Dariva, J.C. Pinto "High-pressure phase equilibria for polypropylene-hydrocarbon systems." Ind. Eng. Chem. Res. 39: 4627-4633 (2000).

53. Y. Xiong, E. Kiran "Miscibility, density and viscosity of polystyrene in n-hexane at high pressures." Polymer 38: 5185 (1997).

54. E. Kiran, Z. Gokmenoglu "High-pressure viscosity and density of polyethylene solutions in n-pentane." J. Appl. Polym. Sci. 58: 2307 (1995).

55. Y. Xiong, E. Kiran "Miscibility, density and viscosity of poly(dimethylsiloxane) in supercritical carbon dioxide." Polymer 36: 4817 (1995).

56. E. Kiran, Y. L. Sen "Viscosity of polymer solutions in near critical and supercritical fluids." In Supercritical Fluid Engineering Science, ACS Symposium Series, no.514. E. Kiran, J.F. Brennecke. Washington, DC, American Chemical Society: 104-125 (1993). 
57. S.-D. Yeo, E. Kiran "High-pressure density and viscosity of polystyrene solutions in methylcyclohexane." J. Supercrit. Fluids 15: 261-272 (1999).

58. J. M. G. Cowie Polymers: Chemistry and Physics of Modern Materials. Intertext Books, Italy (1973).

59. B. A. Wolf, R. Jend "Pressure and temperature dependence of the viscosity of polymer solutions in the region of phase separation." Macromolecules 12(4): 732-737 (1978).

60. K. Kubota, K. Ogino "Pressure dependence of the intrinsic viscosity of poly(dimethylsiloxane) - cyclohexyl bromide solution." Macromolecules 12(1): 74-78 (1979).

61. J. R. Schmidt, B. A. Wolf "The pressure dependence of viscosity of polymer solutions and how it reflects the thermodynamic conditions." Makromol. Chem. 180: 517-521 (1979).

62. B. A. Wolf, H. Geerissen "Pressure dependence of demixing of polymer solutions determined by viscometry." Colloid \&Polymer Sci. 259: 1214-1220 (1981).

63. S. Claesson, J. L. Mcatee, Jr., S. Ali "Pressure dependence of the viscosity of dilute polystyrene solutions in toluene." J. Polym. Sci. 21: 1873-1881 (1983).

64. R. Akki, S. Bair, A. S. Abhiraman "Low shear viscosity and crystallization in dilute solutions of polymers at high pressures: Falling body viscometry of high molecular weight polyethylene solutions." Polym. Eng. Sci. 35(22): 1781-1784 (1995). 
65. H. Geerissen, J. Roos, B. A. Wolf "Continuous fractionation and solution properties of PVC, 5. Pressure dependence of the viscosity - Influence of solvent." Makromol. Chem. 186: 787-799 (1985).

66. R. Mertsch, B. A. Wolf "Solutions of poly(dimethylsiloxane) in supercritical carbon dioxide: Viscometric and volumetric behavior." Macromolecules 27: 3289-3294 (1994).

67. M. Lee, C. B. Park, C. Tzoganakis. "Measurements and modeling of PS/ supercritical CO2 solution viscosities." Polym. Eng. Sci. 39(1): 99-109 (1999).

68. K. Lui, E. Kiran "Kinetics of pressure induced phase separation (PIPS) in solutions of poly(dimethylsiloxane) in supercritical carbon dioxide: Cross over from nucleation and growth to spinodal decomposition." J. Supercrit. Fluids 16: 59-79 (1999).

69. K. Lui M.Sc. Thesis: Kinetics of pressure induced phase separation in polymer solutions by time- and angle-resolved light scattering. Department of Chemical Engineering, University of Maine (1999) (E. Kiran, Advisor).

70. K. Liu, E. Kiran "Pressure-induced phase separation in polymer solutions: Kinetics of phase separation and crossover from nucleation and growth to spinodal decomposition in solutions of polyethylene in n-pentane." Macromolecules 34: 30603068 (2001).

71. A. D. Stein, D. A. Hoffmann, A. H. Marcus, P. B. Leezenberg, C. W. Frank "Dynamics in poly(dimethylsiloxane) melts: Fluorescence depolarization measurements of probe chromopore orientational relaxation." J. Phys. Chem. 96: 5255-5263 (1992). 
72. H. Geerissen, J.R. Schmidt, B.A. Wolf "On the factors governing the presssure dependence of viscosity of moderately concentrated polymer solutions." J. Appl. Polym._Sci. 27: 1277-1291 (1982).

73. M. Bohdanecký, J. Kovár Viscosity of polymer solutions, Elsevier, Netherlands (1982).

74. M. Rodríguez, M. Galán "Viscosity of triglyceride and alcohol solutions: application of the Krone, Doolittle and Macedo-Litovitz equations." Chem. Eng. J. 60: 117-121 (1995).

75. Y. Xiong, PhD Thesis: Kinetics of pressure induced phase separation in polymer solution: a time and angle-resolved light scattering study. Department of Chemical Engineering, University of Maine (1998) (E. Kiran, Advisor).

76. E. Kiran "Polymer miscibility and kinetics of pressure-induced phase separation in near-critical and supercritical fluids". In Supercritical Fluids: Fundamentals and Applications. E. Kiran, P. G. Debenedetti, C. J. Peters Kluwer Academic Publishers:167-192. Netherlands (2000).

77. P.G. Debenedetti "Phase separation by nucleation and spinodal decomposition: Fundamentals". In Supercritical Fluids: Fundamentals and Applications. E. Kiran, P. G. Debenedetti, C. J. Peters. Kluwer Academic Publishers: 123-166. Netherlands (2000).

78. L. Masaro, X. X. Zhu "Physical models of diffusion for polymer solutions, gels and solids." Prog. Polym. Sci. 24: 731-775 (1999). 


\section{APPENDIX A}

Table A.1. n-Pentane Calibration Data at $5^{\circ} \mathrm{C}$

\begin{tabular}{|c|c|c|c|c|c|}
\hline $\begin{array}{c}\mathbf{P} \\
\text { psi }\end{array}$ & $\begin{array}{c}\mathbf{P} \\
\mathbf{M P a}\end{array}$ & $\begin{array}{c}\eta \\
\text { mPa.s }\end{array}$ & $\begin{array}{c}\rho \\
\mathrm{g} / \mathrm{cm}^{3}\end{array}$ & $\begin{array}{c}V_{t} \\
\mathrm{~cm} / \mathrm{sec}\end{array}$ & $\mathbf{K}$ \\
\hline & 10.23 & 0.1988 & 0.6009 & 0.3393 & 0.0198 \\
\hline 2232 & 15.39 & 0.2072 & 0.6075 & 0.3318 & 0.0203 \\
\hline 3001 & 20.70 & 0.2197 & 0.6125 & 0.3143 & 0.0204 \\
\hline 4024 & 27.75 & 0.2348 & 0.6200 & 0.2925 & 0.0203 \\
\hline 4990 & 34.41 & 0.2483 & 0.6262 & 0.2752 & 0.0203 \\
\hline 6490 & 44.76 & 0.2717 & 0.6358 & 0.2513 & 0.0203 \\
\hline & & & & average & 0.0202 \\
\hline
\end{tabular}

\begin{tabular}{ll}
\hline $\boldsymbol{\eta}$ & Viscosity value from literature [15] \\
$\boldsymbol{\rho}$ & Solvent density - measured \\
$\mathbf{V}_{\mathbf{t}}$ & Terminal velocity - determined \\
$\mathbf{K}$ & Instrument calibration constant \\
\hline
\end{tabular}


Table A.2. n-Pentane Calibration Data at $75^{\circ} \mathrm{C}$

\begin{tabular}{|c|c|c|c|c|c|}
\hline $\begin{array}{c}\mathbf{P} \\
\text { psi }\end{array}$ & $\begin{array}{c}\mathbf{P} \\
\mathbf{M P a}\end{array}$ & $\begin{array}{c}\eta \\
\text { mPa.s }\end{array}$ & $\begin{array}{c}\rho \\
\mathrm{g} / \mathrm{cm}^{3}\end{array}$ & $\begin{array}{c}V_{t} \\
\mathrm{~cm} / \mathrm{sec}\end{array}$ & $\bar{K}$ \\
\hline 1540 & 10.62 & 0.1664 & 0.5790 & 0.4129 & 0.0201 \\
\hline 2250 & 15.52 & 0.1783 & 0.5854 & 0.3928 & 0.0205 \\
\hline 3005 & 20.72 & 0.1971 & 0.5929 & 0.3700 & 0.0214 \\
\hline 2256 & 15.56 & 0.1783 & 0.5864 & 0.3923 & 0.0205 \\
\hline 2252 & 1553 & 0.1783 & 0.5864 & 0.3920 & 0.0205 \\
\hline 3009 & 2075 & 01971 & 05935 & 03736 & 00216 \\
\hline 3002 & 2070 & & 05036 & 03737 & 00716 \\
\hline 4117 & & & & & \\
\hline 4116 & 28.39 & 0.2012 & 0.6042 & 0.3352 & 0.0199 \\
\hline 4110 & 28.39 & 0.2012 & 0.6041 & 0.3426 & 0.0203 \\
\hline 4110 & 28.34 & 0.2012 & 0.6042 & 0.3346 & 0.0198 \\
\hline 5291 & 36.49 & 0.2147 & 0.6152 & 0.3147 & 0.0200 \\
\hline 5276 & 36.39 & 0.2147 & 0.6152 & 0.3150 & 0.0200 \\
\hline 5285 & 36.45 & 0.2147 & 0.6152 & 0.3147 & 0.0200 \\
\hline 6541 & 45.11 & 0.2333 & 0.6310 & 0.2971 & 0.0206 \\
\hline 6551 & 45.18 & 0.2333 & 0.6314 & 0.2959 & 0.0205 \\
\hline & & & & average & 0.0204 \\
\hline
\end{tabular}


Table A.3. n-Pentane Calibration Data at $100^{\circ} \mathrm{C}$

\begin{tabular}{|c|c|c|c|c|c|}
\hline $\begin{array}{c}\mathbf{P} \\
\text { psi }\end{array}$ & $\begin{array}{c}\mathbf{P} \\
\mathbf{M P a}\end{array}$ & $\begin{array}{c}\eta \\
\text { mPa.s }\end{array}$ & $\begin{array}{c}\rho \\
\mathrm{g} / \mathrm{cm}^{3}\end{array}$ & $\begin{array}{c}V_{t} \\
\mathrm{~cm} / \mathrm{sec}\end{array}$ & $\bar{K}$ \\
\hline 2292 & 15.81 & 0.1479 & 0.5645 & 0.4382 & 0.0189 \\
\hline 2292 & 15.81 & 0.1479 & 0.5645 & 0.4337 & 0.0187 \\
\hline 2305 & 15.90 & 0.1479 & 0.5645 & 0.4329 & 0.0186 \\
\hline 2305 & 15.90 & 0.1479 & 0.5645 & 0.4378 & 0.0188 \\
\hline repeat & 15.90 & 0.1479 & 0.5647 & 0.4326 & 0.0186 \\
\hline 2305 & 15.90 & 0.1479 & 0.5647 & 0.4369 & 0.0188 \\
\hline 2305 & 15.85 & 0.1479 & 0.5647 & 0.4342 & 0.0187 \\
\hline 2298 & 15.85 & 0.1479 & 0.5647 & 0.4391 & 0.0189 \\
\hline 2298 & 20.86 & 0.1596 & 0.5724 & 0.4144 & 0.0193 \\
\hline & 20.86 & 0.1596 & 0.5724 & 0.4118 & 0.0192 \\
\hline & 20.86 & 0.1596 & 0.5724 & 0.4078 & 0.0190 \\
\hline 3024 & 20.86 & 0.1596 & 0.5724 & 0.4143 & 0.0193 \\
\hline 3024 & 20.97 & 0.1596 & 0.5730 & 0.4054 & 0.0189 \\
\hline 3025 & 20.97 & 0.1596 & 0.5730 & 0.4089 & 0.0190 \\
\hline 3025 & 20.86 & 0.1596 & 0.5730 & 0.4128 & 0.0192 \\
\hline repeat & 20.86 & 0.1596 & 0.5730 & 0.4159 & 0.0194 \\
\hline 3040 & 28.31 & 0.1759 & 0.5835 & 0.3856 & 0.0199 \\
\hline 3040 & 28.28 & 0.1759 & 0.5835 & 0.3858 & 0.0199 \\
\hline 3024 & 38.14 & 0.1999 & 0.5973 & 0.3512 & 0.0206 \\
\hline 3024 & 38.14 & 0.1999 & 0.5973 & 0.3560 & 0.0209 \\
\hline & 38.11 & 0.1999 & 0.5973 & 0.3531 & 0.0207 \\
\hline & 38.11 & 0.1999 & 0.5973 & 0.3570 & 0.0210 \\
\hline & 45.50 & 0.2032 & 0.6041 & 0.3377 & 0.0202 \\
\hline & & & & average & 0.0197 \\
\hline
\end{tabular}


Table A.4. n-Pentane Calibration Data at $125^{\circ} \mathrm{C}$

\begin{tabular}{|c|c|c|c|c|c|}
\hline $\begin{array}{c}\mathbf{P} \\
\text { psi }\end{array}$ & $\begin{array}{c}\mathbf{P} \\
\mathbf{M P a}\end{array}$ & $\begin{array}{c}\eta \\
\text { mPa.s }\end{array}$ & $\begin{array}{c}\rho \\
\mathrm{g} / \mathrm{cm}^{3}\end{array}$ & $\begin{array}{c}V_{t} \\
\mathrm{~cm} / \mathrm{sec}\end{array}$ & $\bar{K}$ \\
\hline & 17.11 & 0.1269 & 0.5440 & 0.4981 & 0.0183 \\
\hline 2481 & 30.02 & 0.1470 & 0.5666 & 0.4256 & 0.0182 \\
\hline 4353 & 30.02 & 0.1470 & 0.5666 & 0.4373 & 0.0187 \\
\hline 4353 & 34.62 & 0.1595 & 0.5737 & 0.4120 & 0.0192 \\
\hline 5020 & 42.03 & 0.1795 & 0.5843 & 0.3885 & 0.0204 \\
\hline & & & & average & $\overline{0.0190}$ \\
\hline
\end{tabular}

The overall average instrument constant from pentane calibration is found to be $\mathbf{0 . 0 1 9 9}$. 
Table A.5. The \% error obtained for experimental viscosities that are calculated using $K_{\text {avg }}$ with respect to viscosities taken from literature (Kiran and Sen [15])

\begin{tabular}{|c|c|c|c|c|}
\hline $\begin{array}{c}\text { Temperature } \\
{ }^{\circ} \mathrm{C}\end{array}$ & $\begin{array}{c}\text { Pressure } \\
\text { MPa }\end{array}$ & 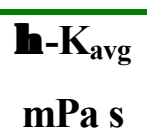 & $\begin{array}{c}\text { n-literature } \\
\text { mPa s }\end{array}$ & \%error \\
\hline 50 & 10.23 & 0.1994 & 0.1988 & -0.29 \\
\hline 50 & 15.39 & 0.2035 & 0.2072 & 1.82 \\
\hline 50 & 20.70 & 0.2145 & 0.2197 & 2.45 \\
\hline 50 & 27.75 & 0.2299 & 0.2348 & 2.12 \\
\hline 50 & 34.41 & 0.2440 & 0.2483 & 1.77 \\
\hline 50 & 44.76 & 0.2664 & 0.2717 & 1.99 \\
\hline 75 & 10.62 & 0.1649 & 0.1664 & 0.93 \\
\hline 75 & 15.52 & 0.1730 & 0.1783 & 3.08 \\
\hline 75 & 20.72 & 0.1832 & 0.1971 & 7.57 \\
\hline 75 & 15.56 & 0.1732 & 0.1783 & 2.97 \\
\hline 75 & 15.53 & 0.1733 & 0.1783 & 2.88 \\
\hline 75 & 20.75 & 0.1815 & 0.1971 & 8.62 \\
\hline 75 & 20.70 & 0.1814 & 0.1971 & 8.65 \\
\hline 75 & 28.39 & 0.2016 & 0.2012 & -0.18 \\
\hline 75 & 28.39 & 0.1973 & 0.2012 & 1.99 \\
\hline 75 & 28.34 & 0.2020 & 0.2012 & -0.38 \\
\hline 75 & 36.49 & 0.2141 & 0.2147 & 0.29 \\
\hline 75 & 36.39 & 0.2138 & 0.2147 & 0.42 \\
\hline 75 & 36.45 & 0.2140 & 0.2147 & 0.32 \\
\hline 75 & 45.11 & 0.2257 & 0.2333 & 3.38 \\
\hline 75 & 45.18 & 0.2266 & 0.2333 & 2.97 \\
\hline
\end{tabular}


Table A.5. Cont'd

\begin{tabular}{|c|c|c|c|c|}
\hline $\begin{array}{c}\text { Temperature } \\
{ }^{\circ} \mathrm{C}\end{array}$ & $\begin{array}{c}\text { Pressure } \\
\text { MPa }\end{array}$ & $\begin{array}{c}\text { n-Kavg } \\
\text { mPa s }\end{array}$ & $\begin{array}{c}\text { n-literature } \\
\text { mPa s }\end{array}$ & \%error \\
\hline 100 & 15.81 & 0.1560 & 0.1479 & -5.20 \\
\hline 100 & 15.81 & 0.1576 & 0.1479 & -6.16 \\
\hline 100 & 15.90 & 0.1579 & 0.1479 & -6.34 \\
\hline 100 & 15.90 & 0.1562 & 0.1479 & -5.29 \\
\hline 100 & 15.90 & 0.1580 & 0.1479 & -6.41 \\
\hline 100 & 15.90 & 0.1565 & 0.1479 & -5.49 \\
\hline 100 & 15.85 & 0.1574 & 0.1479 & -6.06 \\
\hline 100 & 15.85 & 0.1557 & 0.1479 & -5.00 \\
\hline 100 & 20.86 & 0.1646 & 0.1596 & -3.04 \\
\hline 100 & 20.86 & 0.1657 & 0.1596 & -3.66 \\
\hline 100 & 20.86 & 0.1673 & 0.1596 & -4.58 \\
\hline 100 & 20.86 & 0.1646 & 0.1596 & -3.05 \\
\hline 100 & 20.97 & 0.1682 & 0.1596 & -5.13 \\
\hline 100 & 20.97 & 0.1668 & 0.1596 & -4.31 \\
\hline 100 & 20.86 & 0.1652 & 0.1596 & -3.38 \\
\hline 100 & 20.86 & 0.1640 & 0.1596 & -2.66 \\
\hline 100 & 28.31 & 0.1763 & 0.1759 & -0.23 \\
\hline 100 & 28.28 & 0.1762 & 0.1759 & -0.17 \\
\hline 100 & 38.14 & 0.1928 & 0.1999 & 3.68 \\
\hline 100 & 38.14 & 0.1902 & 0.1999 & 5.11 \\
\hline 100 & 38.11 & 0.1918 & 0.1999 & 4.23 \\
\hline 100 & 38.11 & 0.1897 & 0.1999 & 5.38 \\
\hline 100 & 45.50 & 0.2001 & 0.2032 & 1.56 \\
\hline
\end{tabular}


Table A.5. Cont'd

\begin{tabular}{ccccc}
\hline $\begin{array}{c}\text { Temperature } \\
{ }^{\mathbf{0}} \mathbf{C}\end{array}$ & $\begin{array}{c}\text { Pressure } \\
\mathbf{M P a}\end{array}$ & $\begin{array}{c}\boldsymbol{\eta} \text {-K } \\
\mathbf{m P a} \mathbf{a v g}\end{array}$ & $\begin{array}{c}\boldsymbol{\eta} \text {-literature } \\
\mathbf{m P a} \mathbf{~ s}\end{array}$ & \%error \\
\hline 125 & 17.11 & 0.1381 & 0.1269 & -8.09 \\
125 & 30.02 & 0.1605 & 0.1470 & -8.43 \\
125 & 30.02 & 0.1562 & 0.1470 & -5.91 \\
125 & 34.62 & 0.1655 & 0.1595 & -3.62 \\
125 & 42.03 & 0.1750 & 0.1795 & 2.59 \\
\hline
\end{tabular}

- $\%$ error $=\left[\left(\eta_{\text {lit }}-\eta_{\text {Kavg }}\right) / \eta_{\text {Kavg }}\right] \times 100$, $K_{\text {avg }}=0.0199$ 


\section{A.6. Measureme nts with carbon dioxide}

\begin{tabular}{|c|c|c|c|c|c|}
\hline $\begin{array}{c}\mathrm{T} \\
{ }^{\mathbf{o}} \mathrm{C}\end{array}$ & $\begin{array}{c}\mathbf{P} \\
\mathbf{M P a}\end{array}$ & $\begin{array}{c}\mathbf{\eta} \\
\text { mPa.s }\end{array}$ & $\begin{array}{c}\rho \\
\mathrm{g} / \mathrm{cm}^{3}\end{array}$ & $\begin{array}{c}\mathrm{V}_{\mathrm{t}} \\
\mathrm{cm} / \mathrm{sec}\end{array}$ & $\mathbf{K}$ \\
\hline 37 & 30.02 & 0.0956 & 0.9264 & 0.6005 & 0.0187 \\
\hline 37 & 2900 & 0.0796 & 0.8696 & 0.6964 & 0.0177 \\
\hline 52 & 2900 & 0.0671 & 0.8821 & 0.8306 & 0.0179 \\
\hline 52 & 4350 & 0.0835 & 0.8855 & 0.6989 & 0.0187 \\
\hline 52 & 5800 & 0.0963 & 0.9397 & 0.6167 & 0.0194 \\
\hline 77 & 5800 & 0.0787 & 0.8584 & 0.7344 & 0.0184 \\
\hline 77 & 4450 & 0.0667 & 0.8809 & 0.8602 & 0.0184 \\
\hline \multirow[t]{2}{*}{97} & 5800 & 0.0678 & 0.8875 & 0.8459 & 0.0184 \\
\hline & & & & average & 0.0184 \\
\hline
\end{tabular}

The overall average instrument constant from measurements with carbon dioxide is found to be $\mathbf{0 . 0 1 8 4}$. 


\section{APPENDIX B}

\section{Calibration Constant and Assumptions}

In order to validate our results and assumptions, we made a statistical analysis of our data using Stat-Ease DESIGN-EXPERT ${ }^{\circledR}$ software. This program provides highly efficient design of experiments (DOE) and using Response Surface Methods (RSM) it helps to find the ideal process settings in order to achieve optimal formulation and performance. Temperature and pressure are selected as 'factors' and calibration constants obtained for each measurement are analyzed as 'response' .

The software led to a model equation for calibration constant in terms of actual factors as follows,

$\mathrm{K}_{\text {model }}=0.023599-5.27 \mathrm{E}-005 \times \mathrm{A}-6.83 \mathrm{E}-005 \times \mathrm{B}+1.17 \mathrm{E}-006 \times \mathrm{A} \times \mathrm{B} \quad$ Eqn.B. 1

where $\mathrm{K}_{\text {model }}$ is calibration constant, which in this case not a constant but a function of temperature and pressure, $\mathrm{A}$ is the temperature in ${ }^{\circ} \mathrm{C}$ and $\mathrm{B}$ is the pressure in MPa.

Variation of calibration constant from the model equation, $\mathrm{K}_{\text {model }}$, with pressure is plotted at different temperatures in Figure B.1. Experimental calibration constants, K, are also included in the figure. Figure B.2. shows the percent error in experimental viscosities with respect to viscosities taken from the literature data in ref. [15]. Closed symbols represent $\%$ error $\left(\%\right.$ error $\left.=\left[\left(\eta_{\text {lit }}-\eta_{\text {Kavg }}\right) / \eta_{\text {Kavg }}\right] \times 100\right)$ of viscosities that are 
calculated using $\mathrm{K}_{\mathrm{avg}}$ and open symbols represent $\%$ error $\left(\%\right.$ error $\left.=\left[\left(\eta_{\text {lit }}-\eta_{\text {Kmodel }}\right) / \eta_{\text {Kmodel }}\right] \times 100\right)$ of viscosities that are calculated using $K_{\text {model }}$. Viscosity calculations based on $\mathrm{K}_{\text {nodel }}$ leads ess error compared to using $\mathrm{K}_{\mathrm{avg}}$. This is as would be expected.

The percent error in calibration constant also shows how much error will be introduced to the viscosity values, since calibration constant affects viscosity linearly according to Eqn.4.1, if constant $\mathrm{K}_{\mathrm{avg}}$ is used instead of using temperature and pressure dependent $\mathrm{K}_{\text {model }}$. In order to check that effect, the \% error between the $\mathrm{K}_{\text {model }}$, which is calculated for each case, and the constant $\mathrm{K}_{\mathrm{avg}}, 0.0199$, is analyzed (\% error $\left.=\left[\left(\mathrm{K}_{\text {model }}-\mathrm{K}_{\mathrm{avg}}\right) / \mathrm{K}_{\mathrm{avg}}\right] \times 100\right)$ and the results are presented in Figure B.3. The maximum error does not exceed $5 \%$, and the overall average of errors is $2.48 \%$. Taking this error into consideration $K_{a v g}$ is reported as $0.0199 \pm 0.0005$. The difference between the $\mathrm{K}_{\mathrm{avg}}$ and $\mathrm{K}_{\text {model }}$ becomes less at high pressures.

Figure B.4. is a 3-dimensional plot showing the temperature and pressure effect on the calibration constant, $K_{\text {model }}$, determined by the software. As can be seen from the figure, at higher temperatures, as lower pressures are approached the calibration constant, $\mathrm{K}_{\text {model, }}$ is observed to get smaller in value. This deviation is taken into consideration while assigning the upper and lower limits of the average calibration constant.

The upper limit of the calibration constant, 0.0204, is referred as $K_{\max }$ while the lower limit, 0.0194, is referred as $\mathrm{K}_{\min }$. Figure B.5. shows the percent error obtained in experimental viscosities with respect to viscosities taken from literature [15]. Open symbols represent \% error of viscosities that are calculated using 
$\mathrm{K}_{\min }\left(\%\right.$ error $\left.=\left[\left(\eta_{\text {lit }}-\eta_{\mathrm{Kmin}}\right) / \eta_{\mathrm{Kmin}}\right] \times 100\right)$ and closed symbols represent \% error of viscosities that are calculated using $K_{\max }\left(\%\right.$ error $\left.=\left[\left(\eta_{\text {lit }}-\eta_{\text {Kmax }}\right) / \eta_{K \max }\right] \times 100\right)$. From this figure the conclusion is that $85 \%$ of all the measurements fall in the range of \pm 5 $\%$ error where maximum error obtained does not exceed $9 \%$. Based on these analysis we have decided to use a temperature pressure independent value for $\mathrm{K}$ for simplicity. The results are reliable within $5 \%$. For higher accuracy, equation B.1. can be used. 


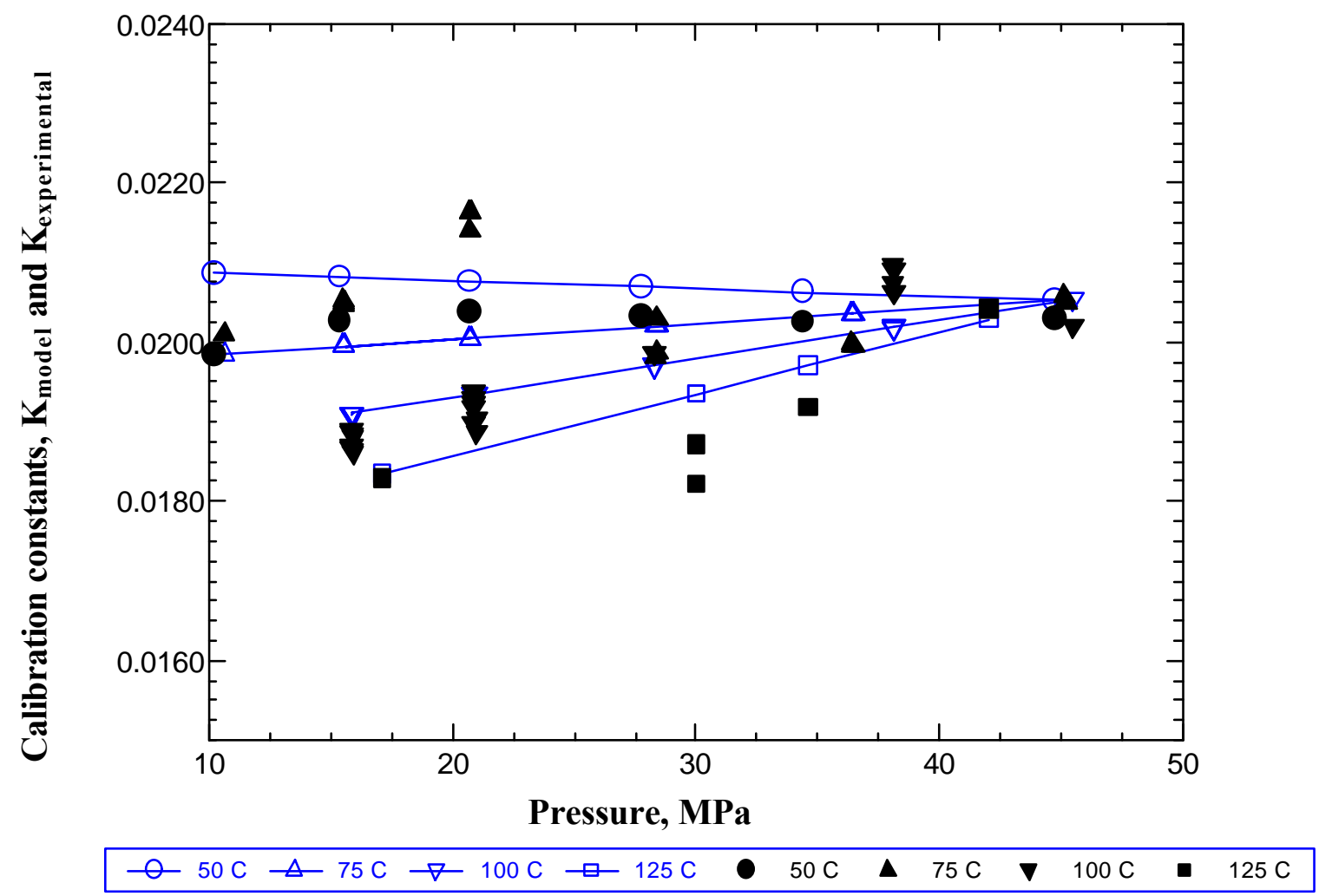

Figure B.1. Variation of $\mathrm{K}_{\text {model }}$ with pressure. Open symbols represent $\mathrm{K}_{\text {model }}$, closed symbols represent $\mathrm{K}_{\text {experimental. }}$. 


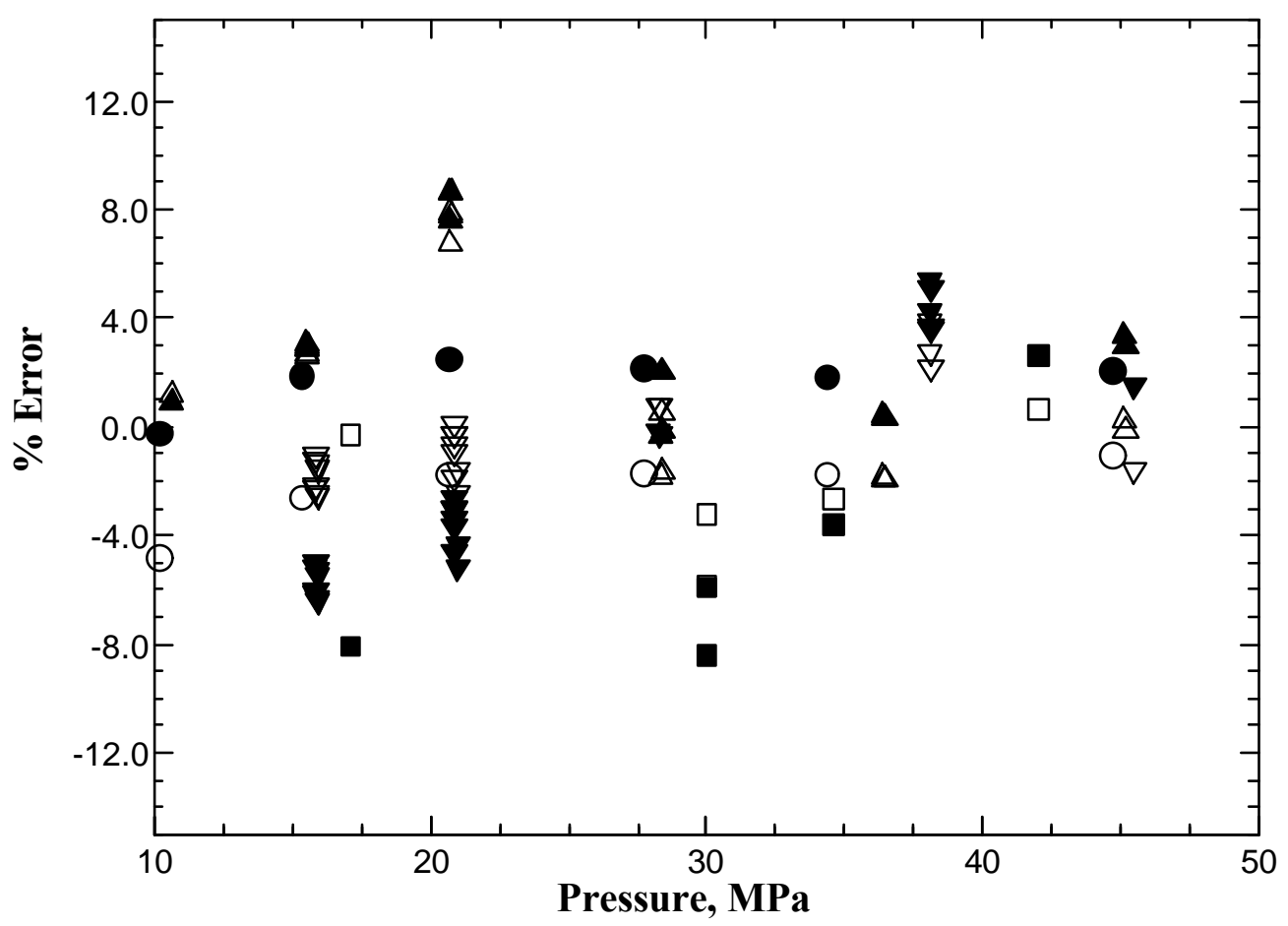

$\begin{array}{lllllllllllllll}50 \mathrm{C} & \Delta & 75 \mathrm{C} & \boldsymbol{\nabla} & 100 & \boldsymbol{a} & 125 \mathrm{C} & \mathrm{O} & 50 \mathrm{C} & \Delta & 75 \mathrm{C} & \nabla & 100 \mathrm{C} & \square & 125 \mathrm{C}\end{array}$

Figure B.2. $\%$ error obtained for experimental viscosities with respect to viscosities taken from literature (Kiran and Sen [15]). Closed symbols represent \% error (\% error $\left.=\left[\left(\eta_{\text {lit }}-\eta_{\text {Kavg }}\right) / \eta_{\text {Kavg }}\right] \times 100\right)$ of viscosities that are calculated using $K_{\text {avg }}$ and open symbols represent $\%$ error $\left(\%\right.$ error $\left.=\left[\left(\eta_{\text {lit }}-\eta_{\text {Kmodel }}\right) / \eta_{\text {Kmodel }}\right] \times 100\right)$ of viscosities that are calculated using $\mathrm{K}_{\text {model }}$. 


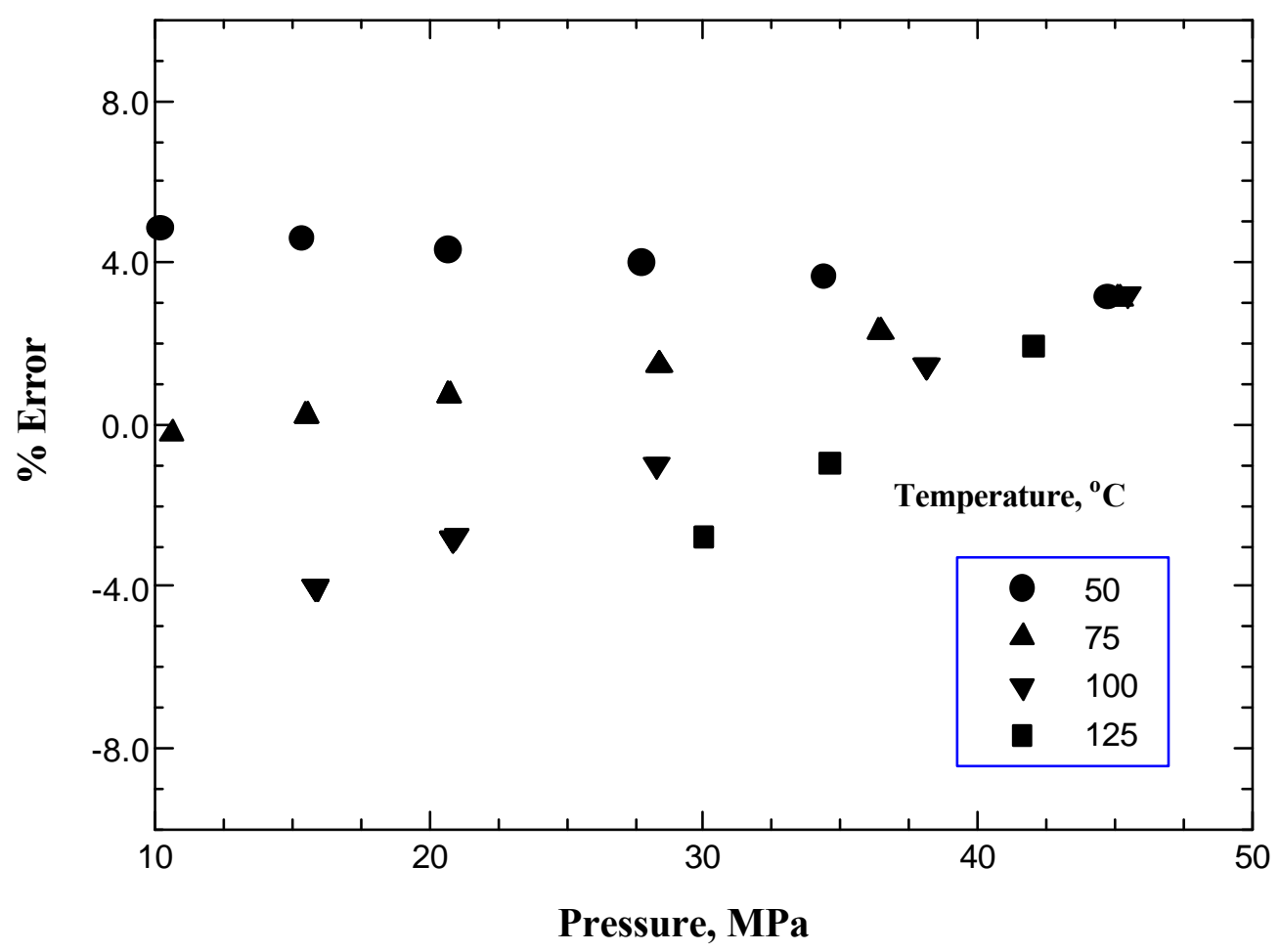

Figure B.3. \% error obtained in calibration constant when $\mathrm{K}_{\mathrm{avg}}$ is used instead of $\mathrm{K}_{\text {model }}\left(\%\right.$ error $\left.=\left(\mathrm{K}_{\mathrm{avg}}-\mathrm{K}_{\text {model }}\right) / \mathrm{K}_{\mathrm{avg}} \times 100\right)$ 


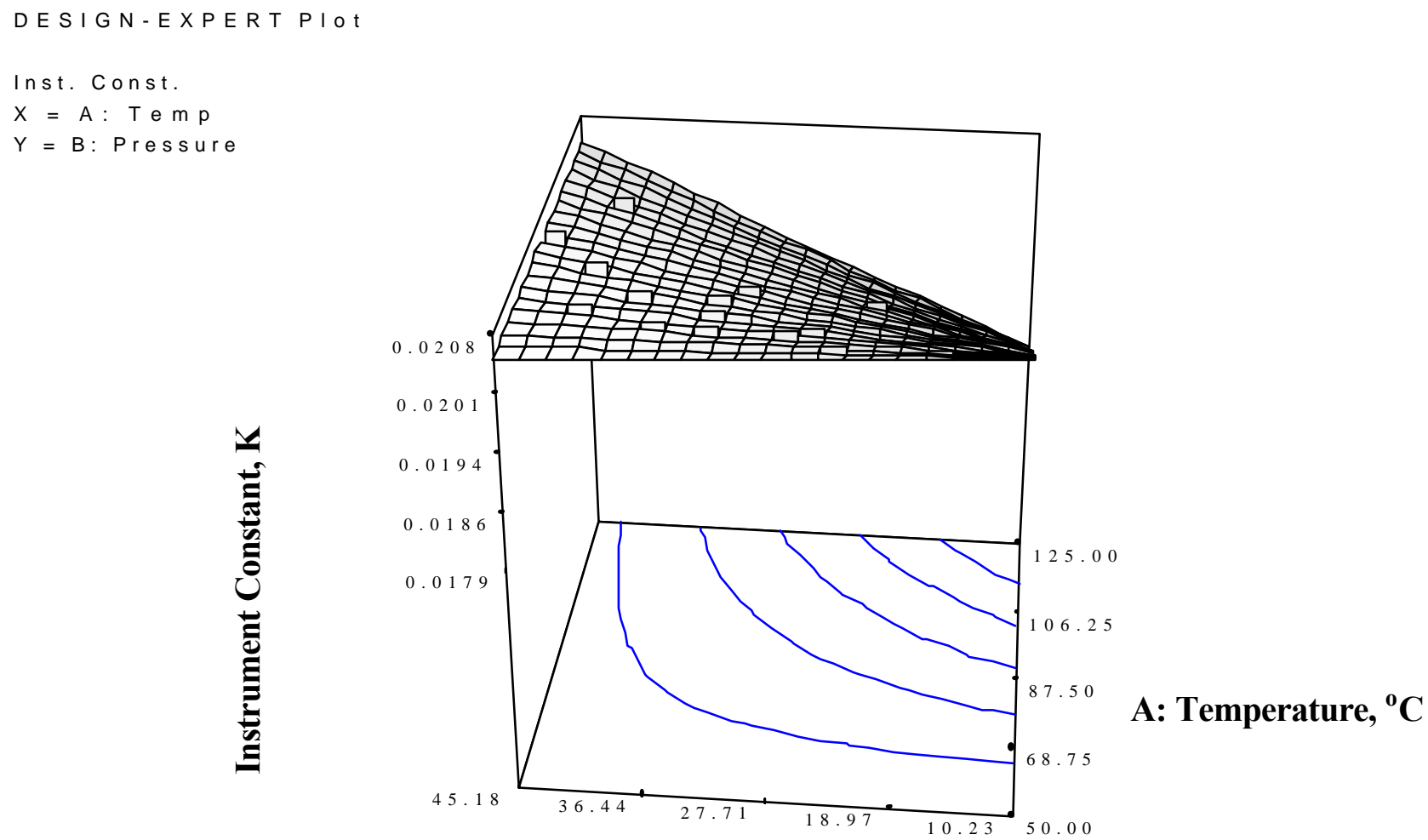

B: Pressure, MPa

Figure B.4. $\mathrm{K}_{\text {model }}$ versus Temperature and Pressure 


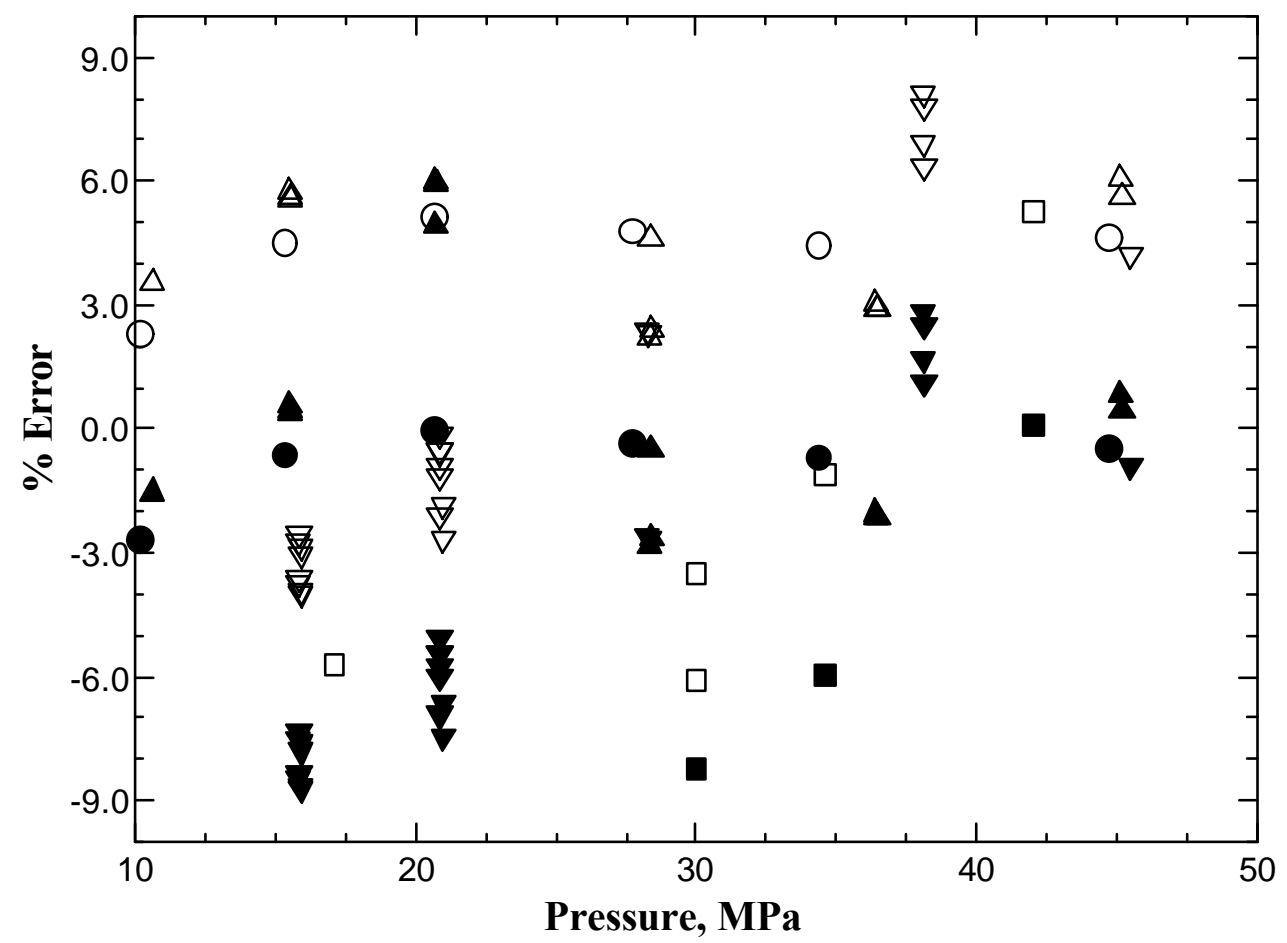

$\begin{array}{lllllllllllllllll}\mathrm{O} & 50 \mathrm{C} & \Delta & 75 \mathrm{C} & \nabla & 100 \mathrm{C} & \mathrm{\square} & 125 \mathrm{C} & \bullet & 50 \mathrm{C} & \boldsymbol{\Delta} & 75 \mathrm{C} & \boldsymbol{\nabla} & 100 \mathrm{C} & \boldsymbol{\bullet} & 125 \mathrm{C}\end{array}$

Figure B.5. The $\%$ error obtained in experimental viscosities with respect to viscosities taken from literature (Sen and Kiran [15]). Open symbols represent \% error of viscosities that are calculated using $\mathrm{K}_{\min }, 0.0194$, $\left(\%\right.$ error $=\left[\left(\eta_{\text {lit }}-\eta_{\mathrm{Kmin}}\right) /\right.$ $\left.\left.\eta_{\mathrm{Kmin}}\right] \times 100\right)$ and closed symbols represent $\%$ error of viscosities that are calculated using $K_{\max }, 0.0204,\left(\%\right.$ error $\left.=\left[\left(\eta_{\text {lit }}-\eta_{\mathrm{Kmax}}\right) / \eta_{\mathrm{Kmax}}\right] \times 100\right)$. 
Table B.1. The \% error obtained for experimental viscosities that are calculated using $K_{\text {model }}$ with respect to viscosities taken from literature (Kiran and Sen [15])

\begin{tabular}{|c|c|c|c|c|}
\hline $\begin{array}{c}\text { Temperature } \\
{ }^{\circ} \mathrm{C}\end{array}$ & $\begin{array}{c}\text { Pressure } \\
\text { MPa }\end{array}$ & $\begin{array}{c}\eta-K_{\text {model }} \\
\text { mPa s }\end{array}$ & $\begin{array}{c}\text { n-literature } \\
\text { mPa s }\end{array}$ & \%error \\
\hline 50 & 10.23 & 0.2090 & 0.1988 & -4.90 \\
\hline 50 & 15.39 & 0.2128 & 0.2072 & -2.64 \\
\hline 50 & 20.70 & 0.2237 & 0.2197 & -1.80 \\
\hline 50 & 27.75 & 0.2391 & 0.2348 & -1.79 \\
\hline 50 & 34.41 & 0.2529 & 0.2483 & -1.82 \\
\hline 50 & 44.76 & 0.2748 & 0.2717 & -1.12 \\
\hline 75 & 10.62 & 0.1645 & 0.1664 & 1.17 \\
\hline 75 & 15.52 & 0.1734 & 0.1783 & 2.83 \\
\hline 75 & 20.72 & 0.1846 & 0.1971 & 6.77 \\
\hline 75 & 15.56 & 0.1736 & 0.1783 & 2.72 \\
\hline 75 & 15.53 & 0.1737 & 0.1783 & 2.63 \\
\hline 75 & 20.75 & 0.1828 & 0.1971 & 7.81 \\
\hline 75 & 20.70 & 0.1828 & 0.1971 & 7.84 \\
\hline 75 & 28.39 & 0.2046 & 0.2012 & -1.66 \\
\hline 75 & 28.39 & 0.2002 & 0.2012 & 0.49 \\
\hline 75 & 28.34 & 0.2050 & 0.2012 & -1.85 \\
\hline 75 & 36.49 & 0.2190 & 0.2147 & -1.95 \\
\hline 75 & 36.39 & 0.2187 & 0.2147 & -1.82 \\
\hline 75 & 36.45 & 0.2189 & 0.2147 & -1.93 \\
\hline 75 & 45.11 & 0.2327 & 0.2333 & 0.24 \\
\hline 75 & 45.18 & 0.2337 & 0.2333 & -0.17 \\
\hline
\end{tabular}


Table B.1. Cont'd

\begin{tabular}{|c|c|c|c|c|}
\hline $\begin{array}{c}\text { Temperature } \\
{ }^{\circ} \mathrm{C}\end{array}$ & $\begin{array}{c}\text { Pressure } \\
\text { MPa }\end{array}$ & $\begin{array}{c}\eta-K_{\text {model }} \\
\text { mPa s }\end{array}$ & $\begin{array}{c}\text { n-literature } \\
\text { mPa s }\end{array}$ & \%error \\
\hline 100 & 15.81 & 0.1497 & 0.1479 & -1.22 \\
\hline 100 & 15.81 & 0.1513 & 0.1479 & -2.23 \\
\hline 100 & 15.90 & 0.1516 & 0.1479 & -2.44 \\
\hline 100 & 15.90 & 0.1499 & 0.1479 & -1.34 \\
\hline 100 & 15.90 & 0.1517 & 0.1479 & -2.51 \\
\hline 100 & 15.90 & 0.1502 & 0.1479 & -1.55 \\
\hline 100 & 15.85 & 0.1511 & 0.1479 & -2.13 \\
\hline 100 & 15.85 & 0.1494 & 0.1479 & -1.03 \\
\hline 100 & 20.86 & 0.1600 & 0.1596 & -0.25 \\
\hline 100 & 20.86 & 0.1610 & 0.1596 & -0.89 \\
\hline 100 & 20.86 & 0.1626 & 0.1596 & -1.84 \\
\hline 100 & 20.86 & 0.1600 & 0.1596 & -0.27 \\
\hline 100 & 20.97 & 0.1636 & 0.1596 & -2.44 \\
\hline 100 & 20.97 & 0.1622 & 0.1596 & -1.59 \\
\hline 100 & 20.86 & 0.1606 & 0.1596 & -0.61 \\
\hline 100 & 20.86 & 0.1594 & 0.1596 & 0.13 \\
\hline 100 & 28.31 & 0.1746 & 0.1759 & 0.74 \\
\hline 100 & 28.28 & 0.1745 & 0.1759 & 0.81 \\
\hline 100 & 38.14 & 0.1956 & 0.1999 & 2.21 \\
\hline 100 & 38.14 & 0.1929 & 0.1999 & 3.62 \\
\hline 100 & 38.11 & 0.1945 & 0.1999 & 2.76 \\
\hline 100 & 38.11 & 0.1924 & 0.1999 & 3.89 \\
\hline 100 & 45.50 & 0.2066 & 0.2032 & -1.63 \\
\hline
\end{tabular}


Table B.1. Cont'd

\begin{tabular}{ccccc}
\hline $\begin{array}{c}\text { Temperature } \\
{ }^{\mathbf{0}} \mathbf{C}\end{array}$ & $\begin{array}{c}\text { Pressure } \\
\mathbf{M P a}\end{array}$ & $\begin{array}{c}\boldsymbol{\eta} \text {-K } \\
\mathbf{m P a} \text { sodel }\end{array}$ & $\begin{array}{c}\boldsymbol{\eta} \text {-literature } \\
\mathbf{m P a} \mathbf{~ s}\end{array}$ & \%error \\
\hline 125 & 17.11 & 0.1273 & 0.1269 & -0.30 \\
125 & 30.02 & 0.1561 & 0.147 & -5.84 \\
125 & 30.02 & 0.1519 & 0.147 & -3.24 \\
125 & 34.62 & 0.1639 & 0.1595 & -2.69 \\
125 & 42.03 & 0.1784 & 0.1795 & 0.63 \\
\hline
\end{tabular}

- $\%$ error $=\left[\left(\eta_{\text {lit }}-\eta_{\text {Kmodel }}\right) / \eta_{\text {Kmodel }}\right] \times 100$

$\mathrm{K}_{\text {model }}=0.023599-5.27 \mathrm{E}-005 \times \mathrm{A}-6.83 \mathrm{E}-005 \times \mathrm{B}+1.17 \mathrm{E}-006 \times \mathrm{A} \times \mathrm{B}$ where $\mathrm{A}$ is the temperature, ${ }^{\circ} \mathrm{C}$, and $\mathrm{B}$ is the pressure, $\mathrm{MPa}$. 
Table B.2. The \% error obtained in calibration constant when $K_{\text {avg }}$ is used instead of $\mathbf{K}_{\text {model }}$

\begin{tabular}{|c|c|c|c|c|}
\hline $\begin{array}{c}\text { Temperature } \\
{ }^{\circ} \mathrm{C}\end{array}$ & $\begin{array}{c}\text { Pressure } \\
\text { MPa }\end{array}$ & $\mathbf{K}_{\text {model }}$ & $\mathbf{K}_{\text {avg }}$ & \%error \\
\hline 50 & 10.23 & 0.0209 & 0.0199 & 4.84 \\
\hline 50 & 15.39 & 0.0208 & 0.0199 & 4.59 \\
\hline 50 & 20.70 & 0.0208 & 0.0199 & 4.33 \\
\hline 50 & 27.75 & 0.0207 & 0.0199 & 3.98 \\
\hline 50 & 34.41 & 0.0206 & 0.0199 & 3.65 \\
\hline 50 & 44.76 & 0.0205 & 0.0199 & 3.14 \\
\hline 75 & 10.62 & 0.0199 & 0.0199 & -0.24 \\
\hline 75 & 15.52 & 0.0199 & 0.0199 & 0.24 \\
\hline 75 & 20.72 & 0.0200 & 0.0199 & 0.75 \\
\hline 75 & 15.56 & 0.0199 & 0.0199 & 0.25 \\
\hline 75 & 15.53 & 0.0199 & 0.0199 & 0.24 \\
\hline 75 & 20.75 & 0.0201 & 0.0199 & 0.75 \\
\hline 75 & 20.70 & 0.0200 & 0.0199 & 0.75 \\
\hline 75 & 28.39 & 0.0202 & 0.0199 & 1.50 \\
\hline 75 & 28.39 & 0.0202 & 0.0199 & 1.50 \\
\hline 75 & 28.34 & 0.0202 & 0.0199 & 1.50 \\
\hline 75 & 36.49 & 0.0204 & 0.0199 & 2.29 \\
\hline 75 & 36.39 & 0.0204 & 0.0199 & 2.28 \\
\hline 75 & 36.45 & 0.0204 & 0.0199 & 2.29 \\
\hline 75 & 45.11 & 0.0205 & 0.0199 & 3.14 \\
\hline 75 & 45.18 & 0.0205 & 0.0199 & 3.14 \\
\hline
\end{tabular}


Table B.2. Cont'd

\begin{tabular}{|c|c|c|c|c|}
\hline $\begin{array}{c}\text { Temperature } \\
{ }^{\circ} \mathrm{C}\end{array}$ & $\begin{array}{c}\text { Pressure } \\
\text { MPa }\end{array}$ & $K_{\text {model }}$ & $\mathbf{K}_{\text {avg }}$ & \%error \\
\hline 100 & 15.81 & 0.0191 & 0.0199 & -4.03 \\
\hline 100 & 15.81 & 0.0191 & 0.0199 & -4.03 \\
\hline 100 & 15.90 & 0.0191 & 0.0199 & -4.00 \\
\hline 100 & 15.90 & 0.0191 & 0.0199 & -4.00 \\
\hline 100 & 15.90 & 0.0191 & 0.0199 & -4.00 \\
\hline 100 & 15.90 & 0.0191 & 0.0199 & -4.00 \\
\hline 100 & 15.85 & 0.0191 & 0.0199 & -4.02 \\
\hline 100 & 15.85 & 0.0191 & 0.0199 & -4.02 \\
\hline 100 & 20.86 & 0.0193 & 0.0199 & -2.79 \\
\hline 100 & 20.86 & 0.0193 & 0.0199 & -2.79 \\
\hline 100 & 20.86 & 0.0193 & 0.0199 & -2.79 \\
\hline 100 & 20.86 & 0.0193 & 0.0199 & -2.79 \\
\hline 100 & 20.97 & 0.0194 & 0.0199 & -2.76 \\
\hline 100 & 20.97 & 0.0194 & 0.0199 & -2.76 \\
\hline 100 & 20.86 & 0.0193 & 0.0199 & -2.79 \\
\hline 100 & 20.86 & 0.0193 & 0.0199 & -2.79 \\
\hline 100 & 28.31 & 0.0197 & 0.0199 & -0.97 \\
\hline 100 & 28.28 & 0.0197 & 0.0199 & -0.97 \\
\hline 100 & 38.14 & 0.0202 & 0.0199 & 1.44 \\
\hline 100 & 38.14 & 0.0202 & 0.0199 & 1.44 \\
\hline 100 & 38.11 & 0.0202 & 0.0199 & 1.43 \\
\hline 100 & 38.11 & 0.0202 & 0.0199 & 1.43 \\
\hline 100 & 45.50 & 0.0205 & 0.0199 & 3.24 \\
\hline
\end{tabular}


Table B.2. Cont'd

\begin{tabular}{ccccc}
\hline $\begin{array}{c}\text { Temperature } \\
{ }^{\mathbf{0}} \mathbf{C}\end{array}$ & $\begin{array}{c}\text { Pressure } \\
\text { MPa }\end{array}$ & $\mathbf{K}_{\text {model }}$ & $\mathbf{K}_{\text {avg }}$ & \%error \\
\hline 125 & 30.02 & 0.0194 & 0.0199 & -2.76 \\
125 & 30.02 & 0.0194 & 0.0199 & -2.76 \\
125 & 34.62 & 0.0197 & 0.0199 & -0.95 \\
125 & 42.03 & 0.0203 & 0.0199 & 1.95 \\
\hline
\end{tabular}

- $\%$ error $\left.=\left(\mathrm{K}_{\mathrm{avg}}-\mathrm{K}_{\text {model }}\right) / \mathrm{K}_{\mathrm{avg}} \times 100\right)$ 


\section{BIOGRAPHY}

The author, Cigdem Dindar, was born on October $24^{\text {th }}, 1974$ in Istanbul, Turkey. After graduating from high school in 1992, she attended the Bosphorous University, in Istanbul, where she got her Bachelor of Science degree in Chemical Engineering in 1998. She worked at the Research and Development Department of the Procter and Gamble Co., in Istanbul, while she was a senior.

Upon graduating from college, in August 1998 she was enrolled for graduate study in the Department of Chemical Engineering at the University of Maine (in Orono, ME) where she worked as a Research Assistant until the end of 1999. Then, in January 2000, she transferred to Virginia Polytechnic Institute and State University (as a result of her thesis advisor's decision to move to Virginia Tech) and enrolled as a graduate student in Chemical Engineering where she worked both as a Research and Teaching Assistant. She is currently a candidate for the Master of Science degree in Chemical Engineering from the Virginia Polytechnic Institute and State University in September 2001. 